\title{
Technical Descriptions of Ten Irrigation Technologies for Conserving Energy
}

May 1983

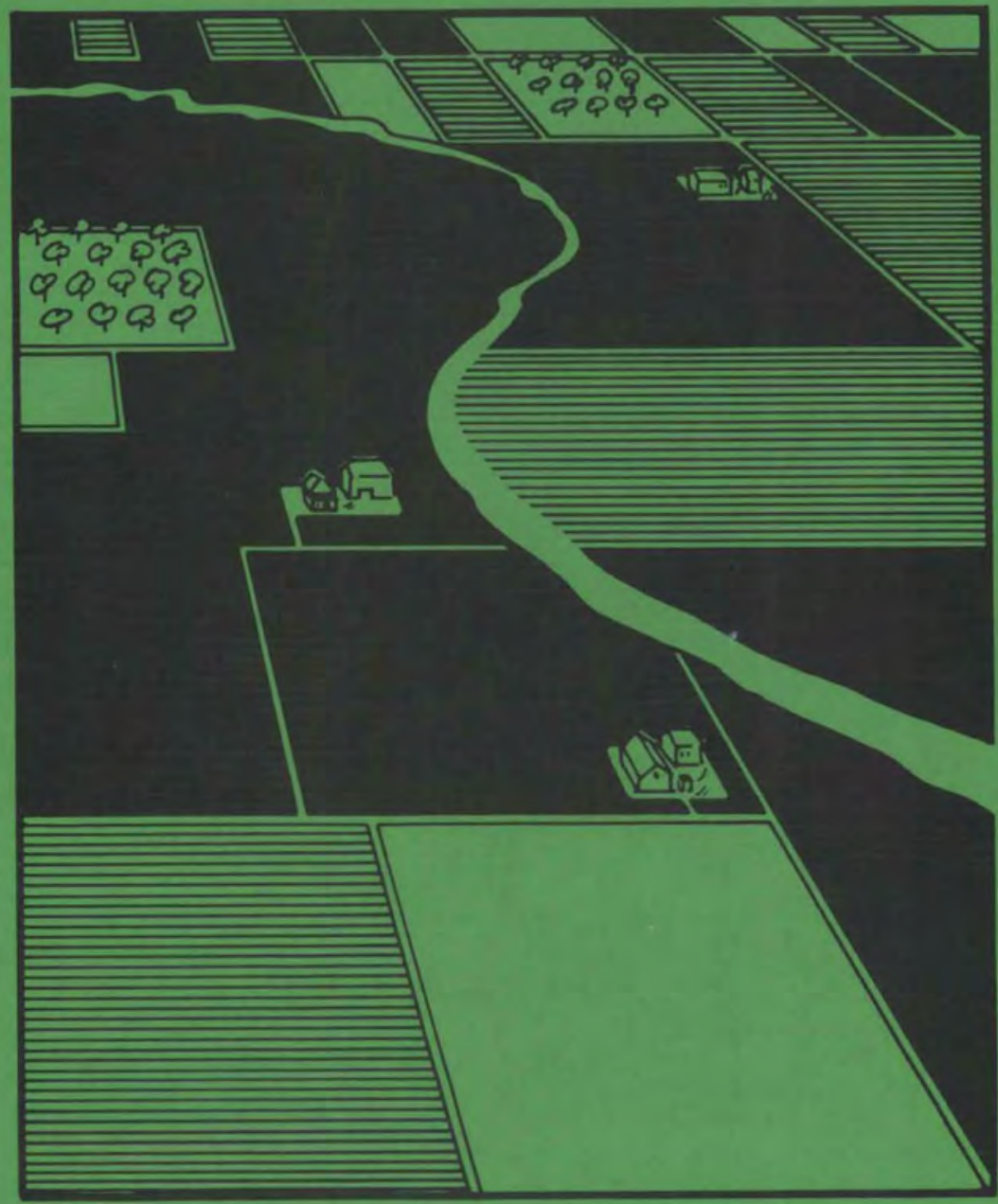

Prepared for the U.S. Department of Energy under Contract DE-AC06-76RLO 1830

Pacific Northwest Laboratory Operated for the U.S. Department of Energy by Battelle Memorial Institute 


\title{
DISCLAIMER
}

This report was prepared as an account of work sponsored by an agency of the United States Government. Neither the United States Government nor any agency thereof, nor any of their employees, makes any warranty, express or implied, or assumes any legal liability or responsibility for the accuracy, completeness, or usefulness of any information, apparatus, product, or process disclosed, or represents that its use would not infringe privately owned rights. Reference herein to any specific commercial product, process, or service by trade name, trademark, manufacturer, or otherwise, does not necessarily constitute or imply its endorsement, recommendation, or favoring by the United States Government or any agency thereof. The views and opinions of authors expressed herein do not necessarily state or reflect those of the United States Government or any agency thereof.

\author{
PACIFIC NORTHWEST LABORATORY \\ operated by \\ BATTELLE \\ for the \\ UNITED STATES DEPARTMENT OF ENERGY \\ under Contract DE-AC06-76RLO 1830
}

Printed in the United States of America Available from

National Technical Information Service United States Department of Commerce 5285 Port Royal Road

Springfield, Virginia 22161

NTIS Price Codes

Microfiche A01

Printed Copy

$\begin{array}{ll}\text { Pages } & \text { Price } \\ & \text { Codes }\end{array}$

$001-025$

$026-050$

$051-075$

076-100

101-125

$126-150$

$151-175$

176-200

201-225

226-250

251-275

276-300

Codes

$\mathrm{A} 02$ 
TECHNICAL DESCRIPTIONS OF

TEN IRRIGATION TECHNOLOGIES

FOR CONSERVING ENERGY

B. J. Harrer

G. L. Wilfert

May 1983

Prepared for

the U.S. Department of Energy

under Contract DE-ACO6-76RLO 1830

Pacific Northwest Laboratory

Richland, Washington 99352 


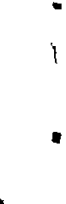




\section{PREFACE}

The Office of Industrial Programs is a research and development program office within the U.S. Department of Energy (DOE). In accordance with DOE goals, the Office is charged with promoting both increased use of existing energy-saving irrigation technologies and the development of new technologies in the Energy Conservation in Irrigation Systems Program. This program involved sharing with industry the development costs of projects having the potential to significantly reduce energy usage in irrigation systems.

Since 1977, the Pacific Northwest Laboratory (PNL), operated by the Battelle Memorial Institute for the Department of Energy, has been supporting the Agriculture and Food Processes Branch in its efforts to issue a program opportunity notice for the design and development of irrigation systems that reduce energy consumption without sacrificing agricultural productivity. Toward this end, PNL has technically and administratively monitored the contracts under the program opportunity notice. This report, which provides technical descriptions of ten energy-saving irrigation technologies, is intended to be of interest to farmers, irrigation equipment vendors, and irrigation equipment manufacturers. 


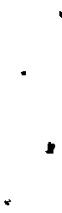




\section{SUMMARY}

Irrigation is a complex process involving: 1) obtaining access to a water supply source, 2) delivering this water to the field level, 3) applying the water to the agricultural crops, and 4) determining the timing and amount of water applications. The U.S. Department of Energy recently sponsored ten research projects designed to encourage energy conservation at all four steps. The ten technologies and those conducting the research are:

1. Well Design and Development, conducted by staff members of the University of Minnesota Irrigation Center, with Hal Werner as the principal investigator (Werner, et. al. 1980).

2. Groundwater Supply System Optimization, conducted by staff members of the University of California at Davis, with Otto Helweg as the principal investigator (Helweg and Scott 1981).

3. Column and Pump Redesign, conducted by Aerospace Research Corporation, with J.T. Hamrick as the principal investigator (Hamrick 1980).

4. Variable-Speed Pumping, conducted by staff members of Foster-Miller Associates (Foster-Miller Associates, Inc. 1981).

5. Pipe Network Optimization, conducted by staff members of Keller Engineering, with G. Z. Watters as the principal investigator (Watters and Keller 1980).

6. Reduced-Pressure Center-Pivot Systems, conducted by staff members of the University of Nebraska, with James R. Gilley as the principal investigator (Gilley, et. al. 1981).

7. Low-Energy Precision Application, conducted by staff members of the the Texas A\&M Research Foundation, with W. M. Lyle as the principal investigator (Lyle and Bordovsky 1981).

8. Automated Gated-Pipe System, conducted by staff members of Kansas State University, with H. L. Manges as the principal investigator (Manges and Blom 1981). 
9. Computerized Irrigation Scheduling, conducted by staff members of J. M. Lord, Inc., with J. M. Lord as the principal investigator (Lord and Gartung 1981).

10. Instrumented Irrigation Scheduling, conducted by Prossen Industries, with Peter Prossen as the principal investigator (Prossen 1981).

In addition to representing the full range of the irrigation steps, the technologies listed above represent a range in level of technological development. Column and Pump Redesign, Automated Gated-Pipe, and Instrumented Irrigation Scheduling are technologies which are in their early stages of development. These technologies will need more development and testing before they are ready for commercialization and widespread use. Well Design and Development, Reduced-Pressure Center-Pivot, and Computerized Irrigation Scheduling appear to be ready for immediate cormercialization and are already being used, to some degree, in commercial farming applications. Other technologies, such as Low-Energy Precision Application, have been successfully demonstrated for use in some irrigation applications, but their widespread applicability is unknown.

New types of irrigation hardware equipment were developed in four of the projects--Column and Pump Redesign, Low-Energy Precision Application, Automated Gated Pipe, and Instrumented Irrigation Scheduling. Performance testing of existing known energy-conserving technologies was the primary emphas is of three of the projects--Well Design and Development, Reduced-Pressure Center-Pivot, and Computerized Irrigation Scheduling. Development of new computer software for analyzing the irrigation system was emphasized in three projects--Pipe Network Optimization, Variable Speed Pumping, and the Groundwater Supply System Optimization. 


\section{CONTENTS}

PREFACE

SUMMARY

1.0 INTRODUCTION

2.0 RESULTS AND CONCLUSIONS

2.1 RESULTS

2.2 CONCLUSIONS

3.0 WELL DESIGN AND DEVELOPMENT

3.1 TECHNOLOGY DESCRIPTION

3.1.1 Drilling Fluid

3.1.2 Gravel Pack.

3.1.3 Screening

3.1.4 Well Development Methods . . . . . . 3.4

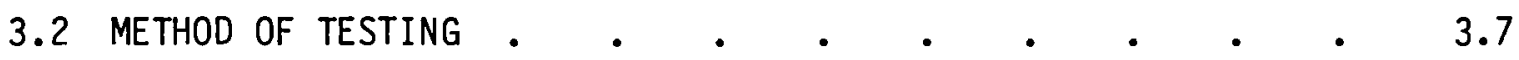

3.2.1 Well Design and Development Alternatives . . . 3.7

3.2.2 Well Development and Pump Tests . . . . . 3.10

3.2.3 Measurement of Well Drawdown, Specific Capacity, Efficiency, and Energy Use . . . . . . 3.10

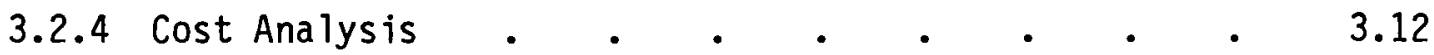

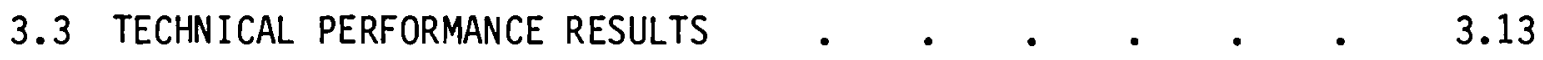

3.4 ENERGY SAVINGS RESULTS • • • • • • • • .

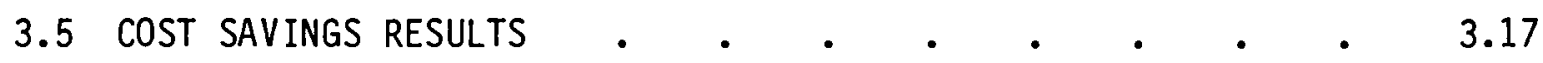

4.0 GROUNDWATER IRRIGATION SUPPLY SYSTEM OPTIMIZATION $\quad \cdot \quad \cdot \quad \cdot \quad 4.1$

4.1 TECHNOLOGY DESCRIPTION

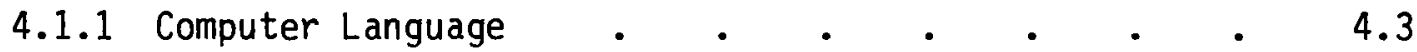

4.1.2 Model Process . . . . . . . . . . .

4.1.3 Analysis Capabilities. . . . . . . . . 4.5

4.2 METHOD OF TESTING

4.2.1 Effects of Pump Head and Efficiency Characteristics . 4.8

4.2.2 Effects of Sand Pumping . • • . . • . 4.8

4.2.3 Effects of Well Efficiency. • . . . . 4.9

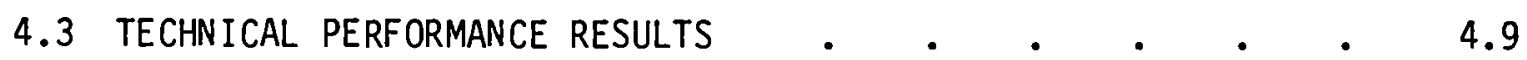

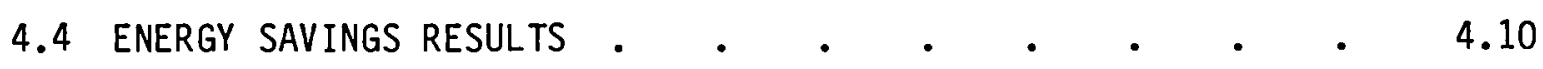

4.5 COST SAVINGS RESULTS . . . . . . . . . . . 4.10 


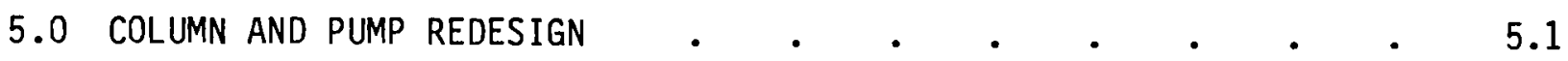

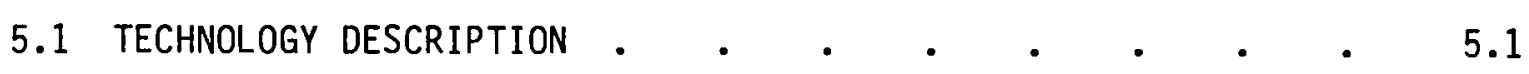

5.1 .1 Well Water Packer . . . . . . . . 5.1

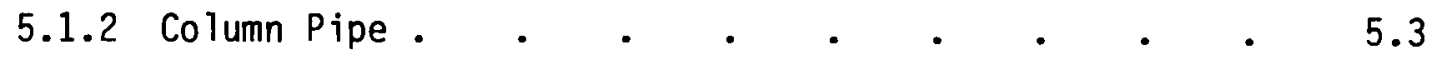

5.1 .3 Line Shaft $. \quad . \quad . \quad . \quad . \quad . \quad . \quad . \quad .5 .3$

5.1.4 Impeller and Diffuser. . . . . . . . . 5.4

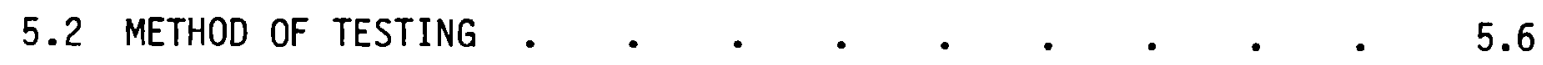

5.2.1 Estimation of Efficiency Changes . . . $\quad . \quad 5.7$

5.2 .2 Field Testing . $. \quad . \quad . \quad . \quad . \quad . \quad .5 .8$

5.2 .3 Cost Analysis . . . . . . . . . . 5.8

5.3 TECHNICAL PERFORMANCE RESULTS $\quad$. $\quad . \quad$. $\quad . \quad$. 5.9

5.4 ENERGY SAVINGS RESULTS . . . . . . . . . . . 5.10

5.5 COST SAVINGS RESULTS $. \quad . \quad . \quad . \quad . \quad . \quad . \quad . \quad 5.10$

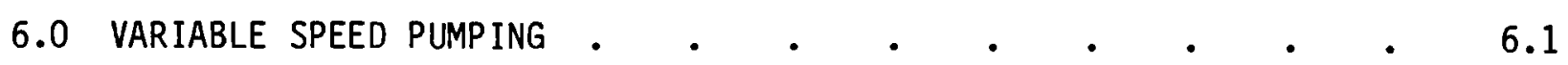

6.1 TECHNOLOGY DESCRIPTION $•$ •

6.1 .1 The Computer Model . . . . . . . . . 6.3

6.1.2 Computer Model Engineering Equations . . . . 6.4

6.1.3 Computer Model Economic Equations . . . . 6.8

6.1 .4 Computer Model Input Parameters . . . . . 6.9

6.1.5 Small Scale-Model Pump and Motor . . . . 6.10

6.1.6 Field Simulation Apparatus . . . . . . 6.10

6.2 METHOD OF TESTING . . . . . . . . . . . . 6.10

6.3 PERFORMANCE RESULTS $. \quad . \quad . \quad . \quad . \quad . \quad . \quad . \quad 6.11$

6.4 ENERGY SAVINGS RESULTS . . . . . . . . . . . 6.12

6.5 COST SAVINGS RESULTS . . . . . . . . . . . . 6.13

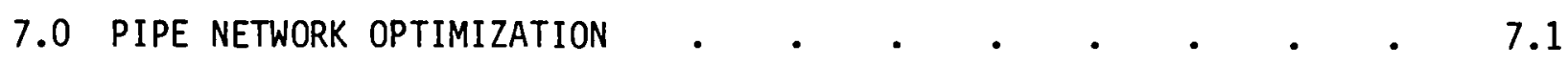

7.1 TECHNOLOGY DESCRIPTION

7.1.1 The Computer Program . . . . . . . . 7.3

7.1 .2 Pipe Design Process . . . . . . . . 7.3

7.1.3 Engineering Equations . . . . . . . . 7.5

7.1.4 Financial Equations . . . . . . . . . 7.6

7.1 .5 Required Input Parameters . . . . . $\quad$. 7.7

7.1 .6 Output Information . . . . . . . . 7.8

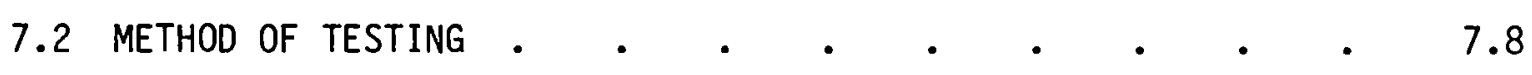

7.3 TECHNICAL PERFORMANCE RESULTS 
8.0 REDUCED-PRESSURE CENTER-PIVOT SYSTEM $\quad \cdot \quad \cdot \quad \cdot \quad \cdot \quad \cdot \quad \cdot \quad \cdot \quad 8.1$

8.1 TECHNOLOGY DESCRIPTION

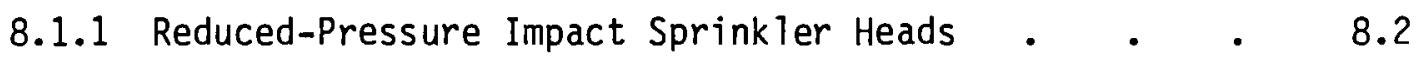

8.1.2 Reduced-Pressure Spray Nozzles . • . • . 8.3

8.1.3 High-Pressure Impact Sprinklers . . . . 8.5

8.2 METHOD OF TESTING.$\quad \cdot \quad \cdot \quad \cdot \quad \cdot \quad \cdot \quad \cdot \quad \cdot \quad \cdot \quad 8.5$

8.2.1 Experimental Plot Design . . . . . . $\quad . \quad 8.5$

8.2.2 Switching-System Design . $\quad . \quad$. $\quad . \quad .8 .7$

8.2.3 Mathematical Models . . . . . . . 8.7

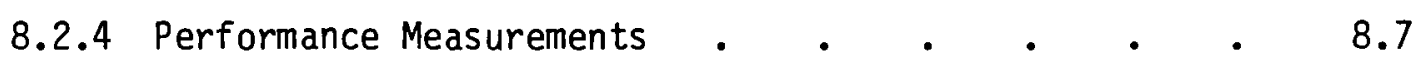

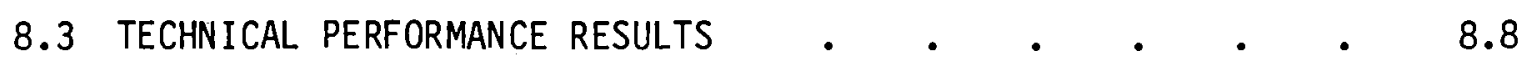

8.4 ENERGY SAVINGS RESULTS •

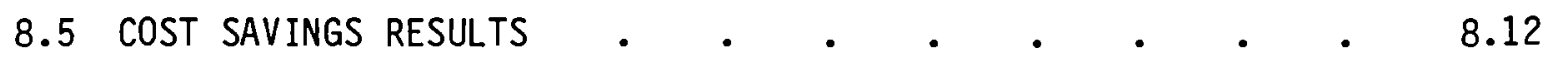

9.0 LOW-ENERGY PRECISION APPLICATION

9.1 TECHNOLOGY DESCRIPTION

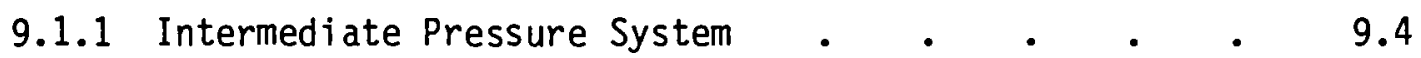

9.1 .2 Hydraulic Design . . . . . . . . . 9.4

9.1.3 Drop Tube Package . . . . . . . . 9.6

9.1.4 Variable Speed Drive and Alignment $\quad . \quad$. $\quad . \quad 9.7$

9.1 .5 Guidance System • • • • • • c • . 9.8

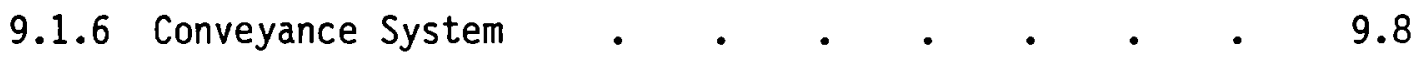

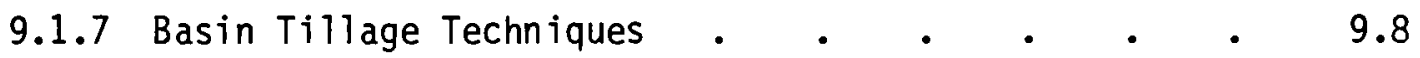

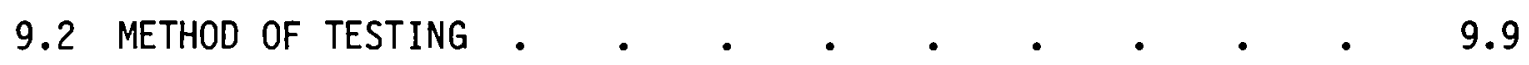

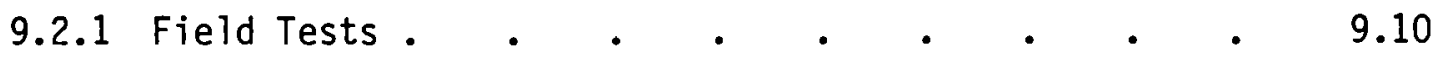

9.2.2 Basin Tillage Testing . . . . . . . . 9.11

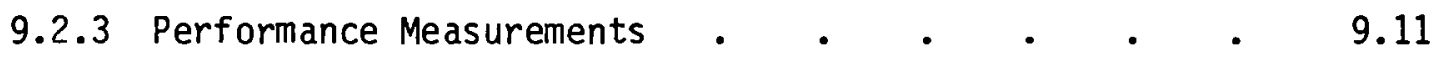

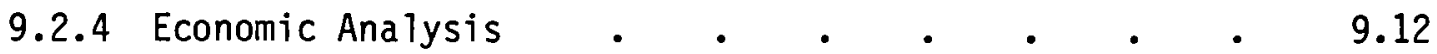

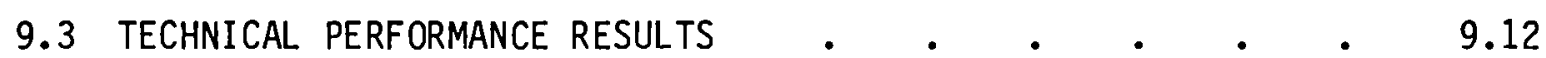

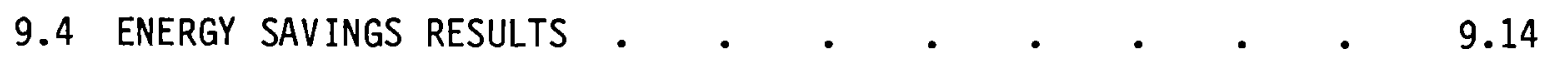

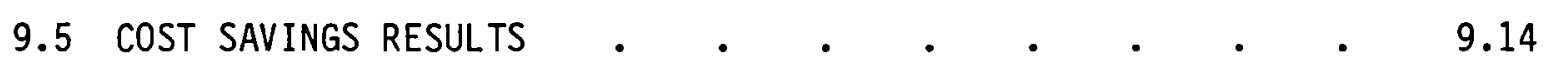

10.0 AUTOMATED GATED-PIPE SYSTEM $•$ •

10.1 TECHNOLOGY DESCRIPTION

10.1.1 Irrigation Controllers and Mini-Computer . . $\quad 10.2$

10.1.2 Radio Transmitters and Receivers . . . . 10.4

10.1.3 Radio-Controlled Servos . . . . . . . 10.5 
10.1.4 Three-Way Pilot Valves . . . . . . 10.5

10.1.5 Flow-Control Valves . . . . . . . . . 10.6

10.1.6 Safety Hose . . . . . . . . . . . 10.6

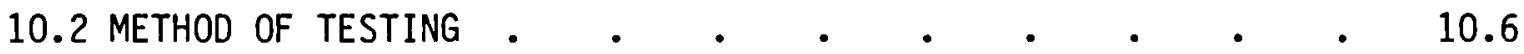

10.2.1 1979 Irrigation Testing . . . . . . . 10.7

10.2.2 1980 Irrigation Testing . . . . . . 10.8

10.3 TECHNICAL PERFORMANCE RESULTS

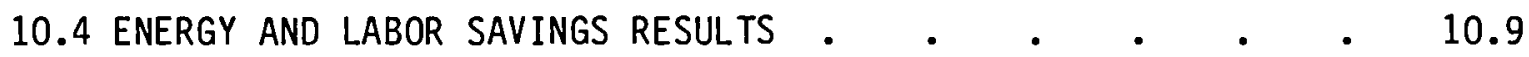

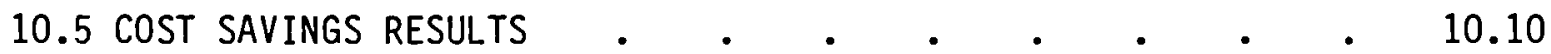

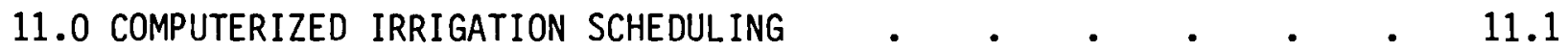

11.1 TECHNOLOGY DESCRIPTION

11.1.1 Field Input Data . • • • • • • . 11.2

11.1.2 The Computer Program . . . . . . . 11.5

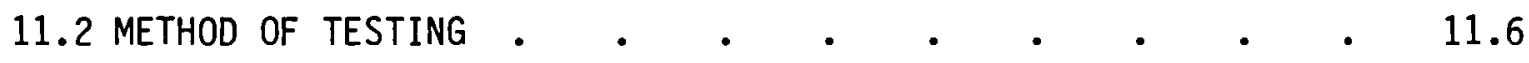

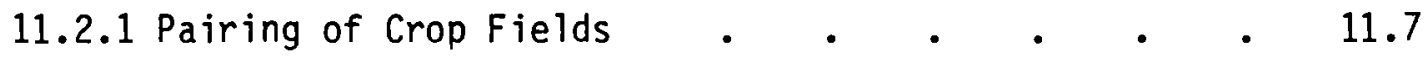

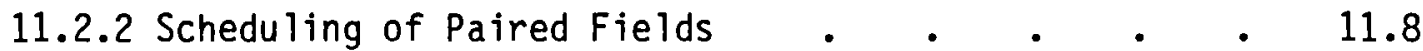

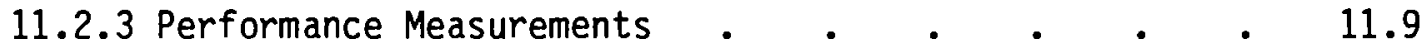

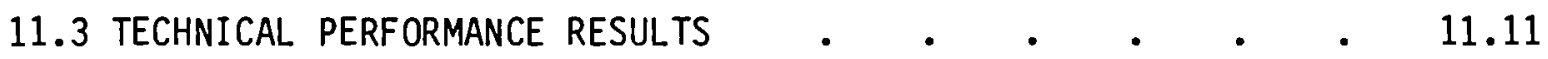

11.4 ENERGY SAVINGS RESULTS • • • • • • • • • • • 11.12

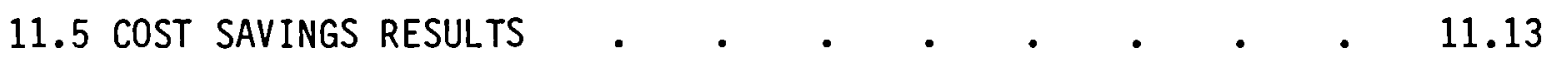

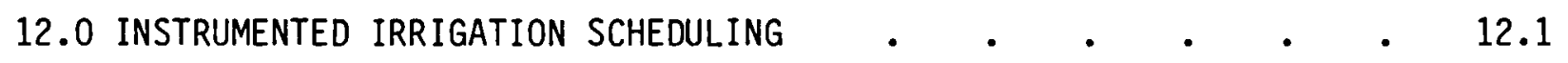

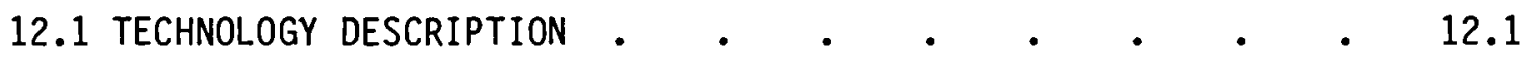

12.1.1 Sensor/Actuator Stations . • • • • • 12.2

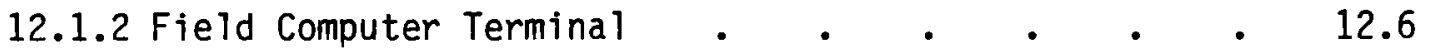

12.1.3 Host Computer Data Processing Center . • • . 12.8

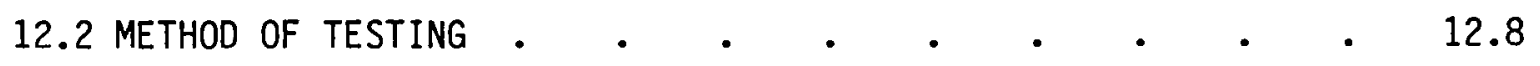

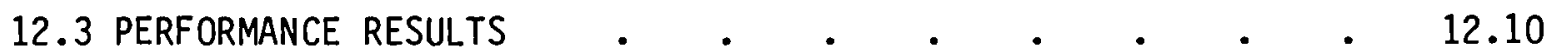

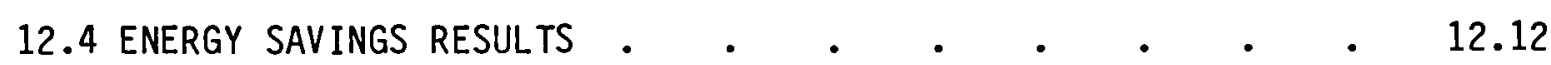

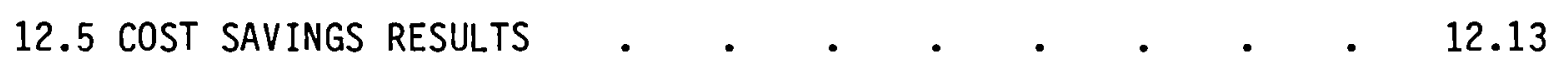

REFERENCES

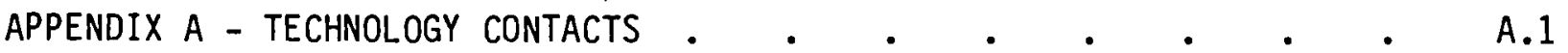




\section{FIGURES}

3.1 Major Components of an Irrigation Well $\quad$ - $\quad$. $\quad$. $\quad$. $\quad 3.2$

3.2 Various Types of Irrigation Well Screens $\quad . \quad \ldots \quad$ e $\quad . \quad$ e $\quad 3.4$

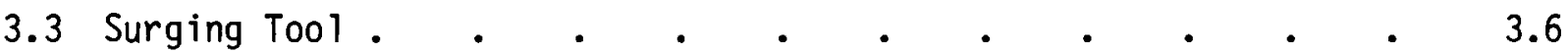

3.4 Jetting Tool •

3.5 Average Specific Capacity for Wells Drilled Using Bentonite Fluid $. \quad . \quad . \quad . \quad . \quad . \quad . \quad . \quad . \quad . \quad .13$

4.1 Locations of Groundwater Supply System Energy Losses $\quad$ • $\quad 4.2$

4.2 Simplified Flow Chart Illustrating Major Steps of Groundwater

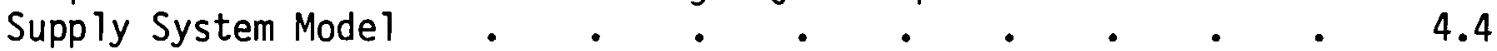

5.1 Schematic Drawing of Pump, Packer, Column Pipe, and Line Shaft Arrangement $\quad . \quad \cdot \quad \cdot \quad \cdot \quad \cdot \quad \cdot \quad \cdot \quad \cdot 5.2$

5.2 Cross Sectional View of Impeller and Diffuser in Place $\quad$ • $\quad 5.5$

5.3 Sketch Showing Passage Modification to Form Labyrinth for More

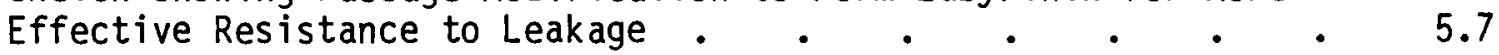

6.1 Foster-Miller Computer Program Flow Chart $\quad . \quad \ldots \quad$ e $\quad . \quad$ e 6.2

6.2 Illustration of Variable Speed Pumping Model . $1 . \quad$. $\quad$. 6.3

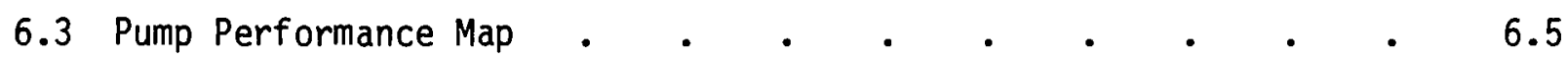

6.4 Scaling Procedure Used to Find the Minimum Pump Speed Curve, $\mathrm{N}_{1} \quad 6.7$

7.1 The Influence of Pipe Size on Capital and Power Costs

Illustrating the Tradeoffs for Deriving Minimal Total Cost $\quad 7.2$

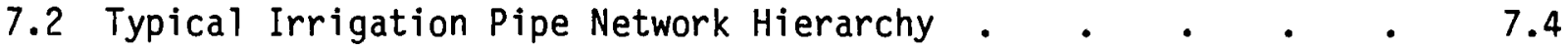

8.1 Sprinkler Arrangement on the Experimental Center-Pivot 8.2

8.2 Organization of Sprinklers on the Experimental Center-Pivot

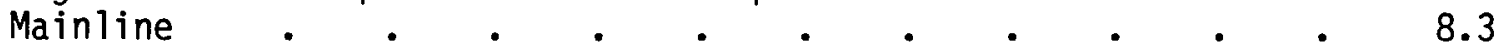

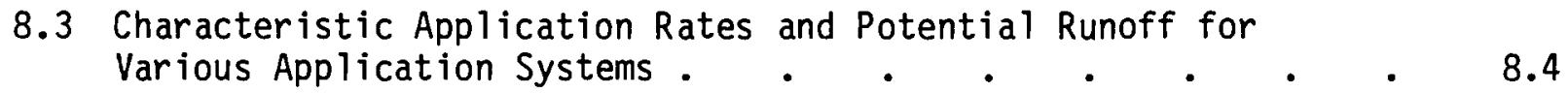

8.4 Layout of Experimental Center-Pivot Test Plot . $\quad$ • $\quad 8.6$

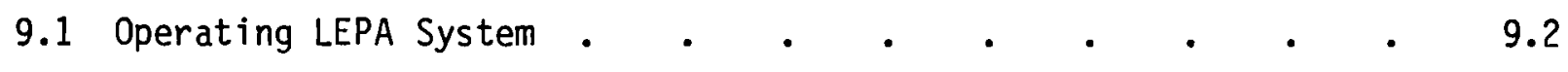




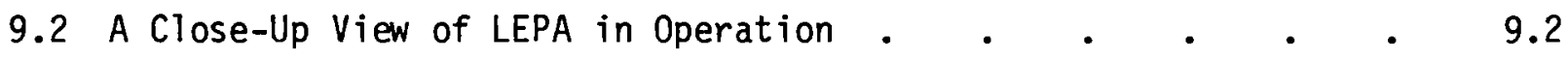

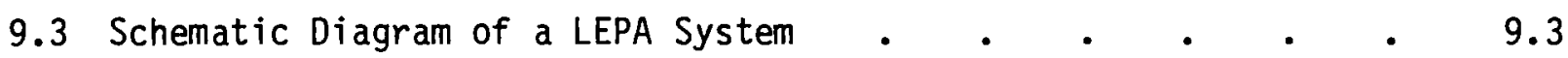

9.4 Arrangement of Manifold Drop Tube Distribution System • 9.6

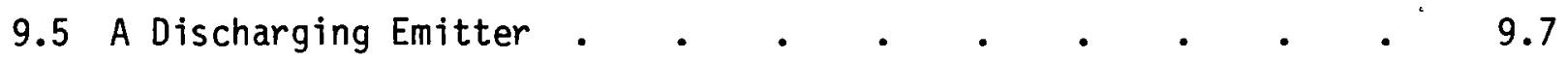

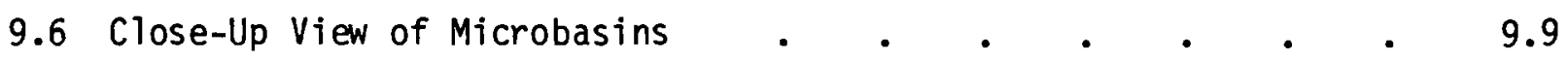

9.7 Hydraulically Operated Basin Tillage Implement . • • • . 9.10

10.1 Operating Automated Gated-Pipe Irrigation System $\quad$ - 10.2

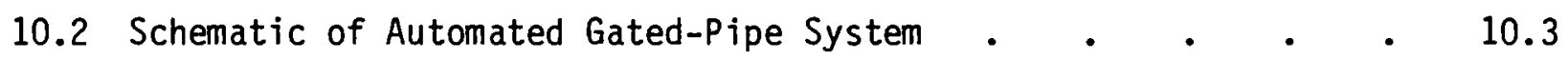

10.3 Radio Servo (A), Pilot Valve (B), and Flow-Control Valve (C) of the Automated-Gated Pipe System . . . . . . 10.7

11.1 Computers Can Quickly Convert Collected Input Data into Useful

Output Data • • • • • • • • • • • • 11.2

11.2 Collecting Field Input Data • • • • • • • • • • 11.4

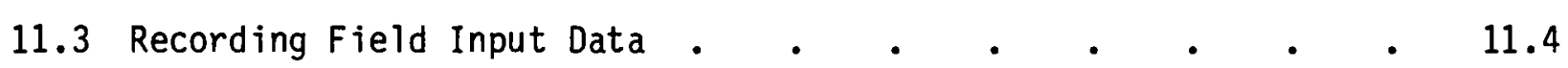

11.4 Operation of the Computerized Irrigation Scheduling Program $\quad 11.6$

12.1 Schematic Diagram of the Total Instrumented Scheduling System $\quad 12.2$

12.2 Typical Root Stress Sensor Station . . . . . . . . 12.4

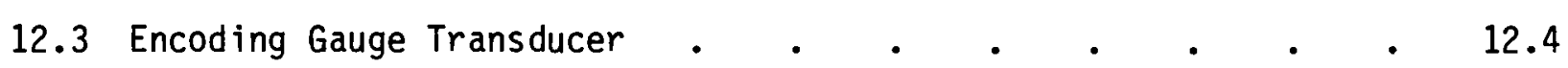

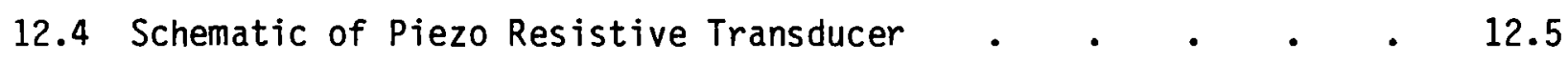

12.5 Flow Chart for System Field Terminal Program . • • • • 12.7

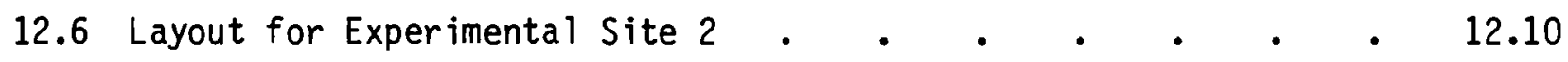




\section{TABLES}

3.1 Construction Materials and Design Alternatives for Wells in Study Area . . . . . . . . . . . . . . 3.9

3.2 Specific Capacities and Well Efficiencies for the Study Wells . 3.14

3.3 Cost Surmary for Example Comparing 2 Well Screens and 3 Well Development Methods on an Unconsolidated Aquifer . . . 3.18

4.1 Input Data Requirements for Simulation Model Operation . 4.7

5.1 System Efficiencies for Various Designs of a Groundwater Turbine Pump . . . . . . . . . . . .

8.1 Allowable Irrigation Amounts for Different Soil and Center-Pivot Types for Various Values of Soil Surface Storage .

8.2 Fuel Saved Through Pressure Reduction with No Decrease in Irrigation Efficiency $. \quad . \quad . \quad \cdot \quad \cdot \quad \cdot \quad \cdot \quad \cdot$

8.3 Diesel Fuel Savings with a Reduced-Pressure Center-Pivot System Operating at 40 psi Compared with a High Pressure System of 80 psi with Both Systems Having a Lift of 300 feet . . . . 8.11

9.1 Predicted Pressure Requirements for LEPA Systems . $\quad$ • $\quad 9.5$

9.2 Total System Energy Coefficients, 1979-1980 . . . . . 9.13

9.3 Average Water and Energy Use Per Unit of Crop Yield for LEPA, Sprinkler, and Gravity F low Irrigation Systems . . . . 9.14

9.4 Estimated Costs of Converting Irrigation Systems to LEPA . . 9.15

10.1 Estimated Annual Labor Requirements for Irrigating 150 Acres . 10.10

10.2 Estimated Annual Energy Requirements for Irrigating 150 Acres of Corn • . . . . . . . . • . . 10.10

10.3 Irrigation System Investment Costs for 150 Acres . . . 10.11

10.4 Total Annual System Costs for 150 Acres . . . . . 10.13

11.1 Computer Input Summary Sheet - Specific Pieces of Data Required for Computerized Scheduling Analysis . . . . . . 11.3

11.2 Average Annual Water Requirements and Rainfall for Three Crops Grown in the San Joaquin Valley of California . . . . 11.8

11.3 Yield and Applied Water Results, 1979-1980 • • • • . 11.11 
11.4 Energy Use Per Unit of Yield Results, 1979-1980 . . . . 11.12

11.5 Expectation of Return (ER) at Current Market Values . . $\quad 11.14$

11.6 Benefit/Cost Ratio of Irrigation Scheduling $\quad$ • . . . 11.15 


\subsection{INTRODUCTION}

This document presents technical descriptions of ten technologies which were researched under the DOE "New Energy Technology in Agriculture" Program to save energy in irrigated agriculture. The information presented in these technical descriptions is based on research conducted by each of the ten program contractors and is oriented toward the technical reader.

Some level of knowledge concerning the various elements of the irrigation process is helpful for following the technical descriptions. For more general information on some of the technologies described here, the reader is referred to a technical briefing report entitled Conserving Energy Through New Irrigation Technologies (Pacific Northwest Laboratory 1982). Specific estimates of the economic benefits of the ten technologies are developed in a companion study entitled Potential Cost Savings from Investments in EnergyConserving Irrigation Systems (Patton, et. a1. 1982). Estimates of the energysaving potential of the ten technologies are contained in a second companion study, Energy Savings Potential for Energy-Conserving Irrigation Systems (Wilfert, et a1. 1982). Assuming that the total irrigated cropland in the United States remains at the same level as today, it is estimated that by the year 2000 energy-saving technologies similar to those discussed herein will be capable of reducing by one-third the energy needed for irrigation.

The primary purpose of this document is to provide, through text and illustrations, a brief but detailed description of how the various technologies work. The primary audience for which it is intended consists of individuals who are involved in the research and development of irrigation systems and methods. The method of testing the performance of each technology is also reported, as well as the performance results. In some cases, the emphasis of the research was on testing rather than development, and in these cases the method of testing is emphasized more heavily in the technical description.

The information contained in this document provides a contribution to the level of knowledge concerning energy-conserving technologies in irrigation, but it does not replace the need to confer with the research contractors if more detailed information is desired. For that purpose, a list of names, addresses 
and phone numbers of the principal investigators on each of the projects is contained in Appendix $A$ of this document.

The discussion of the individual technologies is divided into ten chapters, each of which contains a technical description of the technology and methods that were researched in each of the ten projects. All of the chapters are presented in a similar format: the technology is described in the first section of the chapter, the method of testing is described in the second section, and performance results are described in the final section. 


\subsection{RESULTS AND CONCLUSIONS}

This document describes and summarizes the results of the research on energy-conserving technologies for irrigated agriculture conducted under the Department of Energy Program "New Energy Technology in Agriculture." Evaluation of the technical results of the ten projects reveals vast differences in the potential conservation effectiveness of the technologies.

\subsection{RESULTS}

Among the four projects in which new types of irrigation hardware were developed, the Low Energy Precision Application system appears to be a new technology that is ready for immediate use in some types of farming applications. The other three types of new hardware technologies--Column and Pump Redesign, Automated Gated-Pipe, and Instrumented Scheduling--will require additional testing and development before they are ready for commercial use.

The scientific testing of existing known technologies revealed that technologies that produce few adverse impacts on other aspects of the irrigation process are available for saving energy. Well Design and Development methods, Reduced-Pressure Center Pivots, and Computerized Irrigation Scheduling are all capable of being used to save energy in many types of irrigation situations, and the use of these technologies will generally result in few adverse consequences.

The three computer software technologies--Computerized Pipe Network Design program, Variable-Speed Pumping, and Groundwater Supply System Optimization model--were developed to improve the design process for irrigation systems. The concepts provided in these models (including the tradeoff between higher capital costs of large irrigation pipe and the higher energy costs of smaller pipe, and the proper matching of an irrigation pump with its flow requirements) are critical elements in designing an energy-efficient and low-cost irrigation system. These concepts should be considered in the design of any irrigation system, although they need not be in exactly the same form as that analyzed in the three projects.

The economics of using eight of the ten technologies were considered in a companion volume to this one (Patton, et al. 1982). This analysis revealed 
that the use of Well Design and Development methods, Column and Pump Redesign, the Low-Energy Precision Application system, Reduced-Pressure Center-Pivots, and Computerized Irrigation Scheduling will generally be cost-effective over the life of the irrigation systems. The use of Variable-Speed Pumping, Automated Gated-Pipe and Instrumented Irrigation Scheduling will generally not be cost-effective over the life of the systems. Exceptions to these findings occurred in specific situations, but the reader should refer to the companion volume for more detailed information.

\subsection{CONCLUSIONS}

These research projects provide a large volume of information on how energy use in irrigation can be reduced. In some cases the initial objectives of the research were met; cost-effective, technically reliable technologies that have the potential to substantially reduce energy use in irrigated agriculture were successfully developed and/or tested. In other cases, problems in development and/or testing of the technologies were encountered. However, as is of ten the case in research, information on what cannot be done technically or economically may prove to be just as valuable in the long run as information on what can be done. 


\subsection{WELL DESIGN AND DEVELOPMENT}

We11 design and development techniques that can reduce the energy consumption of an irrigation pumping system are generally available, but they have not found widespread use in the well-drilling industry. Often, well drillers and owners are unaware of the potential benefits of these techniques or they view the techniques as too costly. Little consideration has been given to obtaining a sand-free well with minimum drawdown. A number of we11 design and development techniques were tested on an unconsolidated aquifer in Minnesota as part of the project conducted by the University of Minnesota's Irrigation Research Center. The objective of this study was to assess the effects on well performance and the potential costs and benefits of each of the techniques.

\subsection{TECHNOLOGY DESCRIPTION}

As part of the project, several elements of well design were tested to evaluate their impacts on well performance. These elements included:

- type of fluid used in drilling the well

- gravel packing in the bore hole

- screening used in the well.

The following methods of well development, which are performed after the well is in place, were also tested:

- overpumping

- surging

- jetting.

Each of these well design and development techniques is discussed in detail below. To facilitate understanding of the discussion of the well design and development techniques, an illustration of a well and many of its components is presented in Figure 3.1.

\subsubsection{Drilling Fluid}

Drilling fluid or mud, as it is often called, is used to facilitate the drilling of a well. Six functions of a good drilling fluid are the following: 


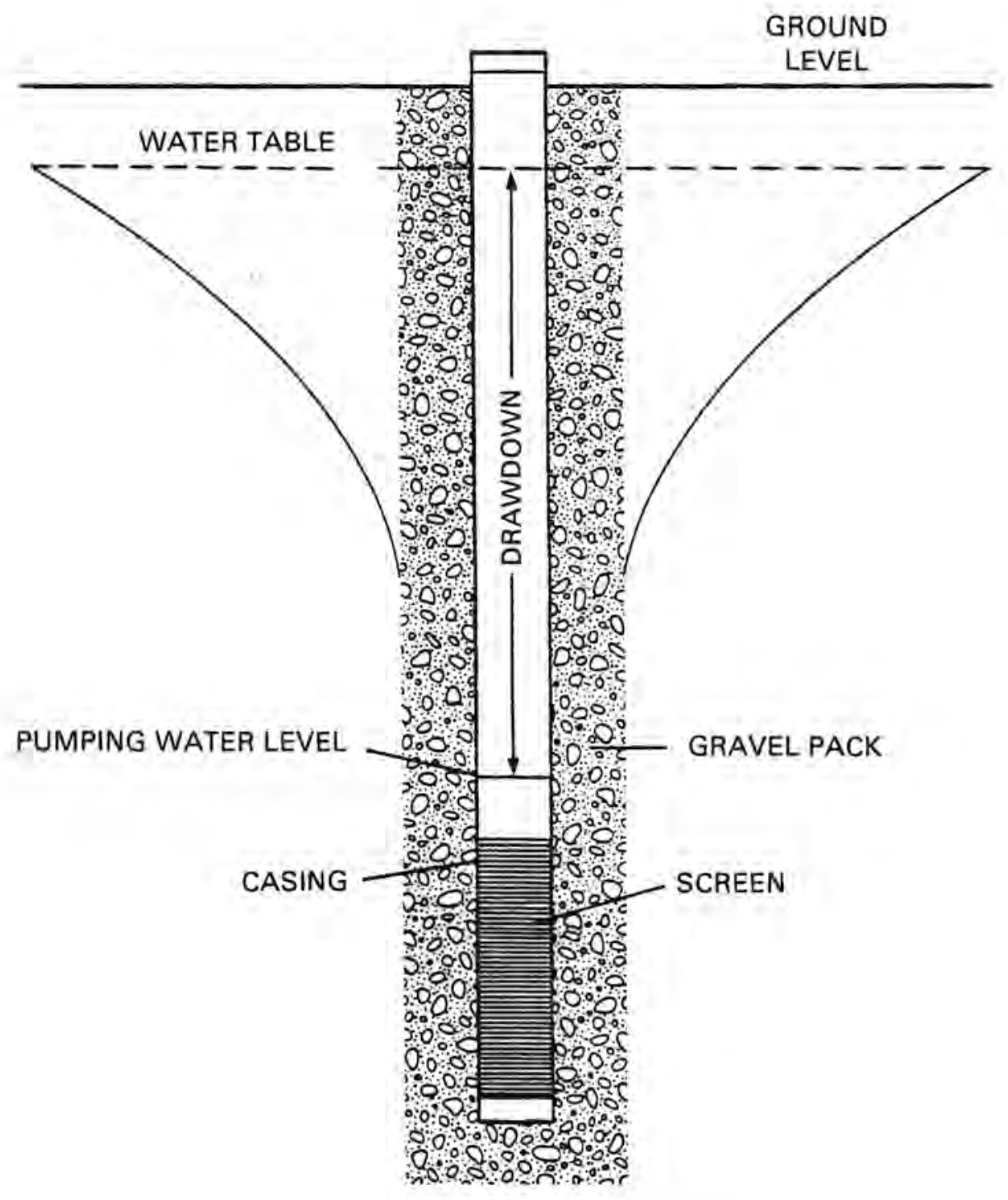

FIGURE 3.1. Major Components of an Irrigation We11 
1. to support the wall of the borehold to prevent caving

2. to remove the cuttings of the drilling process from the bottom of the hole

3. to seal the wall of the borehold to reduce fluid loss

4. to suspend soil cutting when circulation of the drill bit is stopped

5. to cool and clean the drill bit

6. to lubricate bit bearings, mud pump, and drill pipe.

All of these are necessary functions, but the first and third contribute directly to reduced permeability of the well near the borehole. Lower permeability implies higher well energy use because more energy must be expended to move water into the well.

Two major types of drilling fluids used in rotary drilling are bentonite clay with additives and an organic, biodegradeable mixture with additives. Bentonite clay has been commonly used for many years, while organic fluids are relatively new.

\subsubsection{Gravel Pack}

Gravel packs are placed at the bottom of a well primarily to prevent sand pumping. The size of the gravel should be determined by the size of the particle fines at the well's pumping depth.

A recommended procedure is that multiples of the screen slot size that retains 70 percent of the particle fines in a sampling test are used to size the gravel. If the particle fines are fine and uniform, the size of the grave 1 in the packing should be four times as large as the screen slot that retained 70 percent of the particle fines in the well. If the particle fines are coarse and nonuniform, the gravel should be six times as large as the 70 percent retained size. Five should be used as the multiple for fines between the two extremes.

\subsubsection{Screening}

Well screens are used to limit the flow of fine particles into the pumping mechanism. However, if screens are improperly designed, they can also reduce 
water flow from the aquifer into the well. The flow loss associated with a screen is related to the amount of open area on the screen. The open area is affected by the amount of plugging associated with the gravel pack. The closer the diameter of the effective grain size of the gravel pack is to the size of the slot openings in the screen, the more open areas in the screen it will plug.

Once a gravel pack is selected for the we11, it is important to match the size of well screen slots to the size of the gravel in the gravel pack. Slot size should be large enough to prevent small fragments from plugging the screen, but small enough to prevent the pumping of large gravel pieces. In naturally developed wells where a gravel pack is not used, the well screen should be matched to the size of the particle fines in the well formation. A photo of a number of different types of well screens is presented in Figure 3.2.

\subsubsection{Well Development Methods}

We11 development is a process which improves the performance of a well by creating a pressure gradient. The pressure gradient applies a force to the well formation through the screen. This force loosens the drilling mud, removes the finer particles of the well formation, and reduces the effects of

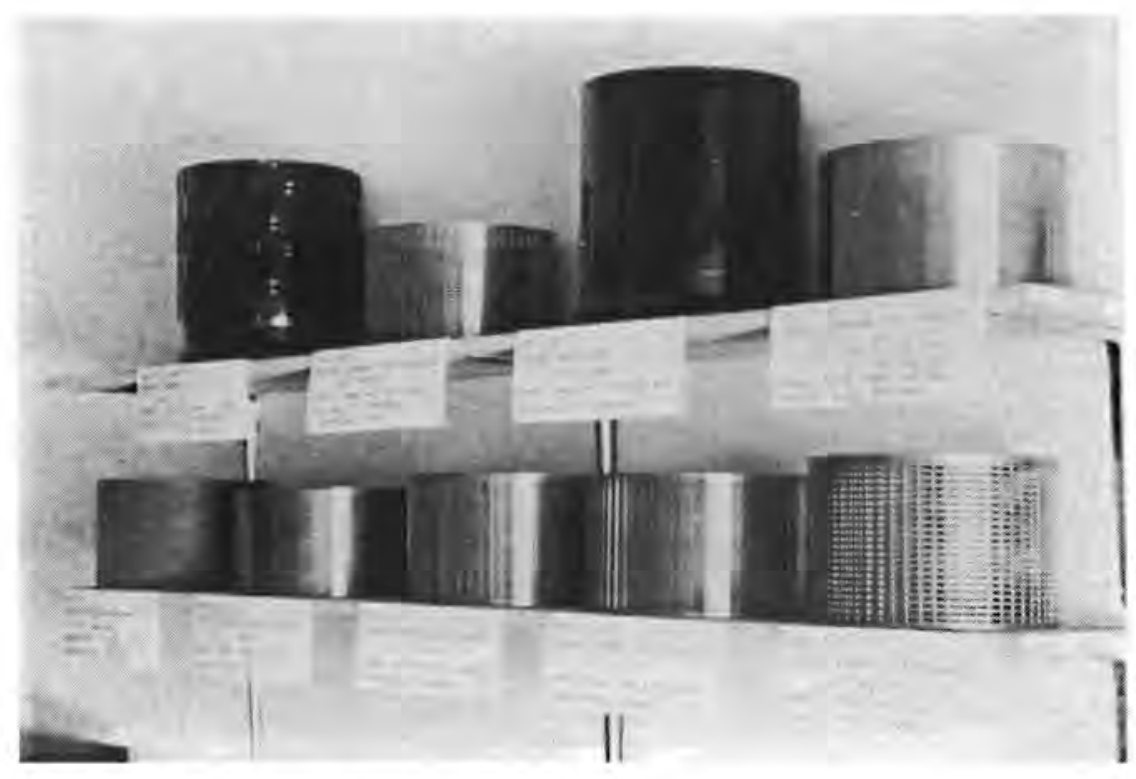

FIGURE 3.2. Various Types of Irrigation Well Screens 
compaction caused by the drilling process. Well development has of ten been considered an "extra" in the well drilling process because it is undertaken after the well is in place, but before the well is in use.

\section{Overpumping}

Overpumping is just what the name implies--pumping the well at a higher rate than the permanent installation calls for. This increases the velocity of water into the well and carries mud and particle fines with it. A variation of this method is known as "rawhiding."

In overpumping, a we11 is pumped to its maximum possible drawdown, then the pump is shut off, allowing water to flow back into the well. This process is repeated until it is felt that maximum development has taken place. The back and forth motion of the water putting pressure on the materials near the screen causes development.

\section{Surging}

In surging, a piston-like device is lowered into the well to approximately the top of the screen and then is moved up and down rapidly. This movement creates a back and forth motion through the screen and effectively moves mud and fine particles into the well. Surging is performed several times in the course of well development and the fines and drilling mud are flushed out after each surging. It should be continued until the quantity of sand removed is negligible. There are many ways to construct a surging device or surge block but a typical design is illustrated in Figure 3.3. Surging is thought to be the best method of well development when both the ease of implementation and effectiveness are considered.

\section{Jetting}

In jetting, a tool with either two or four opposed nozzles is lowered into the well opposite the screen. Water is forced through each nozzle to create a high-speed stream. The diameter of the nozzles commonly used ranges from $3 / 16$ to $1 / 2$ inch. 


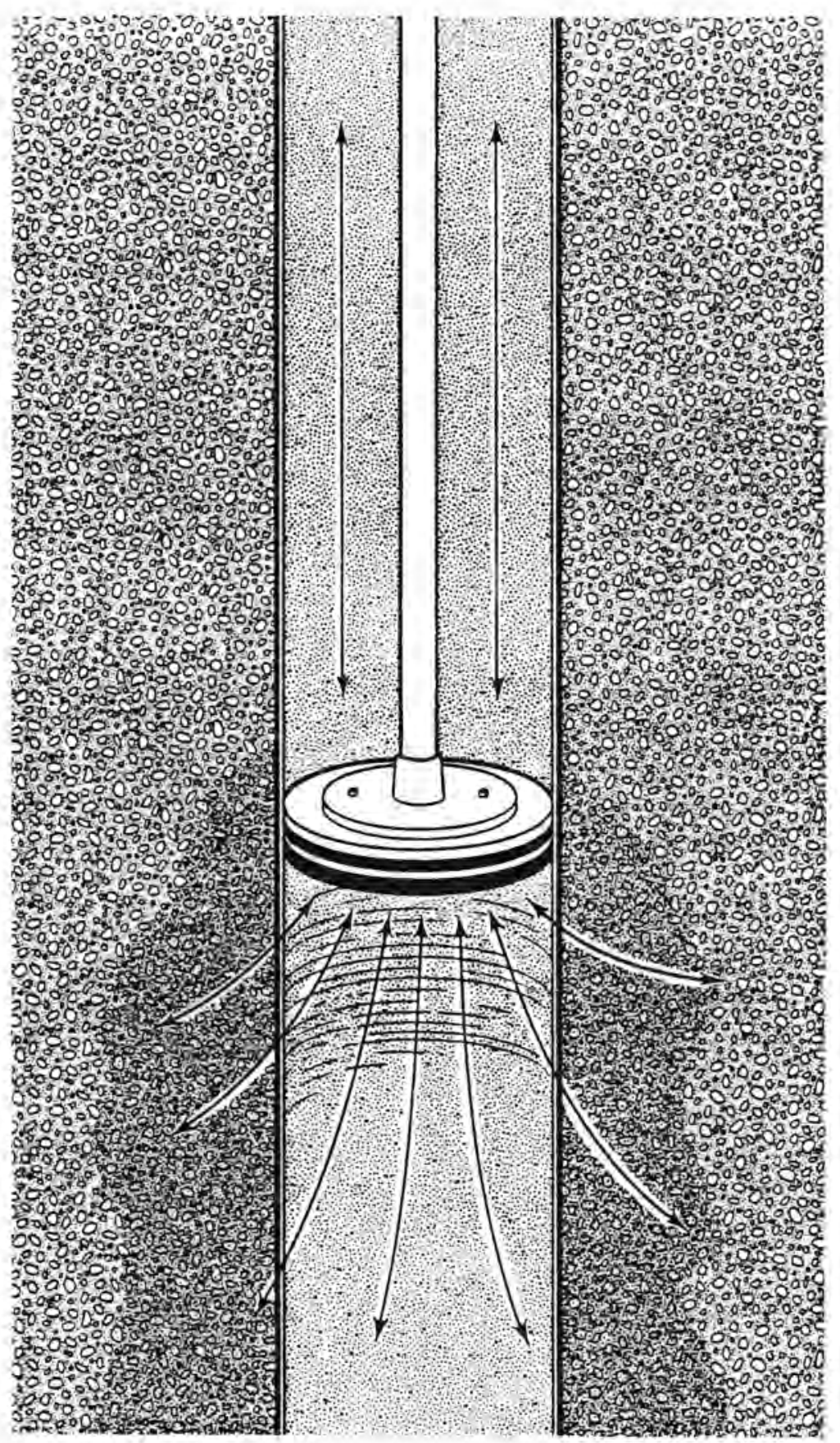

FIGURE 3.3. Surging Tool 
As the jet slowly rotates (at a rate of less than $2 \mathrm{rpm}$ ) and moves up and down, it applies direct pressure to the well formation through the screen. A minimum of two trips up and down the full length of the screen should be performed; each run should start at the bottom of the well and work its way up. Flow rate into the jetting tool should be approximately $50 \mathrm{psi}$ on the initial run up the screen, then increased for each run afterward. In addition, the well is pumped with compressed air at a rate approximately 1.5 times greater than the flow through the nozzles. The actions of jetting and pumping combine to produce a flushing action that removes the fines from the well.

Jetting is generally thought to be the most effective development method in terms of improving well performance, but it is also more difficult and costly to perform than other methods. An illustration of a jetting tool is presented in Figure 3.4 .

\subsection{METHOD OF TESTING}

The following methods were used to test the technical and economic performance of the various we11 design and development techniques:

- alternative well design techniques incorporated into 10 wells drilled in a common geographical location

- well development and pump testing of each of the wells

- measurement of actual and theoretical drawdown, specific capacity, we11 efficiency, and energy use

- cost analysis of the various design and development techniques.

A detailed description of each of these elements is presented below.

\subsubsection{Well Design and Development Alternatives}

The we11 design techniques incorporated into the ten we11s are presented in Table 3.1. Note that a large amount of variation in slot size and open area was incorporated into the screen design. The gravel pack in well nine was deliberately oversized to simulate a design error. 


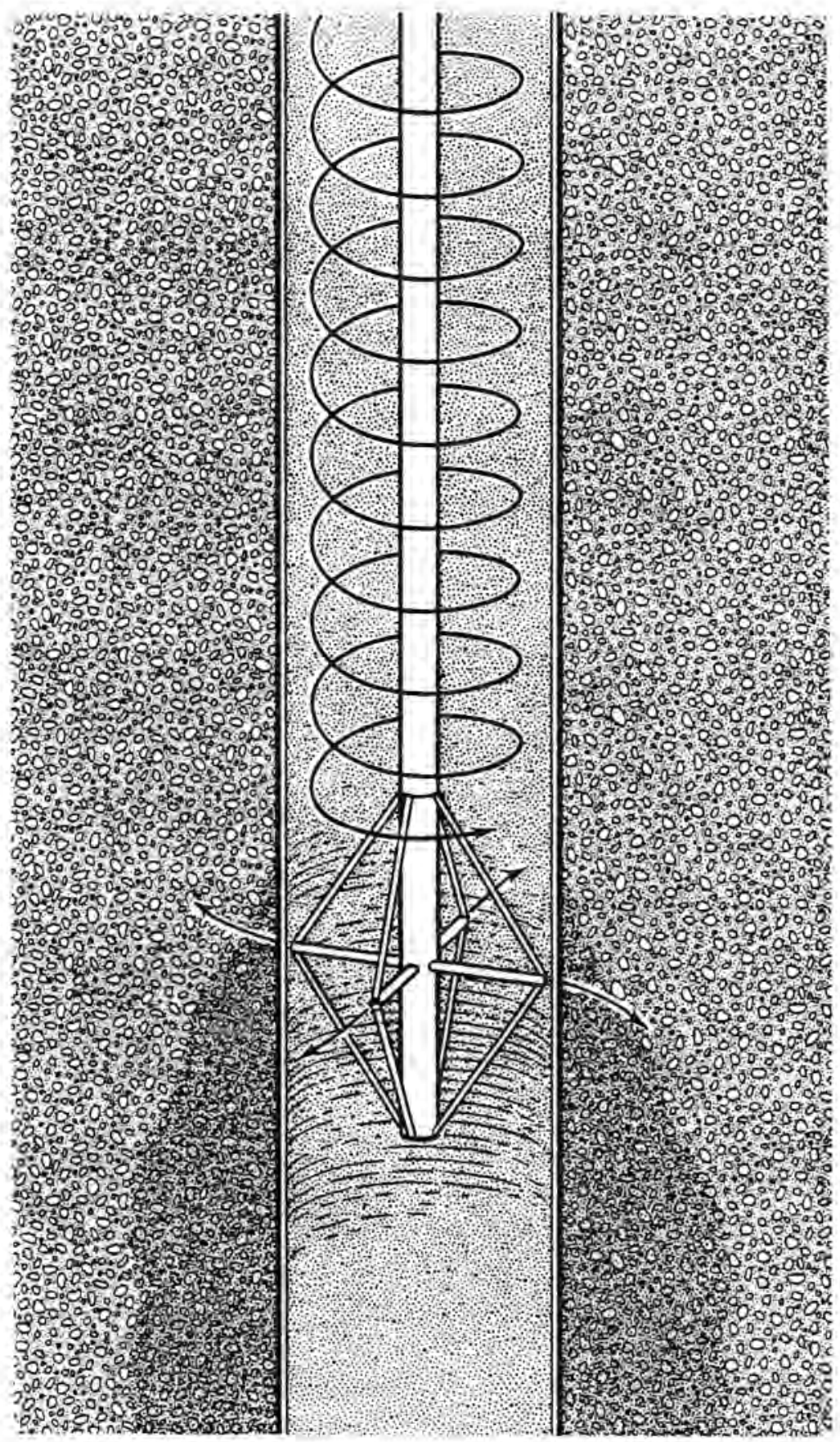

FIGURE 3.4. Jetting Too1 
TABLE 3.1. Construction Materials and Design Alternatives for Wells in Study Area

\begin{tabular}{|c|c|c|c|c|c|c|c|}
\hline \multirow[b]{2}{*}{ We11 Number } & \multirow[b]{2}{*}{$\begin{array}{l}\text { Drilling } \\
\text { Fluid }\end{array}$} & \multirow[b]{2}{*}{$\begin{array}{c}\text { Grave } 1 \\
\text { Pack }\end{array}$} & \multicolumn{4}{|c|}{ SCREEN } & \multirow[b]{2}{*}{ COMMENTS } \\
\hline & & & Type & $\begin{array}{l}\text { Slot Size } \\
\text { (inch) }\end{array}$ & $\begin{array}{l}\text { Percent } \\
\text { Open }\end{array}$ & $\begin{array}{r}\text { Open Area } \\
\left(\mathrm{ft}^{2} / 8 \mathrm{ft}\right)\end{array}$ & \\
\hline 1 & Bentonite & $\begin{array}{c}\# 30 \\
\text { Eau Claire }\end{array}$ & $\begin{array}{l}\text { Cage-wound } \\
\text { Round Wire }\end{array}$ & $45 / 1000$ & 20.3 & 4.6 & \\
\hline 2 & Bentonite & Eau Claire & Bridge & $1 / 32$ & 3.0 & 0.63 & \\
\hline 3 & Bentonite & Natural & $\begin{array}{l}\text { Cage-Wound } \\
\text { Shaped wire }\end{array}$ & $15 / 1000$ & 11.4 & 2.6 & $\begin{array}{l}\text { Screen slot } \\
\text { undersized by } \\
50 \%\end{array}$ \\
\hline 4 & Organic & $\begin{array}{c}\# 30 \\
\text { Eau Claire }\end{array}$ & Bridge & $1 / 32$ & 3.0 & 0.63 & $\begin{array}{l}\text { Similar forma- } \\
\text { tion to well } 2\end{array}$ \\
\hline 5 & Bentonite & $\begin{array}{c}\# 20 \\
\text { Eau Claire }\end{array}$ & $\begin{array}{l}\text { Cage-wound } \\
\text { Shaped wire }\end{array}$ & $75 / 1000$ & 39.9 & 9.0 & \\
\hline 6 & Organic & $\begin{array}{l}\# 20 \\
\text { Eau Claire }\end{array}$ & $\begin{array}{l}\text { Cage-wound } \\
\text { Shaped wire }\end{array}$ & $75 / 1000$ & 39.9 & 9.0 & $\begin{array}{l}\text { Similar forma- } \\
\text { tion to we11 } 5\end{array}$ \\
\hline 7 & Organic & $\begin{array}{c}\# 20 \\
\text { Eau Claire }\end{array}$ & $\begin{array}{l}\text { Cage-wound } \\
\text { Shaped wire }\end{array}$ & $75 / 1000$ & 48.7 & 11.0 & \\
\hline 8 & Bentonite & $\begin{array}{l}\text { P1t Run } \\
\text { Graded }\end{array}$ & $\begin{array}{l}\text { Horizontal } \\
\text { Milled slot }\end{array}$ & $75 / 1000$ & 1.3 & 0.29 & \\
\hline 9 & Bentonite & $3 / 8 \times 3 / 16$ & $\begin{array}{l}\text { Cage-wound } \\
\text { Shaped wire }\end{array}$ & $180 / 1000$ & 60.0 & 13.5 & $\begin{array}{l}\text { Filter pack } \\
\text { oversized }\end{array}$ \\
\hline 10 & Bentonite & Natural & $\begin{array}{l}\text { Cage-wound } \\
\text { Shaped wire }\end{array}$ & 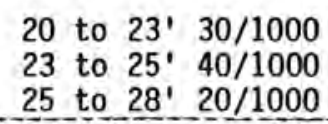 & $\begin{array}{l}20.7 \\
24.2 \\
14.8 \\
\end{array}$ & 4.4 & $\begin{array}{l}\text { Slot sizes de- } \\
\text { signed to match } \\
\text { formation }\end{array}$ \\
\hline
\end{tabular}

*This particular screen has a narrow wire to allow more open area. 
The well design and development alternatives were incorporated into ten wells drilled into an unconsolidated aquifer in a topographically flat region of Central Minnesota. The site chosen was the most homogeneous one available at the Staples Irrigation Center, according to test hole samples taken before the site was selected. Each well was of equal depth and had equal length of screen. The wells were located on two parallel lines, 50 feet apart, with five wells in each line connected by a common discharge manifold The two manifolds were centrally connected to a discharge line which contained a flow meter.

\subsubsection{Well Development and Pump Tests}

In this study pump tests were performed on each well after each method of well development (overpumping, surging and jetting). To avoid interference effects, only one well was pumped at a time, with the other wells acting as observation wells.

In a pump test, a given we11 was pumped for 24 hours and then rested for another 24 hours or until the original static water level was reached. During the pump test, the drawdown in the pumped well and observation wells was recorded every minute for the first 10 minutes, every 10 minutes for the next 90 minutes, then every 20 minutes until the end of the test. The same procedure was followed during the 24-hour resting period. Because of the large volume of data generated in the pump tests, the measuring equipment was linked to an interactive minicomputer.

\subsubsection{Measurement of We11 Drawdown, Specific Capacity, Efficiency, and Energy Use}

Actual well drawdown is easily computed by subtracting the static water level from the water level when pumping is being performed.

Theoretical drawdown is a measure of the potential of a well to deliver water from the aquifer in which it is located. Accurate computation of theoretical drawdown is difficult and is subject to the judgment of the person doing the computation. 
Briefly, the method used in the study for calculating theoretical drawdown is the following:

1. Record 24-hour data on the drawdown at observation wells within 50 feet of the we11 being pump tested and graph this drawdown versus time data on $\log -\log$ graph paper.

2. Superimpose the above graph on standardization graphs and select a match point from the two graphs. From the time-drawdown coordinates at this match point, the transmissability $(T)$ and specific yield coefficient (Sy) were calculated for the aquifer of the well being pump tested.

3. Combine $T$ and Sy parameters with several others, including the permeability of the aquifer vertically $(K z)$ and horizontally $(\mathrm{Kr})$, to estimate the theoretical drawdown of the well via an equation, which is not repeated here because it is computationally quite burdensome. For more specific information on the calculation of theoretical drawdown, the reader is referred to pages 39 to 41 of the Effects of Irrigation Well Efficiency on Energy Requirements Final Report (Werner et al. 1980).

Specific capacity has often been used in the past to measure well performance. It is calculated by the following formula:

$$
\text { S.C. }=\frac{Q}{S W}
$$

where

$$
\begin{aligned}
\text { S.C. } & =\text { abbreviation for specific capacity } \\
Q & =\text { flow rate } \\
\text { SW } & =\text { drawdown in the wel1. }
\end{aligned}
$$

Specific capacity's main asset is that it is easy to compute. It is computed directly after the well is in place, and subsequent changes in well performance are assessed by subsequent specific capacity measurements. The primary problem with specific capacity is that it is not a true measure of the efficiency of the well. Measuring drawdown when the well is constructed does not measure the capacity of the well based on aquifer characteristics. For 
example, a wel1 might be capable of delivering $50 \mathrm{gpm} / \mathrm{ft}$ of drawdown, but measurements of capacity at the time of well construction might equal $30 \mathrm{gpm} / \mathrm{ft}$.

When calculated properly, well efficiency is an accurate measure of a well's performance. The accepted equation for computing well efficiency is the following:

$$
W e=\frac{Q / S a}{Q / S t} \times 100
$$

where

$$
\begin{aligned}
\text { We } & =\% \text { efficiency of the well } \\
Q & =\text { flow rate } \\
\text { Sa } & =\text { actual drawdown in the well adjusted for screen loss } \\
\text { St } & =\text { theoretical drawdown. }
\end{aligned}
$$

The drawback to using this equation is the difficulty of calculating theoretical drawdown, which was discussed earlier.

Two different measures of efficiency were used to assess well performance-point-time efficiency estimates and integrated-time efficiency estimates. Point-time efficiency estimates are simply estimates calculated at different points in time from the well-efficiency equation presented above. Integratedtime efficiency estimates were calculated by integrating the actual drawdown versus time curves with the theoretical drawdown versus time curves. These integrated values were then inserted into the we1l-efficiency equation and an integrated-time efficiency measurement was obtained.

Energy use was calculated for each of the alternative designs examined in the cost analysis, which are listed below. Energy use for each alternative was determined by changes in drawdown caused by changes in well efficiency. Wel1 efficiencies for the design alternatives were obtained directly from the pump test results.

\subsubsection{Cost Analysis}

The costs of several alternative well designs were considered as part of the cost analysis. The alternative well designs analyzed were:

1. a low open area well screen with no development

2. a low open area screen with surging development

3. a low open area screen with jetting development

4. a high open area screen with no development 
5. a high open area screen with surging development

6. a high open area screen with jetting development.

These designs were analyzed for a typical irrigation situation in an unconsolidated aquifer.

\subsection{TECHNICAL PERFORMANCE RESULTS}

The results of the specific capacity measurements computed from the field test data are illustrated in Figure 3.5. The results of the point-time efficiency measurements and the integrated efficiency measurements are presented in Table 3.2, where each pump test is performed after each well development technique is used. Well 9 is omitted from the results because soon after the tests began, it suffered complete failure as a result of excessive sand pumping. It should be noted that these results are subject to the conditions of the aquifer where the tests were performed. Test results in other aquifers with.different characteristics may vary. In particular, the results are probably not applicable to consolidated aquifers.

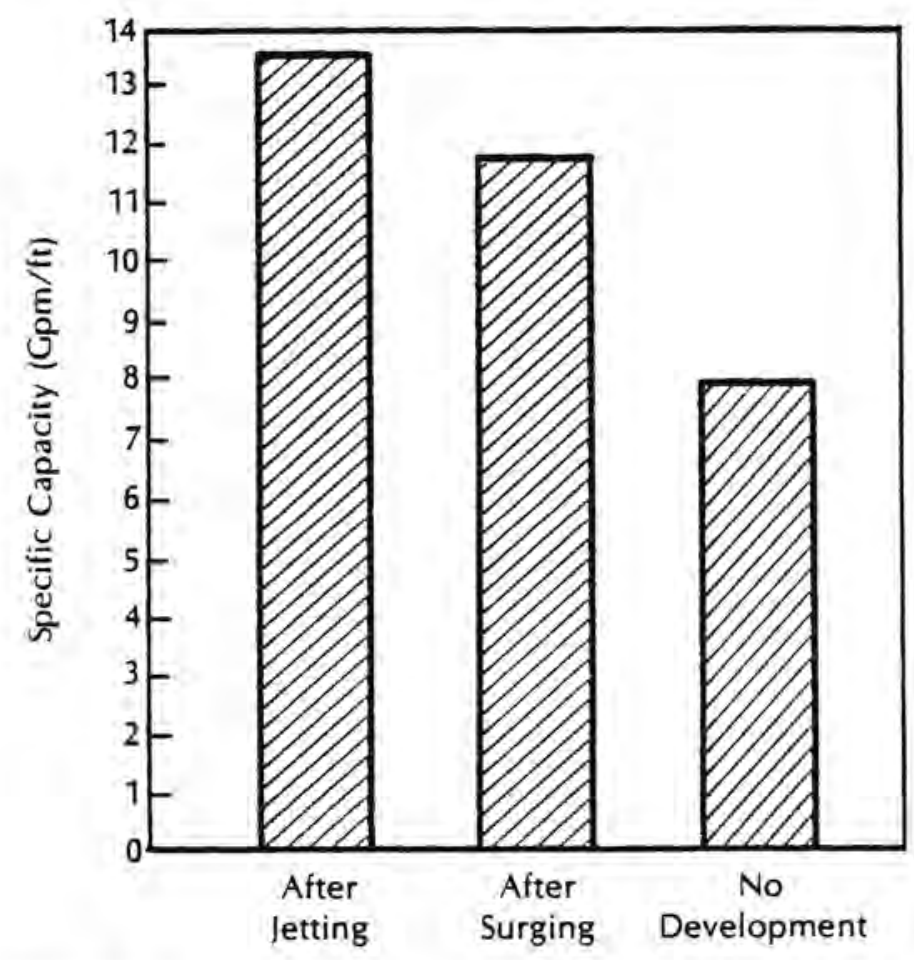

FIGURE 3.5. Average Specific Capacity for Wells Drilled Using Bentonite Fluid 
TABLE 3.2. Specific Capacities and Well Efficiencies for the Study Wells

We11

No development

1 Surging

Jetting

No development

2 Surging

Jetting

No development

3 Surging

Jetting

No development

4 Surging

Jetting

No development

5 Surging

Jetting

No development

6 Surging

Jetting

No development

7 Surging

Jetting

No development

8 Surging

Jetting

No development

10 Surging Jetting
Specific

Capacity

(GPM/FT)

5.06

9.23

10.05

2.56

5.36

5.68

5.76

8.66

10.43

12.53

11.40

11.78

15.3

25.8

27.8

21.0

20.7

22.5

16.2

14.8

16.2

15.1

16.7

16.3

3.5

4.8

11.3
Point-Time

Efficiency

(Percent)

15.5

28.3

30.7

8.3

17.4

18.5

18.1

27.2

32.8

40.8

37.2

38.4

50.0

84.1

90.8

71.3

70.4

76.2

55.4

50.4

55.4

41.5

45.8

44.8

11.7

16.1

38.0
Integrated

Efficiency

(Percent)

14.1

26.2

28.7

8.2

17.3

17.2

25.5

30.8

38.4

34.9

36.6

49.4

81.8

90.1

68.0

68.0

73.8

52.7

47.4

52.4

40.1

45.8

43.4

11.2

15.4

36.4 
Based on the results obtained in the field tests and computations, the following conclusions are evident:

1. Errors in well design, such as improper screen slot size openings or filter materials, will cause a well located in an unconsolidated aquifer to operate at substantially less than its potential efficiency and can result in complete well failure from excessive sand pumping.

2. Screen open areas (not slot-size openings) can limit the production of a well in an unconsolidated aquifer if open areas are minimal.

3. Wells drilled in an unconsolidated aquifer with bentonite drilling fluid responded to development by high pressure water jetting and airlift pumping with a 45 percent reduction in drawdown and responded to development by surging with a 35 percent reduction in drawdown.

4. For wells drilled in an unconsolidated aquifer with bentonite drilling fluid:

- The average increases in well efficiency were 12.7 points for surging and 18.4 for jetting. The absolute increase in well efficiency resulting from development appears to be negatively related to the open area of the screen, because the increase in efficiercy resulting from well development was greater in wells with a small amount of open area on the screen.

- The relative increase (i.e., percentage increase) in efficiency resulting from development is not a function of the open area of the screen, because all wells responded to development with approximately the same relative improvement.

5. Although the discharge and efficiency of wells drilled with an organically based drilling fluid were initially higher than for wells drilled with a bentonite-based drilling fluid, wells drilled with an organic-based drilling fluid did not respond significantly to any development method.

6. Wel1 development reduces energy use and resulting operating costs by reducing drawdown in wells drilled in unconsolidated aquifers with 
bentonite drilling fluid. Development also increases the life of the we 11 and system components by reducing sand pumping.

Several recommendations for well drillers and well owners can be inferred from the results of this study, including:

1. Well sampling and well design based on the results of this sampling should be undertaken before drilling a well. Optimum well design depends on the particular situation of the well being considered. Poor design will result in low production and efficiency and/or sand pumping.

2. Quality materials, including uniform, properly sized gravel packs and high open-area, corrosive-resistant screens, should be used to obtain maximum operating performance from a well drilled in an unconsolidated aquifer.

3. Well development should be performed on wells drilled in unconsolidated aquifers to insure peak efficiency and sand-free production. For several of the wells, efficiency nearly doubled with development. In addition, the reduction in sand pumping as a result of development will maintain system efficiency over time and increase the life of the system. Development methods should be used that will give the largest net increase in efficiency for the lowest economic input. The selection of the optimum method using this criteria will depend on the drilling method and construction materials used.

4. Numeric presentation of well efficiency should be attempted only after highly discriminant analysis of the aquifer. Accurate well-efficiency values are difficult to determine since most aquifers are not ideal and pumping data may not satisfy commonly used methods for calculating theoretical drawdown for a well.

\subsection{ENERGY SAVINGS RESULTS}

Surging with a low open-area screen resulted in estimated annual energy savings of nearly 50,000 kWh for a typical well located in an unconsolidated aquifer. Surging with a high open-area screen resulted in a savings of 6,400 kWh. The annual savings resulting from jetting were slightly higher than these 
figures. The largest annual energy savings, more than $79,000 \mathrm{kWh}$, were realized by switching from a low open-area screen to a high open-area screen. The amount of energy savings obtained from the use of any well design technique will be site specific. However, in a companion study to this one (Wilfert, et al. 1982) the annual nationwide energy savings from using surging and jetting in all locations where their use is cost-effective were estimated to be nearly 18 trillion Btu.

\subsection{COST SAVINGS RESULTS}

All indications are that use of well design and development techniques in unconsolidated aquifers will result in significant cost savings over the life of the we11, even when the additional capital costs of implementing these techniques are accounted for. A summary of the results for the six alternative designs examined in the cost analysis is presented in Table 3.3. Note that surging and jetting on low open-area screens would return their capital costs in less than one year and all other alternatives would return their costs in less than two years.

In another companion volume (Patton, et al. 1982), the net costs of surging and jetting (annual capital minus annual operating costs) were examined for various regions in the country. The results of this analysis determined that surging in unconsolidated aquifers would result in net cost savings in every state among the 17 largest irrigation states except one. Jetting would result in net cost savings in 13 of the 17 largest irrigation states. 
TABLE 3.3. Cost Summary for Example Comparing 2 Well Screens and 3 We11 Development Methods on an Unconsolidated Aquifer (1980\$)

\begin{tabular}{|c|c|c|c|}
\hline & $\begin{array}{c}\text { Added } \\
\text { Investment } \\
\text { Cost } \\
\$ \\
\end{array}$ & $\begin{array}{c}\text { Cost to } \\
\text { Overcome } \\
\text { Drawdown } \\
\$ / y r \\
\end{array}$ & $\begin{array}{c}\text { Savings in Operating } \\
\text { Cost Versus Low Open } \\
\text { Area Screen--No } \\
\text { Development } \\
\$ / y r \\
\end{array}$ \\
\hline $\begin{array}{l}\text { Low open area screen - } \\
\text { no development }\end{array}$ & 0 & 4761 & -- \\
\hline $\begin{array}{l}\text { Low open area screen - } \\
\text { surging }\end{array}$ & 400 & 2268 & 2493 \\
\hline $\begin{array}{l}\text { Low open area screen - } \\
\text { jetting }\end{array}$ & 1600 & 2134 & 2627 \\
\hline $\begin{array}{l}\text { High open area screen - } \\
\text { no development }\end{array}$ & 4400 & 789 & 3972 \\
\hline $\begin{array}{l}\text { High open area screen - } \\
\text { surging }\end{array}$ & 4800 & 469 & 4292 \\
\hline $\begin{array}{l}\text { High open area screen - } \\
\text { jetting }\end{array}$ & 6000 & 439 & 4322 \\
\hline
\end{tabular}




\subsection{GROUNDWATER IRRIGATION SUPPLY SYSTEM OPTIMIZATION}

Although it is generaT7y acknowledged that groundwater irrigation supply systems are not as energy efficient as they could be, the specific causes of inefficiency within a water supply system and the costs and benefits of correcting this inefficiency are not well known. For example, although we11 and pump testing programs can tell farmers that their wells are inefficient, the testers are often not able to provide information on what can be done to correct the problem and the costs and benefis of undertaking the possible corrections. A simulation model has been developed to aid in analyzing the causes of water supply system inefficiencies and the costs and benefits of correcting the inefficiencies. This model was expanded as part of the research project undertaken by the University of California at Davis.

\subsection{TECHNOLOGY DESCRIPTION}

The simulation model expanded in the project is a digital computer program that has the ability to take a set of groundwater supply input parameters supplied by the user, and generate energy use, pumping costs, and other types of measurements. The model has the following characteristics:

- It is written in a computer language and format that is readily adaptable to most computer systems in use today.

- It will match the technical characteristics of a specified pump with the requirements for the pumping system in terms of head and discharge and will generate estimates of pumping costs per month if the pump and system requirements are found to be compatible.

- It is capable of performing sensitivity analyses on the impacts of pump and/or well characteristics on pumping energy use and costs and can provide guidelines for the correct design of new water supply systems based on aquifer characteristics.

The basic objective of the model is to simulate the characteristics of a groundwater supply system similar to the one shown in Figure 4.1. 


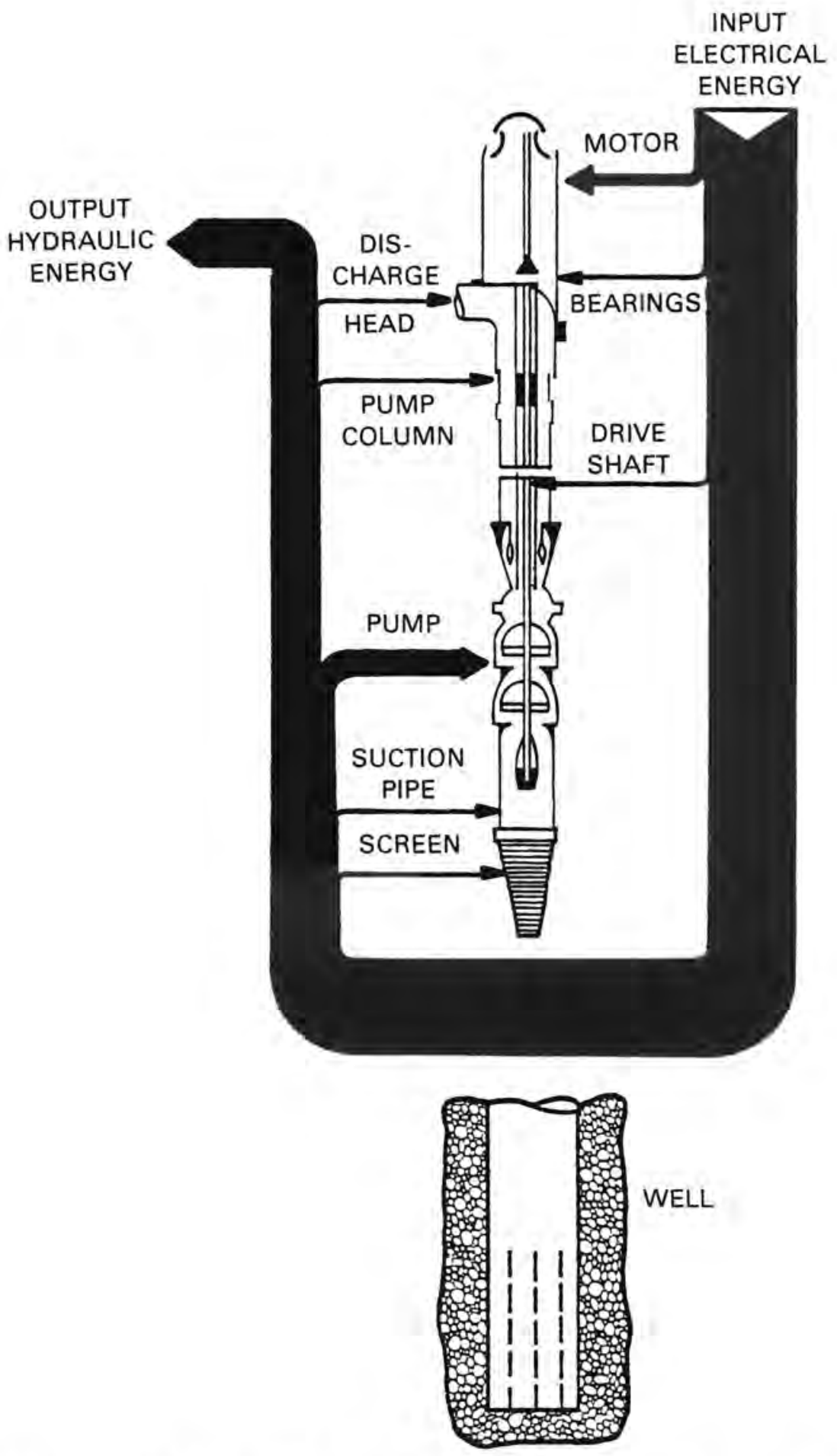

FIGURE 4.1. Locations of Groundwater Supply System Energy Losses 


\subsubsection{Computer Language}

The model is written in BASIC computer language but can be converted to FORTRAN IV if necessary. The calculations performed within the model are not particularly complex, but the quantity of calculations performed requires the use of a computer. Computers with storage and memory capacities equal to or greater than that of a Hewlett-Packard 9830A are generally adequate to perform the required calculations.

\subsubsection{Model Process}

A simplified flow chart for the simulation model is shown in Figure 4.2 . The program starts with a set of data on water demands, groundwater pumping lifts, required system operating pressures, and other site-specific requirements (Box 1 in Figure 4.2). Then, based on pump testing data for either new or existing pumps, the head-discharge curve for a particular pump is input into the model (Box 2 in Figure 4.2). From this head-discharge curve, the model calculates the best least-squares fit for a cubic polynomial equation that estimates the total dynamic head of the pump (in feet) as a function of the discharge of the pump (in gallons per minute) (Box 3 in Figure 4.2).

The next step in the model procedures is a determination of the validity of the head-discharge curve that has been input into the model (Box 4 in Figure 4.2). This is done by comparing the maximum value of the input head to the sum of the static water level head and the discharge head for each month of the water year. If the maximum value of the input head is less than the sum of the static water level head and the discharge head for any particular month, the head-discharge curve is rejected and the program instructs the user to enter a new head-discharge curve for another pump.

Next, the operating discharge for each month of the water year is calculated (Box 5). This is done by finding the operating discharge at which the total dynamic head generated by the previously calculated least-squares equation is equal to the system head, which is comprised of drawdown, the static water level and the discharge head. The calculated operating discharge is then checked against the minimum and maximum allowable operating discharge for the system (Box 6). If, for any particular month, the calculated operating discharge is not within the range of the minimum and maximum operating 


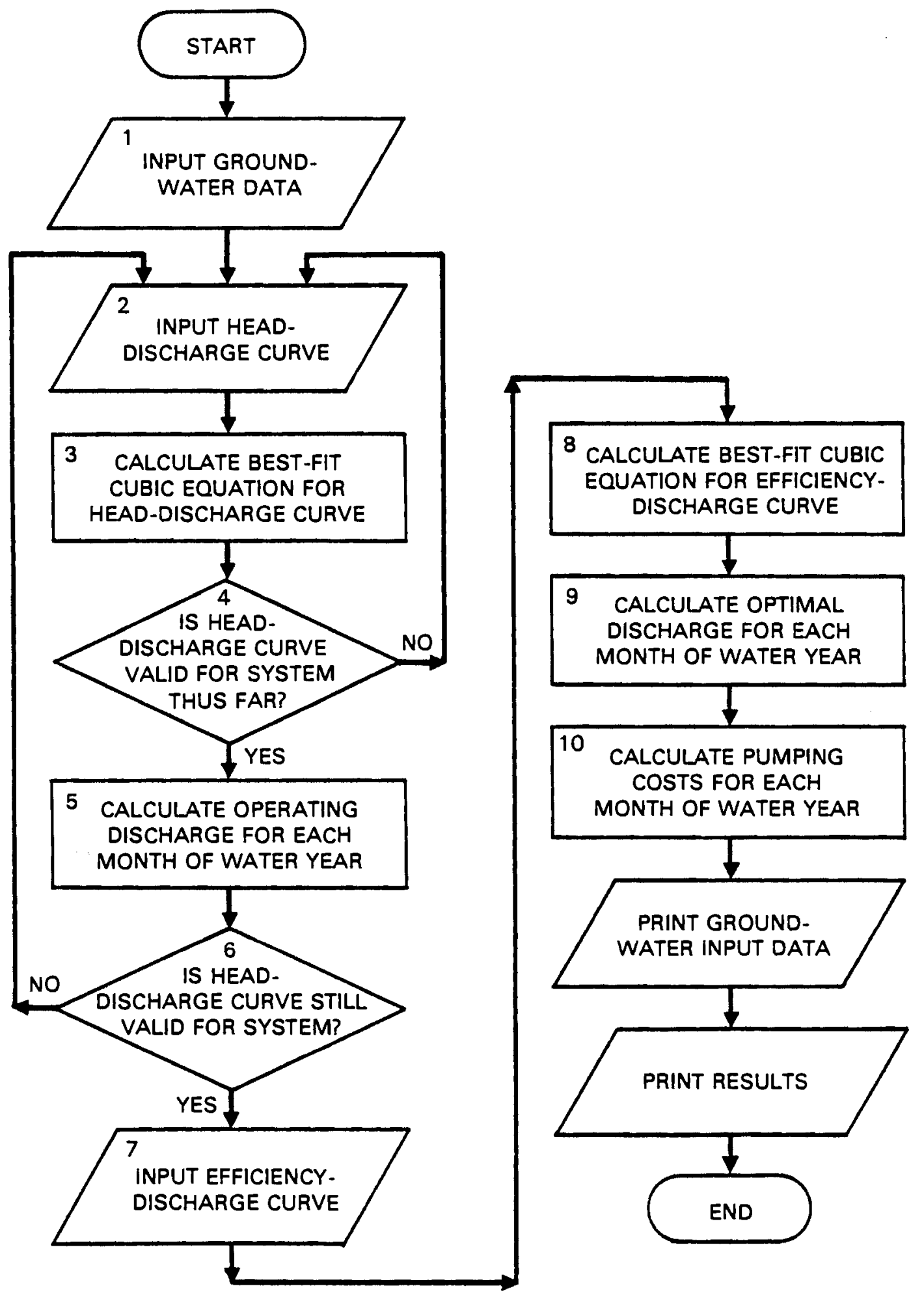

FIGURE 4.2. Simplified Flow Chart Illustrating Major Steps of Groundwater Supply System Model 
discharge, the head-discharge curve is rejected and the user is instructed to input a new head-discharge curve.

The efficiency-discharge curve for the pump being analyzed is then input into the model (Box 7). This efficiency discharge curve is a set of coordinates comprised of the efficiency of the pump bowl (in percent) and the pump discharge (in gallons per minute). From this data, the best least-squares fit for a cubic polynomial equation that estimates the pump efficiency in percent as a function of the discharge of the pump (in gallons per minute) is calculated (Box 8).

In the next step, the optimal discharge for the well for each month of the year is calculated (Box 9). The optimal discharge is the discharge at which the difference between the benefits of the well and the pumping costs are maximized. The benefits of the well are specified in the model to be equal to the cost of obtaining water from another source.

The final analytical step of the model is to calculate the pumping costs per month (Box 10). These pumping costs are based on the time of pumping required to meet demand, the operating head, and the operating pump efficiency, all of which are calculated in this final step of the model process.

Time of pumping is calculated knowing the water demand required (from Box 1) and the calculated operating discharge (from Box 5). Operating head and operating pump efficiency are computed by inserting the calculated values for operating discharge into the equations generated for head-discharge (from Box 3) and for pump efficiency-discharge (from Box 7).

From estimates on time of pumping, operating head, and pump efficiency, total energy use requirements per month are determined. By multiplying these requirements by a cost of electricity input, estimates of monthly pumping costs are obtained.

\subsubsection{Analys is Capabilities}

The model is capable of analyzing a number of different types of problems, including well efficiency problems, pump efficiency problems, problems involving the proper selection of a pump to match aquifer characteristics, and 
others. Some specific examples of uses of the model will be described later in this chapter.

The model is able to analyze problems, such as the ones cited above, because it can use a number of supplied input parameters on a water supply and pumping system to derive system performance measurements. Sensitivity analyses of the impacts of various factors on system performance can be conducted by changing the input parameters.

The general input parameters required for the model are summarized in Table 4.1. If a problem involving well characteristics is to be analyzed with the mode1, step-drawdown parameters for the well are needed. These parameters are a measure of a well's ability to deliver water up to the maximum discharge of the pump and are also a measure of well efficiency.

In simple terms, a step-drawdown test involves measuring the amount of drawdown (the difference between static water elevation in the well and water elevation when the pump is operating) at separate intervals and the amount of pump discharges over a given time period. The test parameters required here are a head-loss coefficient for laminar flow in the aquifer, a head-loss coefficient for turbulent flow into the borehole and screen, and an exponent that indicates the severity of the turbulent flow. These parameters are quite complicated for the average person to calculate, but a computer code is available at the University of California at Davis to calculate the parameters using simple discharge and drawdown data from the pumping system.

The primary input parameters of interest for analysis purposes are the head-discharge points, the pump efficiency-discharge points, and the parameters of the step-drawdown test. The potential impacts on pumping costs of inefficiencies in pumps and wells can be evaluated using this data.

\subsection{METHOD OF TESTING}

To demonstrate its potential uses, the model was used to analyze the following specific problems:

- What effect does the head and efficiency of a pump at a given discharge rate have on total pumping cost? 


\section{TABLE 4.1. Input Data Requirements for}

Simulation Model Operation

1. The extraordinary annual benefits, such as the salvage value of old equipment, associated with a proposed project.

2. The extraordinary annual costs, such as the capital costs of new equipment, of a proposed project. (In cases where only existing pumping costs are being analyzed, the above two input parameters would equal zero.)

3. The price of alternate water from another source.

4. The cost of electricity.

5. The efficiency of the electric motor.

6. The maximum energy efficiency of a potential pump for the system.

7. The average discharge head over the water year.

8. The average static water level for each month of the water year.

9. The average water demands for each month.

10. The total number of head-discharge points. A head-discharge curve is a plot of the energy contained in a unit weight of flowing fluid (head) versus pump discharge.

11. The total dynamic head and discharge points. At a minimum, these figures must include the maximum head of the pump and the minimum and maximum discharge for which the curve is valid.

12. The total number of pump efficiency-discharge points. A pump-efficiency discharge curve is a plot of the energy efficiency of the pump versus the pump discharge.

13. The pump bowl efficiency and discharge points. The minimum number of points for each is 3 ; the maximum is 15 . 
- What effect does sand in the aquifer have on energy efficiency and pumping cost?

- What effect does well energy efficiency have on total pumping plant energy use and cost?

\subsubsection{Effects of Pump Head and Efficiency Characteristics}

To test the impacts of pump head and efficiency characteristics, four different head-discharge curves and two different pump efficiency curves were input to the simulation model. The head-discharge and pump efficiency curves ranged from steep (rapidly decreasing head or efficiency with changing discharge) to flat (slowly decreasing head or efficiency with changing discharge). The specific objective of this example problem was to select the proper pump for a well supplying water to the municipal water supply of the city of Davis, California.

The City of Davis requested that the pump installed in the well be able to deliver 1300 gallons per minute of discharge against a total pumping head of 250 feet. To meet these requirements, a discharge head of 129 feet was calculated and the range of operating discharges throughout the year was evenly distributed on each side of the design rate of $1300 \mathrm{gpm}$. Other appropriate input parameters for the problem were also identified.

\subsubsection{Effects of Sand Pumping}

For this example, data from a sand pumping test performed by a private pump manufacturer were used. In this sand pumping test, head-discharge and pumping efficiency-discharge curves were calculated for various discharge rates before and after 40 percent of volume sand was pumped through a five-stage turbine pump. One sand pumping test was run for a total of 23 hours, starting and stopping the pump three times over the course of the test. Another test was run for 19 hours. The impacts of sand pumping were evaluated by feeding head-discharge and pump efficiency-discharge data from the tests through the simulation model. 


\subsubsection{Effects of Well Efficiency}

In addition to actual drawdown, the theoretical drawdown based on acquifer characteristics is necessary to calculate well efficiency. This theoretical drawdown was calculated, based on a number of different types of well data, for a well located on a farm in Chico, California.

Once the theoretical drawdown was calculated for the well, various hypothetical levels of actual drawdown at different discharges were used to calculate various levels of well efficiency. The well test parameters required for simulation model operation were calculated for each hypothetical level of actual drawdown and corresponding well efficiency, then input to the model to evaluate the impacts of improving well efficiency.

\subsection{TECHNICAL PERFORMANCE RESULTS}

A number of different types of output parameter estimates were obtained from using the simulation model to analyze the three problems. However, for the sake of brevity and because the level of these output parameter estimates is dependent on the specific input parameters used, only the major conclusions drawn from the simulation model results are presented here.

From the simulation modeling of the three types of problems, the following major conclusions were reached:

1. The energy efficiency of one pump compared to another is not nearly as important in determining system energy consumption as is operating a pump near the point of its maximum efficiency.

2. A pump with a steep head-discharge curve and a flat head-efficiency curve uses less energy than a pump with a flat head-discharge curve and a steep efficiency curve.

3. Energy-use efficiency decreases as the amount of sand pumped increases, and the relationship may be linear.

4. As well efficiency increases, the annual pumping cost decreases, but at a decreasing rate. Therefore, while it may be economically beneficial to have the well rehabilitated to increase well efficiency at the lower values, the same may not be true at higher values of well efficiency. 


\subsection{ENERGY SAVINGS RESULTS}

The energy savings resulting from using the simulation model will depend on how inefficient present pumping plants are, how much the simulation model aids in diagnosing the problems of present pumping plants, and the degree to which the problems of the present pumping plants are corrected after the model is used.

Because of the informational nature of the simulation program, it is impossible to develop quantitative estimates of the potential energy savings of the model. However, this model and others like it have the potential to significantly increase the level of knowledge on pumping plant energy use efficiency, especially when used in conjunction with well and pump testing programs. These testing programs are generally able to provide good estimates of the relative energy efficiency of an overall pumping plant, but are not able to provide information on the specific causes of energy inefficiency and the costs and benefits of correcting this inefficiency. Simulation models like the one developed in this project have the potential to provide this information.

\subsection{COST SAVINGS RESULTS}

Quantitative cost savings estimates from using the simulation model are also impossible to calculate because of the informational nature of the model. However, if the necessary input data for the model can be collected during well and pump tests, the economic benefits of using a simulation model will usually outweigh the costs. 


\subsection{COLUMN AND PUMP REDESIGN}

The energy efficiency of a pumping plant (i.e., energy output relative to energy input), is an important factor in determining overall energy use for irrigation. While conventional turbine pumping plants are generally reliable and have low initial investment costs, energy is lost because of the design of these pumps.

In a research project conducted by Aerospace Research Corporation of Roanoke, Virginia, a turbine pumping plant and well column were redesigned for increased energy efficiency. The redesigned column and pumping plant were then field tested in a 124-foot-deep well and were evaluated for efficiency, performance, ease of installation, and cost effectiveness.

\subsection{TECHNOLOGY DESCRIPTION}

The redesigned column and turbine pumping plant included the following major components:

- a well water packer installed between the column pipe and well casing

- a column pipe with pump outlet ports and with a smaller diameter than those of conventional turbine pumping plants

- a high-strength steel line shaft with a smaller diameter than those of conventional turbine pumping plants

- a redesigned pump impeller and diffuser.

A schematic diagram of the redesigned column with some of its major components is shown in Figure 5.1 .

\subsubsection{Well Water Packer}

The well water packer is a key element in improving the lift efficiency of the redesigned turbine pumping plant. It is installed to seal the space between the column pipe of the pumping plant and the well casing. This allows water to flow upward through the space between the column pipe and well casing, as well as through the column pipe. By allowing water to flow through a larger conduit area, friction losses and resulting energy losses are reduced. The 


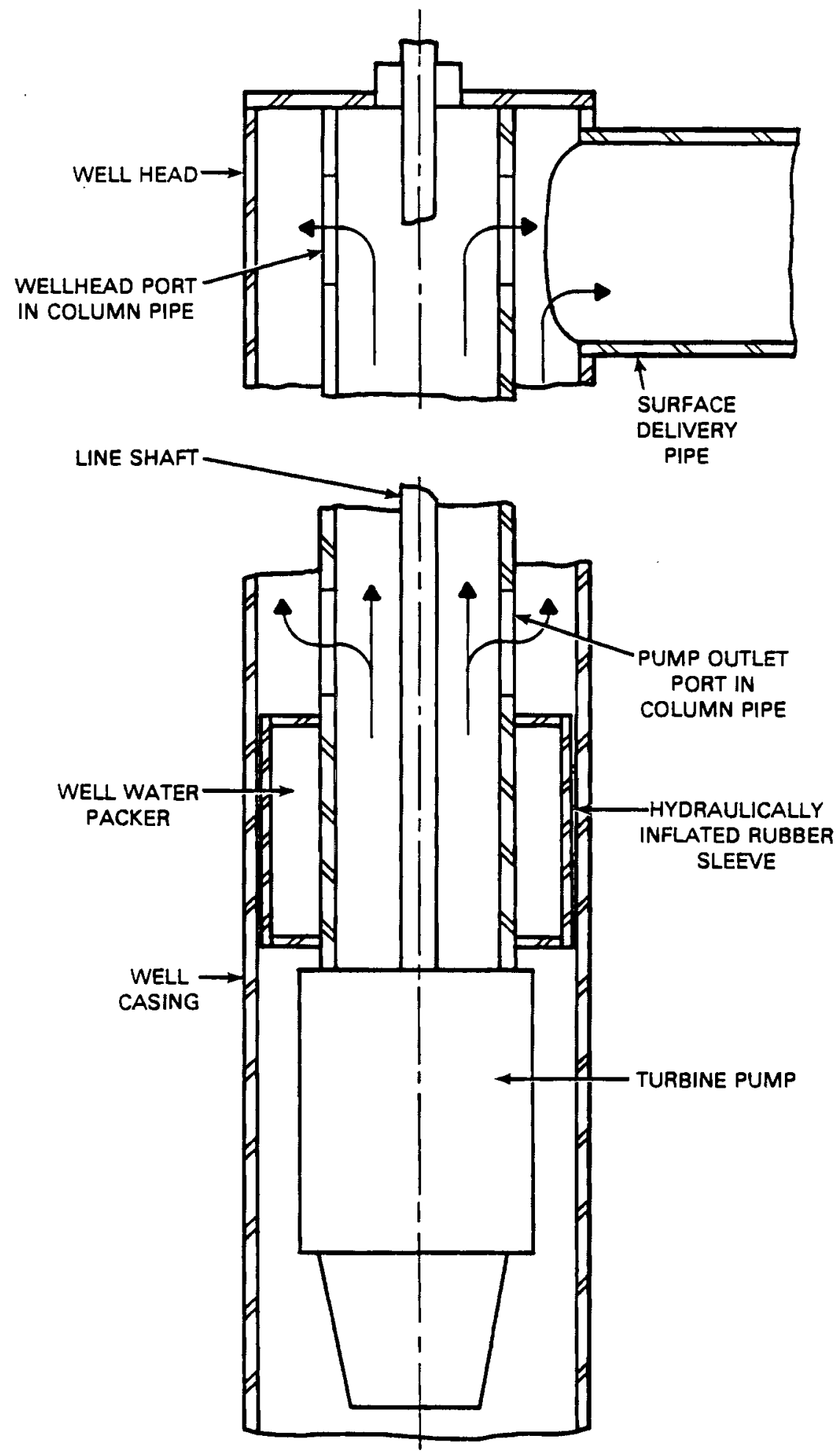

FIGURE 5.1. Schematic Drawing of Pump, Packer, Column Pipe, and Line Shaft Arrangement 
packer is equipped with a hydraulically inflated rubber sleeve that serves to seal the well casing to the packer. The sleeves are inflated to $100 \mathrm{psi}$ through an air line from the surface. The bottom of the packer is threaded to fit the standard top component of the turbine pump; the top is threaded to fit a standard four-inch pipe coupling. The packer is approximately five feet in length.

\subsubsection{Column Pipe}

The column pipe of the redesigned pumping plant is equipped with outlets to allow water to flow out of the column pipe into the well casing. These outlets are located just above the level of the well packer.

The configuration of the redesigned column allows for a substantial reduction in column pipe size compared to a conventional turbine pumping system. The column pipe of the redesigned column that was field tested during the project was approximately four inches in diameter and was used to deliver a design flow rate of $600 \mathrm{gpm}$. This pipe is smaller than that recommended for a flow rate of $600 \mathrm{gpm}$ on a conventionally designed turbine pump. However, the use of the well casing as a supplementary water conduit allows the size of the column pipe to be determined by the cross section of metal needed to support the pump and head of water, rather than by flow considerations.

\subsubsection{Line Shaft}

The turbine pump of the redesigned pumping plant is driven by a highstrength open line shaft $3 / 4$ inch in diameter, with water lubricated bearings at 10-foot intervals. The use of high-strength heat-treated steel in the line shaft permits a reduction in the diameter of the line shaft for the same amount of required shaft strength. Because line shaft bearing friction losses increase proportionally to the square of the diameter of the line shaft, a smaller line shaft reduces these losses.

The use of a smaller line shaft together with a smaller column pipe substantially reduces the weight of the redesigned pumping plant compared to a conventional pumping plant. This can be a substantial advantage when removing the redesigned pumping plant for modifictions and repairs. Installations and 
removals of the redesigned pumping plant in wells that are 125 feet deep or less can be accomplished with on-farm tools, such as a tripod and three-ton chain hoist, in 12 to 16 man-hours.

\subsubsection{Impeller and Diffuser}

Several aspects of the pump impeller, including impeller blade design, its surface finish, and the impeller-to-bowl seal, were redesigned to reduce energy losses. The diffuser, which converts some of the velocity head leaving the impeller into pressure and also converts water flow to an upward direction, was also redesigned. All of the design changes were studied theoretically before actually being implemented.

Theoretical analysis of the impeller blade revealed that slowing down water flow within the inlet annulus of the impeller apparatus could result in a positive angle of fluid attack at the inlet walls and a larger negative angle of attack at the mid-blade height of the impeller. Such an occurrence would increase the efficiency of the impeller's operation by increasing the velocity, relative to impeller tip speed, of fluid flow at the impeller outlet shroud. Theoretical analysis also revealed that a more equal distance between the hub of the pump impeller and the shroud could improve the angle of fluid attack within the pump impeller apparatus.

Figure 5.2 illustrates the original and redesigned impeller configuration; the area of impeller redesign is designated by Point $A$. The impeller blade redesign is accomplished by cutting back the trailing edge of the impeller hub in a straight line from the existing shroud tip so that the new radius on the hub is 3.3 inches.

The angle of the diffuser relative to incoming and outgoing water flow is an important factor in determining the efficiency of diffuser operation. For maximum overall efficiency at the design flow condition, the angle of entry into the diffuser vanes, as well as the impeller at inlet, must be such that flow around a sharp corner does not occur. For most turbine pumps, however, a sharp turning radius occurs in the transition zone between the impeller outlet and the inlet to the diffuser vanes. 


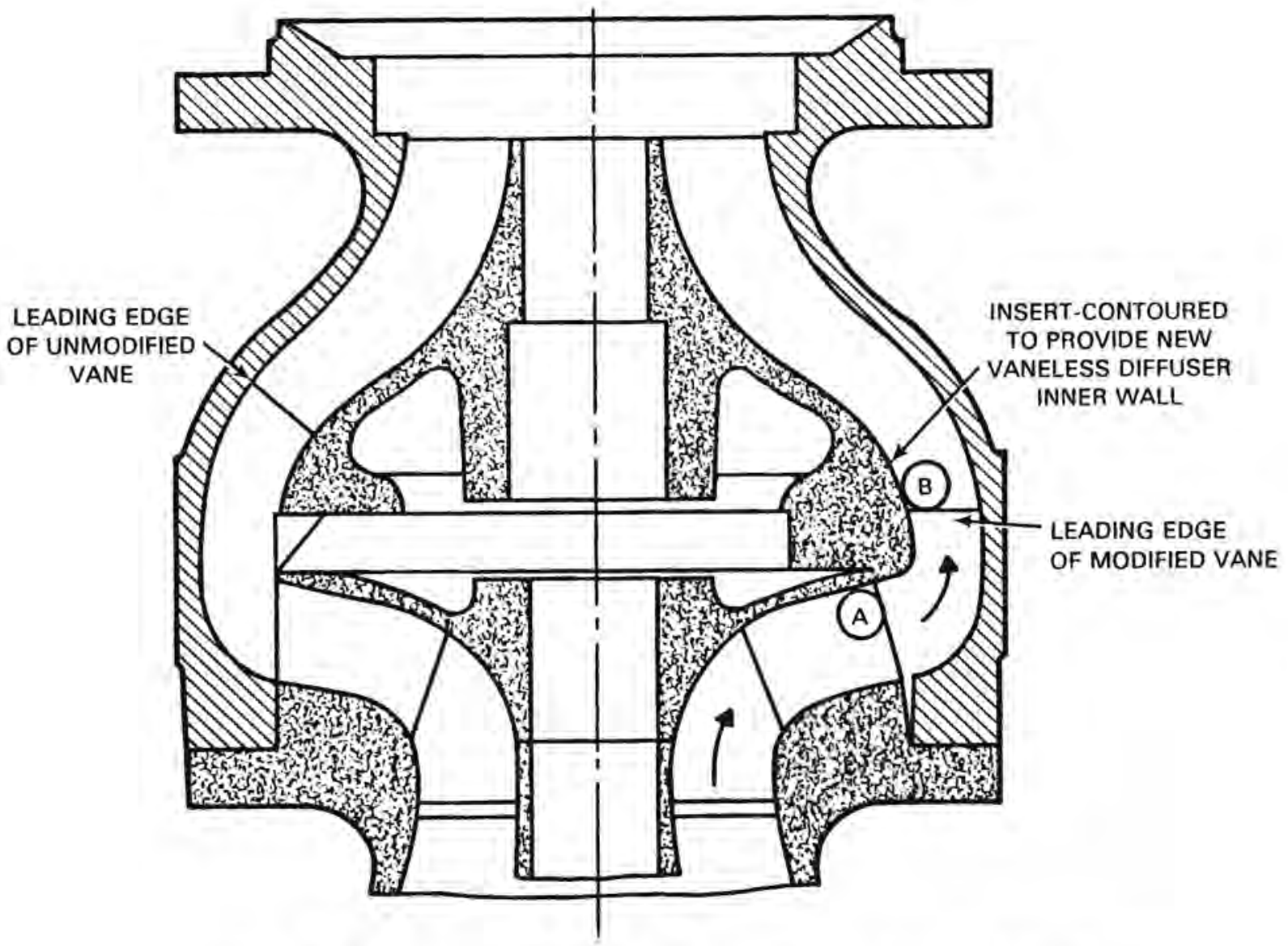

FIGURE 5.2. Cross Sectional View of Impeller and Diffuser in Place. Portion to the right of centerline shows original configurations; left of centerline shows modified configurations.

To improve the efficiency of diffuser operation, an insert was developed to fit between the impeller and the diffuser. This insert reduces the angle at which water must flow from the impeller to the diffuser. The area of diffuser redesign is indicated by Point B in Figure 5.2 .

Improving the surface finish of pump impellers reduces pumping friction losses. The general history of such improvements indicates that pumping plant efficiency can be increased by 1 to 4 points when they are used. Improvement of surface finish can be accomplished by either polishing or coating, or a combination of the two. 
The vane surfaces of an impeller are normally not easily accessible. Machines that move an abrasive slurry over the impeller parts have proved to be effective for polishing. However, a brief study of the problem found that machines utilizing circulation of the slurry by the impeller being polished have generally not been considered as the primary means of polishing.

Coating materials that can be used to provide smooth surfaces range from thin coatings of Teflon to thicker coatings such as enamels and epoxies. Dip coating is usually required to fully coat shrouded impellers.

In spite of the demonstrated effectiveness of impeller polishing and/or coating, such practices are not widespread in the industry and are normally undertaken only at customer request for extra cost. One potential reason for this is that improving pump energy efficiency has not yet become a priority for either pump manufacturers or their customers. Another possible reason is that the beneficial effects of polishing or coating impellers can frequently be short-lived if the pump is pumping sand or other fine particles that can erode the smooth finish of the polished or coated impellers.

Flow of fluid from the impeller outlet and the bowl that houses it at the impeller-to-bowl seal can result in large energy losses. A typical passage configuration for an impeller and bowl at the impeller inlet is shown in the top half of Figure 5.3.

To reduce fluid flow, grooves were cut in the annulus walls to form a labyrinth. This labyrinth, shown in the bottom half of Figure 5.3, was the impeller-to-bowl-sealing arrangement used in the redesigned pumping plant. As water flows into each successive groove, it loses its velocity head and water loss is reduced.

\subsection{METHOD OF TESTING}

To evaluate the performance of the redesigned pumping system the following methods were employed:

- estimation of efficiency changes from using the packer, smaller column pipe and smaller line shaft based on data from hydraulic friction loss charts 

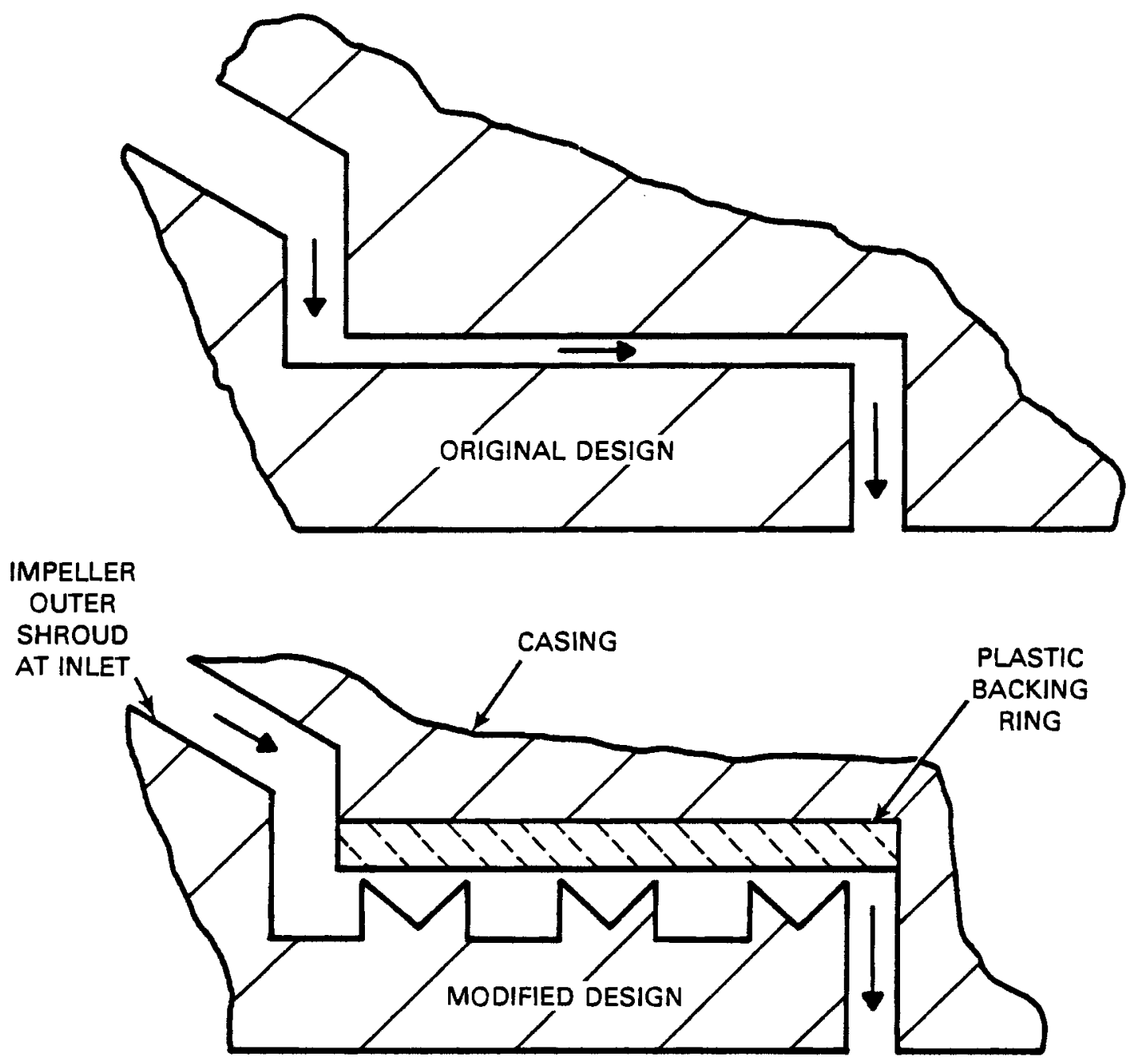

FIGURE 5.3. Sketch Showing Passage Modification to Form Labyrinth for More Effective Resistance to Leakage

- field testing of the redesigned pumping system

- cost analysis of system components.

\subsubsection{Estimation of Efficiency Changes}

Manufacturer's hydraulic friction loss charts provide estimates of the head loss per 100 feet of column pipe or line shaft for various sizes of pipes and line shafts. For the redesigned system, the head loss per 100 feet for the 10-inch casing and column pipe was assumed to be equal to that estimated from friction loss charts for a 10-inch pipe and 4-inch enclosed line shaft. This was combined with the loss from the friction loss charts for a 3/4-inch line 
shaft and a 4-inch column pipe to estimate total head loss for the redesigned system.

For comparison, head loss for a nominal standard 6-inch column pipe and 1-inch open line shaft was estimated from the friction loss charts and taken to be representative of losses for a conventional system design. The difference in head loss between the conventional and redesigned pumping system was then used to estimate the change in efficiency that will result from using the redesigned system.

\subsubsection{Field Testing}

To field test the redesigned pumping system, the packer, 4-inch column pipe, line shaft and a conventional turbine pump were installed in a 124-footdeep well with a 10-inch diameter casing and a cradle-mounted $30 \mathrm{hp}$ electric motor. Flow was measured with a turbine type flow meter, torque with a 5-foot arm and spring scale, and inlet and outlet head with bourdon pressure gauges. Motor rpm was measured with a magnetic pickup and electronic counter.

Head rise across the pump was measured over a pump flow range from approximately 125 to $630 \mathrm{gpm}$ at intervals of approximately $50 \mathrm{gpm}$. The motor speed varied from $1777 \mathrm{rpm}$ at maximum flow rate to $1787 \mathrm{rpm}$ at minimum flow rate.

Performance tests of the redesigned pumping system were done sequentially with the pump as received, after polishing of the pump impellers, after impeller modification, and after modification of diffuser and seal ring. Because of the type of measurement instruments used and because a number of tests were used to derive final values for efficiency and head, it was estimated that the test efficiency values were accurate within plus or minus one efficiency point.

\subsubsection{Cost Analysis}

The costs of the packer, column pipe, line shaft and inner column shaft assembly for the redesigned system were compared to pipe column and line shaft costs for a conventional pumping system. Costs for impeller and diffuser design changes were assumed to be all research and development, with no 
additional manufacturing costs. Costs for impeller polishing and improved impeller-to-bowl seals were not assessed.

\subsection{TECHNICAL PERFORMANCE RESULTS}

It was estimated from the hydraulic loss charts that use of the redesigned column pipe with packer will reduce head loss by 3.86 feet per 100 feet of pumping depth by allowing the well casing to be used as a conduit for water flow. This head loss reduction was calculated to amount to an increase in energy efficiency of 3 points for the redesigned column pipe and packer. The reduction in head loss from using a smaller line shaft in the redesigned system was calculated to increase efficiency by 0.6 points compared to a conventional system.

Results of field tests of the system's pump are summarized in Table 5.1. The results for the attempted pump redesigns were somewhat mixed. Polishing impellers was very effective in increasing pumping system efficiency, but the increase in pump efficiency may be somewhat temporary if wear and corrosion deplete the smooth surface of the polished impellers. In some situations, polishing may have to be done frequently to maintain the 3-point increase in efficiency achieved for polishing. TABLE 5.1 System Efficiencies for Various Designs
of a Groundwater Turbine Pump

\begin{tabular}{lc}
\multicolumn{1}{c}{ Design } & Efficiency \\
\hline Pump as received & $78 \%$ \\
Polished impellers & $81 \%$ \\
Cut-Back impellers & $82.6 \%$ \\
Modified seal and diffuser & $78 \%$
\end{tabular}

The cut-back redesign of the pump impellers increased pump efficiency by 1.6 percent. This redesign appears to have substantial potential for application to the design of commercial turbine pumps, and its benefits are likely to be much more lasting than those of impeller polishing. 
When the modified diffuser and seal were incorporated into the pump design, pumping system efficiency declined by 4.6 percent. Because of these results, it was concluded that the proper alignment of the impeller vanes with a dimensionally correct diffuser configuration was not achieved. A smooth angle of entry into the vanes appears to be more important than achieving a matching impeller and diffuser configuration, but this is a topic that needs more investigation.

The results with regard to the effectiveness of the modified impeller-tobowl seal were inconclusive. The only conclusions that could be drawn are that pump performance can be adversely affected by impeller-to-bowl seal abrasion and wear and that further work needs to be done with impeller-to-bowl seal arrangements and with abrasion resistant materials.

\subsection{ENERGY SAVINGS RESULTS}

No formal estimates of the energy savings that could result from using the redesigned turbine pump rather than new conventional turbine pumps for groundwater irrigation were computed in the original study. However, in a companion study to this one (Wilfert, et al. 1982), such estimates were developed. The potential energy savings of using the redesigned pump column and the cut-back impellers in the 17 largest irrigation states are estimated to be nearly 12 trillion Btu.

\subsection{COST SAVINGS RESULTS}

The pump packer cost $\$ 600$ in 1978 . This packer cost in the redesigned system is largely offset by substantially lower piping costs resulting from the use of smaller column pipe. The pipe cost savings from using 5-inch column pipe in a redesigned system designed to deliver $1300 \mathrm{gpm}$ rather than 10-inch column pipe in.a conventional system designed to deliver $1300 \mathrm{gpm}$ equalled $\$ 930$ per 100 feet of installation in 1978. Only in shallow wells would the cost of the packer not be offset by reduced piping costs.

The costs of using high-strength heat-treated steel in the line shaft would be offset by savings in the costs of inner column and shaft assembly for the smaller diameter shaft of the redesigned system. For example, a 200-foot, 1 -inch diameter high-strength heat-treated shaft cost $\$ 321.20$ in 1978, compared 
to $\$ 207.46$ for 200 feet of 1 -inch diameter cold-rolled steel shafting. However, the inner column and shaft assembly for 200 feet of a 1-inch diameter heat-treated shaft cost $\$ 760$ less in 1978 than the inner column and shaft assembly for a 1-3/16-inch diameter cold-rolled steel shaft.

Cost analysis also indicated that $\$ 60$ to $\$ 100$ an hour are saved in installing or removing the redesigned pumping system compared to installing or removing a conventional pumping system. These cost savings result from the lighter weight of the redesigned system which allows for installation or removal with on-farm tools, thus negating the need to hire the services of expensive cranes and drilling rigs.

The cost analysis of the redesigned system demonstrates a large potential for market acceptance. If successful performance of the redesigned system over time can be demonstrated, farmers will be very interested in a pumping system that saves energy at a lmost no additional cost. 


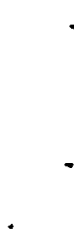




\subsection{VARIABLE SPEED PUMPING}

Variable speed electric motors are commonly used to drive pumps in chemical processing and various other industries, but they have not been accepted for use in irrigated agriculture. Variable speed electric motors have generally been regarded as too expensive for irrigation applications; especially since the energy savings benefits of variable speed pumping are perceived to be uncertain.

Farmers who use internal combustion engines of ten vary the pump/engine speed according to their watering requirements so that fuel consumption can be reduced. With a constant speed electric motor, such practices are not possible. By allowing for the pump speed to be varied according to watering requirements, variable speed motors appear to have considerable potential for reducing the energy use of electric pumping installations. However, the energy saving benefits of variable speed motors should be measured and evaluated against their higher initial investment costs.

Foster-Miller Associates have developed a computer simulation model that can be used to determine the costs and benefits of using variable speed irrigation pumps in various types of irrigation pumping situations. This model addresses the questions of how much energy can be saved from using a variable speed pump, and whether the savings in energy cost are sufficient to justify the added cost of the variable speed motor. In addition, Foster-Miller has developed a portable small-scale hardware model of a variable speed irrigation pumping installation which is believed to be a forerunner to the development of a full-scale prototype.

\subsection{TECHNOLOGY DESCRIPTION}

Both the computer simulation model and the small-scale hardware model will be described in this summary. A schematic diagram of the computer model is shown Figure 6.1. The model includes the following components:

- a computer code originally developed on a large mainframe computer, but later adapted for use on small-scale computers 


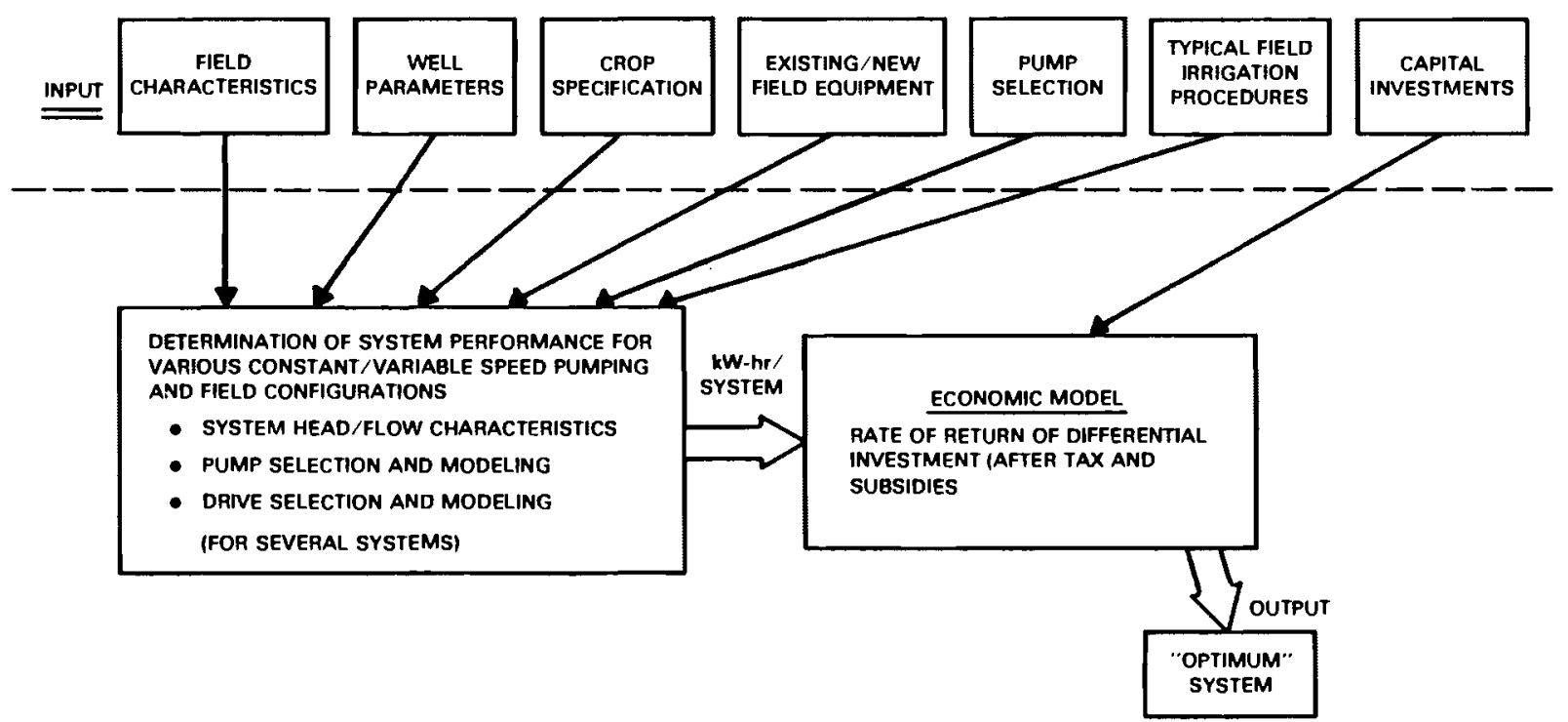

\section{FIGURE 6.1. Foster-Miller Computer Program Flow Chart}

- a system of engineering equations that simulate the operation of irrigation pumping systems

- a system of economic equations used to determine the cost-effectiveness of variable speed motors

- user-supplied input parameters.

A schematic diagram of the small-scale hardware model of a variable speed pumping plant is shown in Figure 6.2. The model includes the following elements:

- a pump with a geometry similar to that of large high lift pumps but with a fraction of the horsepower requirements

- a variable speed motor and control

- a system of hoses, gages, flow meters and valves that are used to simulate the field factors affecting the operation of an irrigation pumping plant.

Each of these elements is described in detail below. 


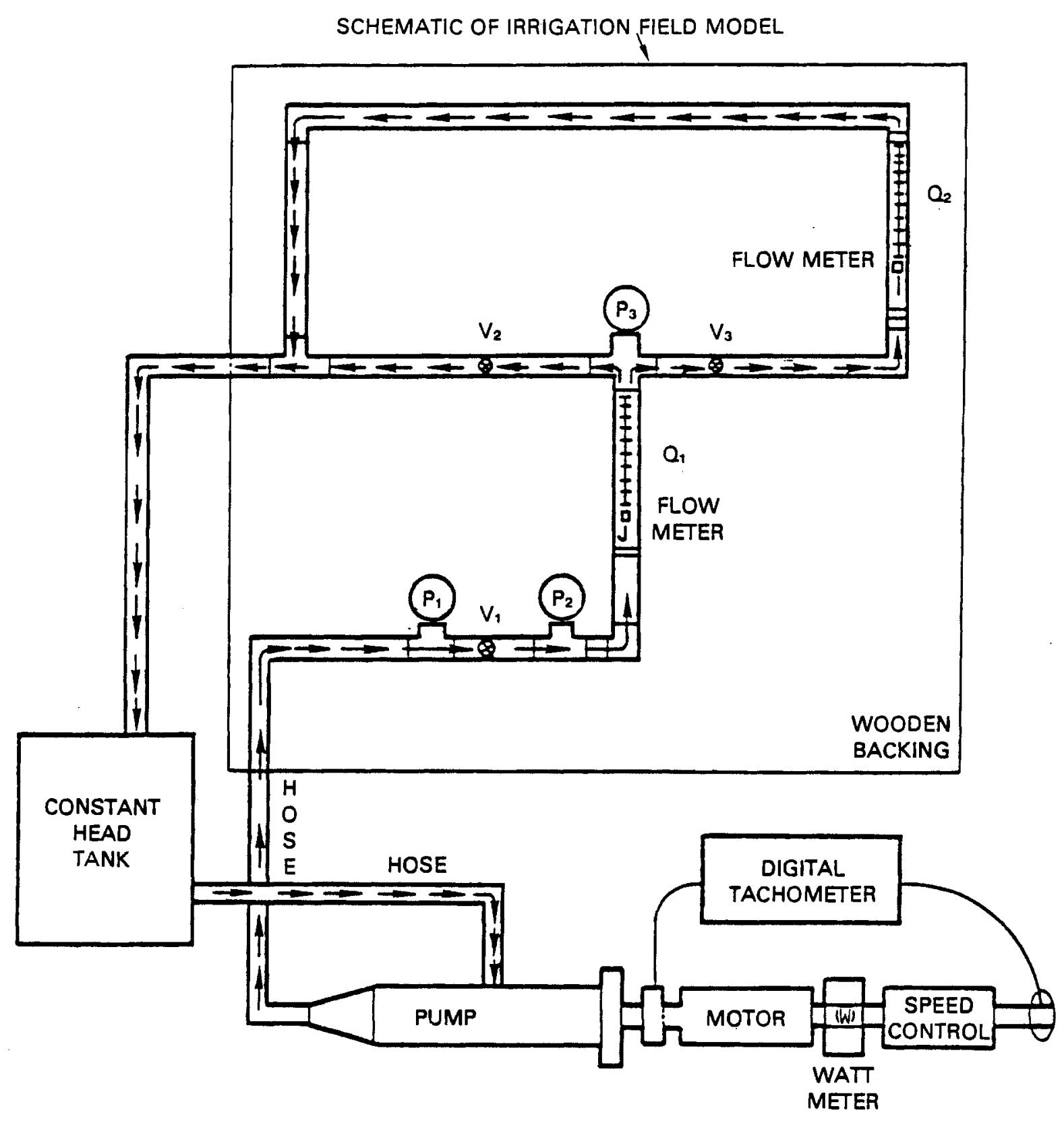

FIGURE 6.2. Illustration of Variable Speed Pumping Model

\subsubsection{The Computer Model}

The original computer model was developed on a large-scale Digital Equipment Model DEC-10 and was written in FORTRAN programming language. To provide for wider usage of the model, it has now been rewritten in Hewlett-Packard Basic Language format and is small enough to fit on most types of small-scale computers. The second generation program is designed to interact with the user so that a minimum amount of programming is required. 
The computer model is capable of simulating a number of different types of pumping systems. In addition to comparing the performance and economics of variable speed and constant speed motors, the model provides a guide for proper pump selection based on the characteristics and requirements of the overall irrigation system.

As illustrated in Figure 6.1, the basic model process is to take a number of user-supplied input parameters on the irrigation system, run these parameters through a system of engineering simulation equations to determine system performance for various types of pumping plants and motors, generate annual kWh-use estimates for each system, run the $\mathrm{kWh}$ usage estimates and usersupplied economic input data through a system of economic equations to determine the levelized life-cycle cost of the various systems, and finally, determine the optimal pumping system for the specified situation.

\subsubsection{Computer Model Engineering Equations}

The basic engineering problem of determining the proper pump to use in an irrigation system is one of matching the pump's flow rate and head characteristics with the required head and flow rate for the irrigation system. The model uses data from pump performance maps, watering schedules and system head-flow requirements to match pump characteristics with system requirements, integrates pumping energy use over the growing season, and finally, estimates the energy savings potential of using a variable speed motor to drive the pump.

A performance map for a typical constant speed pump is shown in Figure 6.3. In the example shown in Figure 6.3, the pump delivery and system requirement curves match at a single point, point $A$. If the pump is called upon to deliver 100 percent of its design flow, it will be at 100 percent head. If the water flow rate needs to be reduced, the head also has to be reduced because the delivered head is too large for the system. A valve could be inserted to obtain the necessary head reduction, but what is normally done is to reduce the operation time of the irrigation system to meet the reduced water flow requirements. A valve would have to be used, however, if a reduction in head is required at the same 100 percent flow rate. 


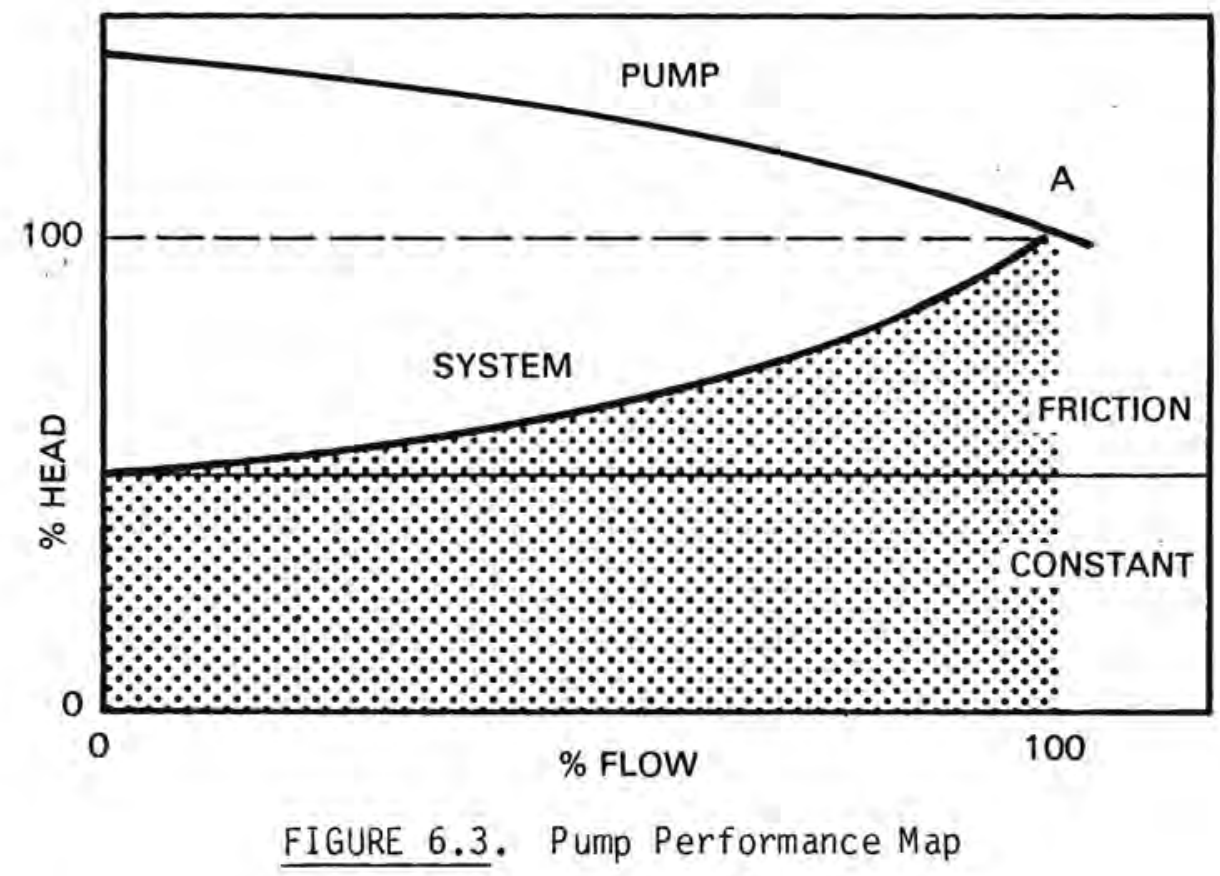

A pump with a variable speed motor can be operated so pump head and flow match the system requirements during continuous operation. Reducing the flow-rate and reducing head requirements during pump operation reduces water horsepower requirements. However, pump efficiency is reduced when a pump is operated at heads and flow rates that are significantly lower than it is designed for. Thus, in determining whether the use of a variable speed motor will save energy, the reduction in energy use as a result of decreased water horsepower requirements should be traded off against the higher energy use resulting from lower pump efficiency.

In many cases, the loss in pump efficiency from reducing pump speed is insignificant and the minimum energy use to meet water requirements occurs when the pump is operated for 24 hours a day. In other cases, the impacts of reduced efficiency at very low pumping rates may cause the minimum energy use to occur at some higher level of pump speed and shorter operation time. In some cases, the impacts of the loss in pump efficiency may be large enough to offset completely the impacts of reduced horsepower requirements, in which case, variable speed pumping would provide no direct energy saving benefits. 
The computer simulation model developed in the project calculates energy consumption for constant speed operation, for 24-hr variable speed operation, and also finds the minimum energy use per day. In this way, the relative energy consumption of variable versus constant speed pumping can be compared for any particular pumping situation.

To predict pump efficiency and head in the simulation model, full speed pump test data are fit to second degree polynomial equations by the least squares statistical regression method. The equations are of the following form:

$$
Y=a+b Q+c Q^{2}
$$

where $\quad Y=$ efficiency or head

$Q=$ water flow rate

$\mathrm{a}=$ regression intercept

$b, c=$ regression coefficients.

Once parameters for full speed pump operation are established, similar parameters are calculated for lower speeds. The first step is to determine the minimum flow in gpm necessary to supply the daily watering rate over 24 hours for each irrigation time segment. The daily watering rate at any point in the growing season depends upon the user-supplied watering schedule. With this minimum flow rate established, the program then determines the required head for the minimum flow rate.

A scaling procedure utilizing triangulation is used to find the intersection of the pump speed curve, $N_{1}$, which will provide the minimum flow and head. Referring to Figure 6.4 , the values of $Q_{1}$ (flow rate) and $H$ (head) corresponding to the minimum flow rate have already been calculated. The maximum pump speed curve, $\mathrm{N}_{2}$, has also been developed. Using the scaling, $\mathrm{N}_{2}$, relationship, an intermediate value, $Q_{2}^{1}$, is found by the expression:

$$
Q_{2}{ }^{1}=Q_{1} \frac{{ }^{{ }^{1}}}{\mathrm{H}_{1}}
$$




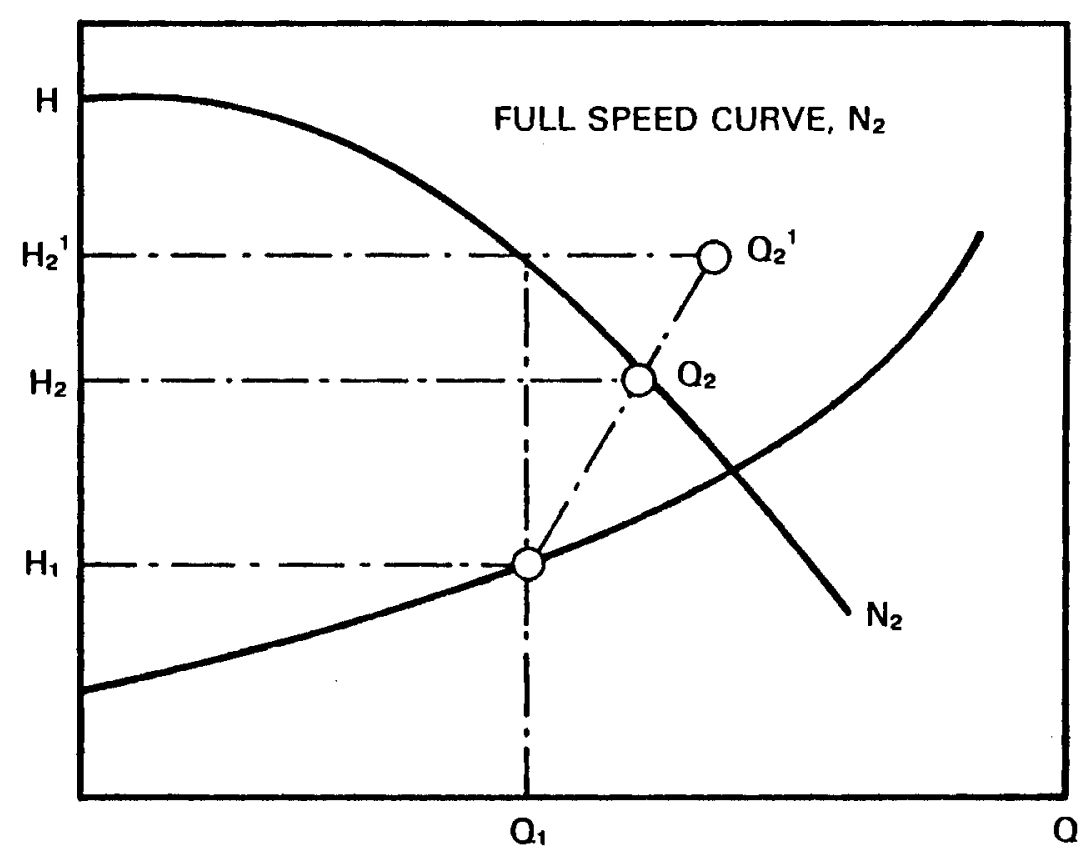

FIGURE 6.4. Scaling Procedure Used to Find the Minimum Pump Speed Curve, $N_{1}$

The point $Q_{2}$ on the curve is located by finding, through iteration, where on the curve $\mathrm{N}_{2}$ the line $\mathrm{H}_{1}$ to $\mathrm{Q}_{2} 1$ intersects. This intersection is the point $\mathrm{H}_{2}, \mathrm{Q}_{2}$. Now, using pump simularity laws that describe the scaling properties of pump curves, the pump speed curve corresponding to the minimum allowable flow rate is found by the equation:

$$
N_{1}=\frac{Q_{1}}{Q_{2}} N_{2}
$$

A family of reduced speed curves are found in this fashion.

The program calculates irrigation system energy losses from wel1, aquifer and piping information. The lift is calculated from the level of the well water by knowing the depth of the aquifer from the surface and the well drawdown. These properties can be varied in the model according to the time of the growing season. 
Well drawdown is calculated based upon parameters from a step-drawdown test. This test is described in Chapter 4 of this report and was developed by researchers at the University of California at Davis.

Friction losses in the well column and pipe network are calculated using the Darcy-Weisbach equation. This equation is described fully on page 7.5 of Chapter 7.0 of this report.

\subsubsection{Computer Model Economic Equations}

The program uses the total economic cost of providing the required watering schedule as a basis for making economic comparisons between various types of pumps. All annual labor, maintenance and energy costs over the life of the irrigation system are converted to present worth and added to the initial cost of the system to determine the total present worth cost for each alternative system.

The basic equation used for making economic evaluations within the program is the following:

$$
P W C=I+\sum_{n=1}^{N}[(0 n+M n+F n) \cdot(1-T)-D \cdot(T)] \frac{1}{(1+i)^{n}}
$$

where: $\quad$ PWC $=$ present worth cost of owning and operating an irrigation pump

$I=$ user-supplied net investment in equipment and capitalized first year costs

On = user-supplied annual operating labor costs

$M n=$ user-supplied annual maintenance requirements; typically based on a percentage of capital cost

$\mathrm{Fn}=$ user supplied annual cost of power to operate the system

$T=$ effective tax rate paid on income by the business considering the pump

$D=$ annual depreciation on investment

$N=$ final year of equipment life.

A11 annual labor, maintenance, and fuel costs are escalated over the life of the investment using user supplied inflation rates for the various costs. 
Taxes include provisions for state income taxes and for federal income taxes that are adjusted according to the state tax rate. Depreciation (D) can be calculated in the model for any of three methods--straight line, double declining balance, and sum-of-the-years digits.

The annual cost of power is calculated based on energy usage estimates generated by the engineering equations of the model, base power cost per kWh, and an annual rate of power cost escalation. In terms of variable speed motors, the critical question, for which the model can provide an answer, is whether the reduced annual costs of power over the life of the pumping system from using variable speed motors are sufficient to overcome the substantially higher investment costs and slightly higher maintenance costs of the motors.

\subsubsection{Computer Model Input Parameters}

The interactive capabilities of the model allow data inputting to be relatively easy. However, the model requires an extensive amount of data in order to run successfully. For brevity, all of the necessary input data is not described in detail in this summary. The input data can be broadly categorized as the following:

- pump performance data, including flow rate-efficiency data, flow rate-head data, pump speeds, and number of pumps to be examined

- required system operating characteristics, including required flow rate and head at various periods in the growing season, number of hours of pump operation during the various periods, and number of days per period

- if the flow/head requirements are unknown, it is necessary to input data on well characteristics, pipe network characteristics, and pump column characteristics so that the model can calculate the desired flow/head requirements for the field

- cost data, including the initial capital costs and salvage values of the constant and variable speed motors, labor costs, maintenance costs, energy costs, tax rates, expected inflation rates, etc. 


\subsubsection{Small Scale-Model Pump and Motor}

The development of the small-scale model was intended to supplement the computer program by physically demonstrating how variable speed pumping can save energy.

After surveying pumps with a geometry similar to large high lift irrigation pumps, but with fractional horsepower, a Gould Water Gun Model HB7-148BD1 was chosen for use in developing the small-scale hardware model. For analysis purposes, the characteristics of the nominal $1 \mathrm{hp} \mathrm{model}$ pump were scaled upward to reflect the characteristics of a potential prototype variable speed irrigation pump having a 10-inch diameter impeller and a speed of $1760 \mathrm{rpm}$. Because pumps generally scale well, the operational characteristics of the small-scale model should generally be applicable to full-scale systems.

A Minarich Blue Chip II variable speed motor and control is coupled to the model pump. The motor is $1 / 2 \mathrm{hp}$ dc. A digital tachometer, Red Lion Control Ditak II, is attached so that motor speed can be measured. Motor and line power is measured by attached wattmeters.

\subsubsection{Field Simulation Apparatus}

The field simulation apparatus, which includes gages, flow meters and valves, is capable of representing a number of different types of field conditions. Flow rates in the system are dependent upon field resistances, flow-rate and supply tank elevation. Referring back to Figure 6.2, field water flow resistance can be varied by pre-setting the throttling valves of the simulation system $\left(V_{1}, V_{2}\right.$, or $\left.V_{3}\right)$ to full open, $1 / 2$ open or $1 / 3$ open. Pressure at various flow rates is measured by pressure gages $\left(\mathrm{P}_{1}\right.$, $P_{2}$, and $P_{3}$ in Figure 6.3). Flow rates at different points in the simulation system are measured by two flow meters $\left(Q_{1}\right.$ and $Q_{2}$ in Figure 6.3).

\subsection{METHOD OF TEST ING}

The primary purpose for developing both the computer model and the smal1-scale hardware model was to gain more knowledge about the viability of 
using variable speed motors to drive irrigation pumping stations. Consequentiy, the primary method of testing the models was to use them to evaluate the merits of variable speed pumping versus constant speed pumping in various types of simulated situations.

Several types of sample problems were run on the computer simulation model as a means of testing model performance. These sample problems ranged from modeling a simple problem involving proper pump selection to modeling more complex problems involving total gated-pipe and center-pivot irrigation systems. Various cases incorporating changes in the base case irrigation parameters were run within each sample problem. For example, one of the cases examined the impacts on the relative energy consumption of constant speed versus variable speed pumping of a change in crop watering requirements during the growing season.

The operation of the small-scale model was tested in a sample problem and the results of the test were compared to those generated for the same problem by the computer program. The first step in testing the small-scale model was to develop a set of pump performance maps. This was done by taking pressure, flow rate, and wattage readings at various pump speeds. With this and other data, head-flow rate and efficiency-flow rate plots for the small-scale pump were developed.

The coordinates of the pump performance maps were then fitted to the second degree polynomial equations of the computer model. This provided the necessary data for a computer analys is of the smali-scale model pump. Parameter estimates for a specific simulated problem were then obtained and compared to the parameters obtained from the computer model through the smali-scale pump's actual performance.

\subsection{PERFORMANCE RESULTS}

The computer simulation model successfully modeled five different sample problems, with up to five different cases included within each probiem. On the basis of these resuits, it was conciuded that the development of a computer simulation model which can evaluate the relative merits of variable 
speed pumping versus constant speed pumping was sucessful. The overal1 usefulness of the simulation mode1, however, depends upon how well it represents the reality of actual pumping situations.

Comparison of computer simulation results to the actual performance of the small-scale pump indicates that the computer model has the capacity to represent reality quite closely. The difference between the flow rate predicted by the computer model at a specified head and the flow rate actually measured on the small-scale model was relatively small. Similarly, the difference in pump speed between the computer model estimate and the actual measured speed was smal1. Difference in pump efficiency levels between the computer model estimates and the measurements from the small-scale model were quite large, but it is believed that the large differences should be attributed to the way in which the small-scale model was scaled upward, rather than to any imperfections in the computer model.

\subsection{ENERGY SAVINGS RESULTS}

Based on the simulation modeling results, it was concluded that the relative energy savings of using variable speed pumps will be highly variable depending upon the type of irrigation situation in which the pump is used. In general, variable speed characteristics will yield the largest energy savings in the following types of situations:

- situations where large variations in the pump output head (pressure) occur during the use of the irrigation pumping system

- situations where large variations in water flow (gpm) occur during the use of the irrigation pumping system

- situations where significant declines in aquifer water levels occur over the growing season.

It was also generally concluded that the use of variable speed pumping is much more viable for sprinkler irrigation systems than for gravity flow irrigation systems because of the inherently low energy use of gravity flow sytems per unit of water applied. 
The developer of the variable speed simulation model estimates that for a typical irrigation situation the use of variable speed motors rather than constant speed motors in conjunction with individual irrigation systems will result in an increase in pumping efficiency of 5 percent. In a companion study, the aggregate energy savings of using variable speed motors where their use is cost-effective were estimated to be extremely small (Wilfert 1982).

\subsection{COST SAVINGS RESULTS}

Except for the irrigation situations cited above, it is generally concluded that the use of variable speed motors in conjunction with individual irrigation application systems is not cost-effective (Patton et al. 1982). The energy cost savings of the variable speed motors are generaily not sufficient to return their additional investment costs, but the use of variable speed motors should be considered for irrigation situations similar to those listed above. The use of variable speed pumps may be particularly viable in situations where a pump is used to supply water to several irrigation application systems with differing flow rate and head requirements. 



\subsection{PIPE NETWORK OPTIMIZATION}

Designing irrigation pipe networks by hand is a time-consuming and tedious process, and often the impacts on energy use of pipe sizing and design are not fully considered. The energy use of an irrigation system is influenced by friction losses and pressure variations with in the system. Higher friction losses require that greater amounts of energy be expended in pumping a given volume of water. Greater pressure variation results in less uniform water distribution, causing energy to be wasted.

Smaller pipes result in greater friction losses than larger pipes, but larger pipes have higher capital costs than smaller pipes. In order to economically optimize pipe size, the higher energy costs of smaller pipes should be traded off against the higher initial capital costs of larger pipes. In addition, pipe sizing should be done in detailed and systematic fashion so that unwanted pressure variations within the pipe network are minimized.

The computerized pipe network design program improvements made by Keller Engineering provides an easy-to-use, systematic method for optimal sizing of irrigation pipes within an irrigation system. The piping networks for solid set sprinkler, mobile sprinkler, and drip irrigation systems are all capable of being analyzed with the computerized model. A users manual provides an aid for learning to use the pipe design model.

\subsection{TECHNOLOGY OESCRIPTION}

Economic and engineering principles are incorporated into the computer program to produce an optimal economic design of irrigation pipe networks. The program is a life-cycle-cost (LCC) program which has the objective of minimizing the sum of capital, pumping, maintenance, and operational costs during the life of the irrigation system. An illustration of the basic concept behind the pipe design program is presented in Figure 7.1. Throughout the pipe network pipes are sized so that the minimum estimated sum of fixed and power costs is obtained. 


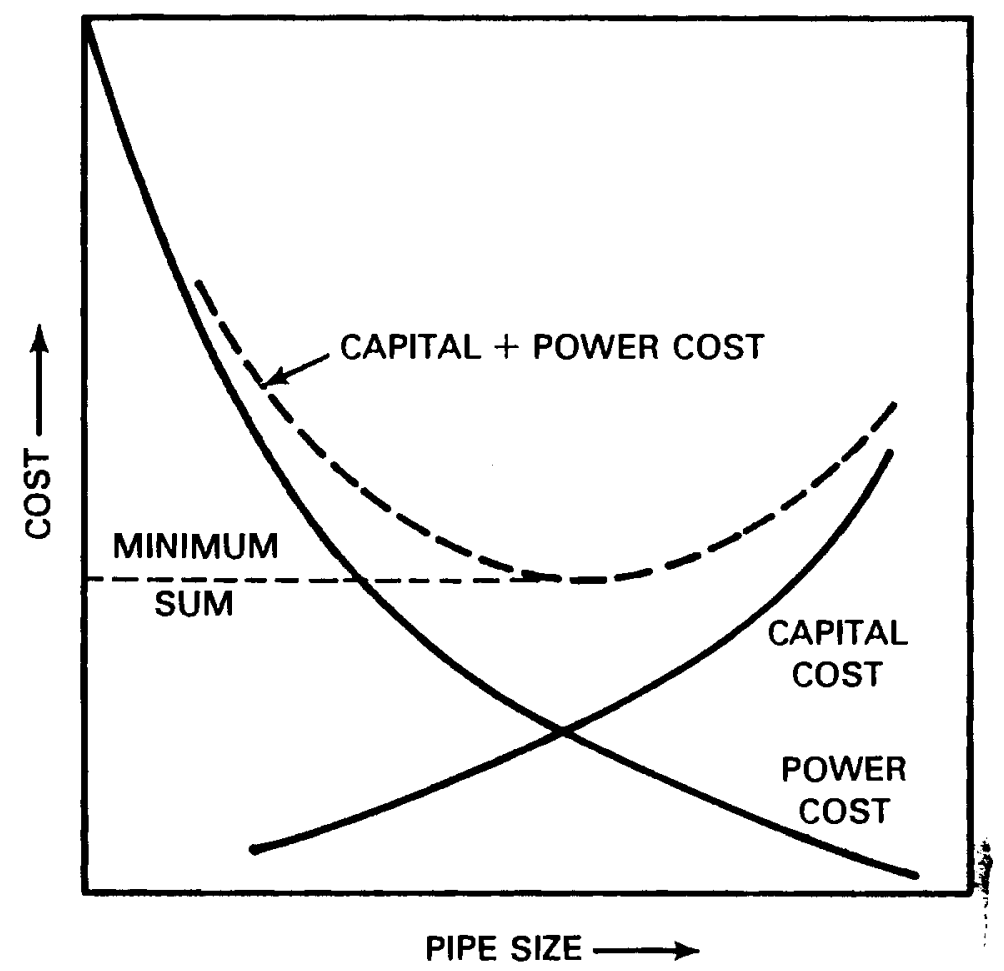

FIGURE 7.1. The Influence of Pipe Size on Capital and Power Costs Illustrating the Tradeoffs for Deriving Minimal Total cost

The pipe design computer program includes the following basic elements:

- a computer program written in FORTRAN programming language

- a pipe design process that designs irrigation systems in a hierarchical order. The hierarchy includes: 1) mainlines and submains; 2) manifolds; and 3) laterals

- engineering equations for estimating friction losses within the pipe design network

- financial equations for levelizing capital and operating costs for the system

- user-specified system engineering and economic input parameters

- a number of different types of output information.

Each of these elements is described in detail below. 


\subsubsection{The Computer Program}

The FORTRAN computer design program requires 40,000 to 60,000 words of storage for the program and its data. Thus, the user of the program must have a machine that can accept large programs and can perform FORTRAN calculations rapidly.

The actual program code is comprised of approximately 4500 FORTRAN statements and requires 21,000 words of storage. However, a technique known as overlaying can be used to reduce the core storage requirement for the program code to 6,000 words. The computer design program code is composed of a main program and several subroutines. Overlaying stores the segments of the program that are not being used at a particular time in a program run. The stored segments are then recalled when needed.

Overlaying has little impact on data storage requirements because most of the numbers have to be available all the time. However, if the program is used on a computer with disk storage capabilities, core storage requirements can be reduced substantially.

\subsubsection{Pipe Design Process}

The three levels of pipe hierarchy within the computer program simulate the design of irrigation pipe systems. First, mainlines are optimally sized, then manifolds, and finally laterals. Trickle irrigations systems normally require that only mainlines and manifolds be sized, since lateral hoses are usually all the same size. The three levels of pipe hierarchy incorporated into a pipe network are shown in Figure 7.2.

The basis for the method used in the pipe design program is that water flow rates are not the same at all points within an irrigation system and that pipes should be sized accordingly. Larger pipes should be used where flow rates are the highest, such as in mainlines, because the energy costs due to friction losses from using smaller pipes outweigh the higher capital costs of larger pipes. As flow rates are reduced, optimal pipe sizes also decrease because of lower friction losses. 


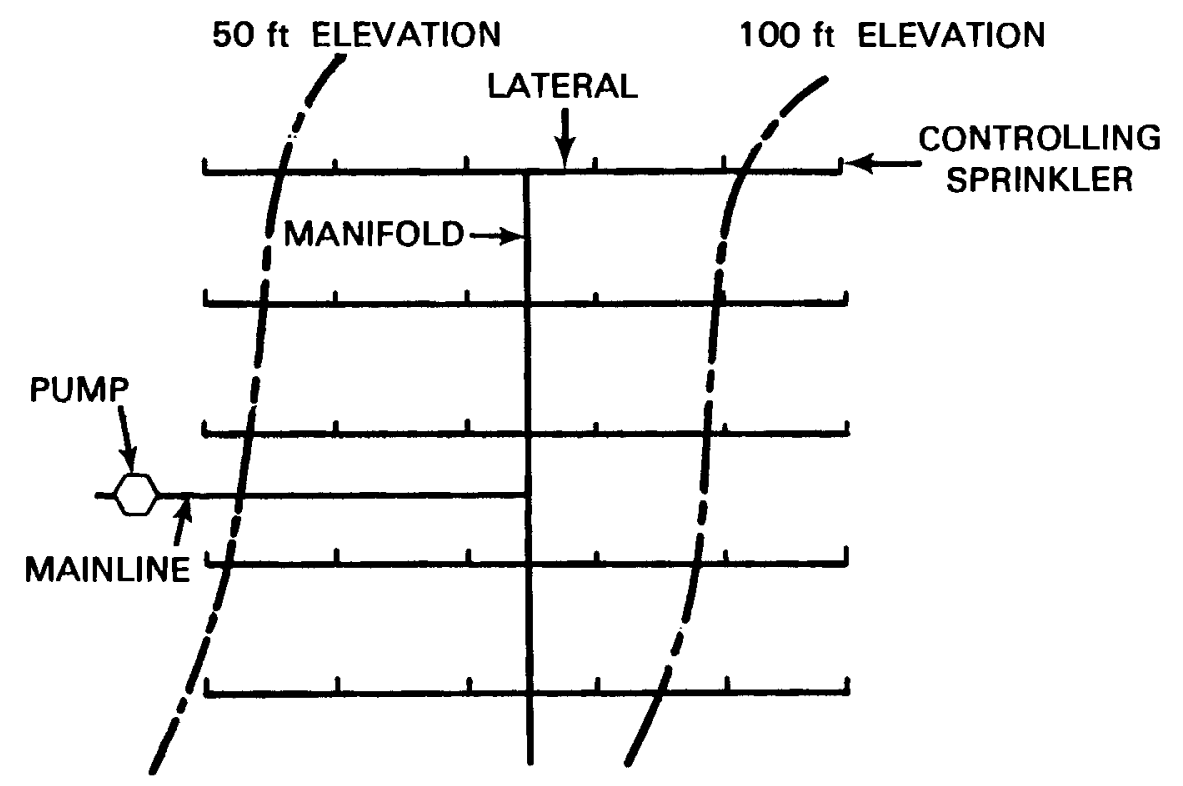

FIGURE 7.2. Typical Irrigation Pipe Network Hierarchy

Economic tables for selecting pipe sizes based on the pump discharge are generated by the program as a first step in obtaining an economic design for the irrigation system. This process uses two facts: 1) that a discrete set of pipe sizes is available; and 2) that for a given pump capacity, an annual power cost per water-horsepower, and a set of capital cost values, a range of flow rates exists for which a given size of pipe will be the most economical. The high end of this flow rate range is where the next larger pipe would have the same capital-plus-power cost as the pipe in question. The low end of the most economical flow rate range is where the next smaller pipe will have the same capital-plus-power cost. The process yields an economic pipe size for the various flow rates occurring throughout the irrigation system and is the first "cut" in obtaining an economic design for the system.

To begin the second design cut, the mainlines of the system are sized according to the economic tables established in the first cut. Next, another economic table is established for each manifold by assuming a pump is 
placed at the upstream end of the manifold. All the pipes except mainlines are sized according to this table.

A third design cut is developed by sizing the manifold and lateral pipes according to the controlling lateral containing the sprinkler that forces the pump head to its highest value. A pump is assumed to be placed at the head of the controlling lateral and an economic pipe selection table is computed accordingly.

Generally, after each of the economic sizings, a substantial excess head can be found in the system. After each of the design cuts, this excess head is reduced using two methods. First, starting at the extreme downstream ends of the system, the size of all laterals is reduced where excess head is available. When the diameter has been reduced for every lateral possible, the size of manifold pipes is reduced where excess head is available. Finally, the same approach is applied to the mainline pipes. The second method starts the pipe reduction process at the mainlines and subsequently reduces the mainfold and lateral pipes where excess head is available. The reduction process is carried out by always first reducing the size of the pipe that will yield the greatest capital cost savings for a given head loss.

The process yields six alternative designs for the system (three design cuts $x$ two methods of reducing excess head). Each design configuration and its cost is saved on a scratch disk file after it has been computed. The normal procedure is to try all six designs and select the one with the lowest cost. If it is desirable to try fewer than six alternatives, it is possible to select, within certain constraints, any one or combination of the six alternatives and ignore the rest.

\subsubsection{Engineering Equations}

Frictional losses within the irrigation system are measured in the pipe design program using the Darcy-Weisbach formula. This formula is believed to provide more flexibility and acuracy than the Hazen-Williams formula that has often been used in the past for evaluating pipe friction losses in an irrigation system. The Darcy-Weisbach formula is the following:

$$
h_{L}=f \frac{L V^{2}}{D 2 g}
$$


where $h_{L}=$ Head loss

$$
\begin{aligned}
& f=\text { a calculated friction factor } \\
& L=\text { pipe length } \\
& D=\text { pipe diameter } \\
& V=\text { flow velocity } \\
& g=\text { acceleration of gravity }
\end{aligned}
$$

The friction factor, $f$, is a measure of friction loss based on the material that the pipe is composed of and the relative roughness of the pipe surface. The design program computes this friction factor by first computing a Reynold's number for the pipe using a standard temperature of $20^{\circ}$ centigrade and the maximum and minimum flow velocity within the pipe.

\subsubsection{Financial Equations}

A capital recovery factor equation and an equation for calculating the equivalent annualized cost of escalating energy factors are the two principal financial equations in the design model. The capital recovery factor equation (CRF) is a standard method of annualizing the cost of a capital investment and is computed by the following formula:

$$
\mathrm{CRF}=\frac{i(1+i)^{n}}{(1+i)^{n}-1}
$$

where $\quad$ CRF = the capital recovery factor

$$
i=\text { required rate of return on investment }
$$$$
n=\text { economic life of investment }
$$

The equation for calculating the equivalent annualized cost of escalating energy factors is the following:

$$
\operatorname{EAE}(r)=\frac{(1+r)^{n}(1+i)^{n}}{(1+r)-(1+i)} \times \frac{i}{(1+i)^{n}-1}
$$

where $\operatorname{EAE}(r)=$ Equivalent annualized cost of escalating energy factors.

$$
\begin{aligned}
r & =\text { expected annual rate of energy price inflation } \\
i, n & =\text { same as in previous equation }
\end{aligned}
$$


The first term is the factor for computing the difference between total required payments at the specified rate of return and the total required payments for energy at the specified energy price escalation rate. The second term converts the results of the first term to an equivalent annual payment.

\subsubsection{Required Input Parameters}

The required input parameters for the design program are user-specified engineering and economic data. User-specified irrigation system engineering parameters subject the pipe sizing process to limitations. Key irrigation system input parameters include the following:

- the maximum velocity of water flow in the system's mainlines, manifolds, and laterals

- the minimum pressure head at which the nozzles and emitters will give the desired flow rate

- the allowable pressure head difference along manifolds in trickle systems or manifolds and laterals in sprinkler systems.

Economic data must also be supplied by the user of the design program. The data include the following:

- the capital costs of various sizes and types of pipe

- the expected inflation rate of energy prices

- the required rate of return on investment

- the expected economic life of the pipe network.

The initial annual power cost to overcome friction losses not offset by elevation must also be calculated by the program user and supplied to the program as an input parameter. This initial annual power cost can be computed using the following formula:

$$
\text { CWHP }=\frac{\text { HRSOP } \times \text { (Unit cost of fue } 1)}{\text { OVEFF/100 } \times \text { BHP/(Unit of fue })}
$$

where CWHP = annual power cost per water horsepower

HRSOP = hours of pumping plant operation per year 
OVEFF = overall efficiency of the pumping plant in percent

BHP = brake horse power output of the engine

The annual cost for water horsepower (taking energy price inflation into account) is computed in the design program by multiplying CWHP by the factor for the equivalent annualized cost of escalating energy prices $[E A E(r)]$.

\subsubsection{Output Information}

The amount of output data provided by the model can be varied by the user. If complete information on the system being designed is desired, a considerable amount of information can be printed on system hydraulics, pressure control, elevations, etc. However, if less detailed information is desired, output printing can be terminated at various points. A design summary table is always printed which shows the fixed and operational cost of each of the design alternatives and the recommended sizes for the various types of pipe in each alternative pipe network.

\subsection{METHOD OF TESTING}

The pipe network design program was tested by conducting several workshops in which participants learned to use the design program with the aid of a specially prepared user's manual. A total of four 3-day workshops were held, and participants included graduate engineering students, professional irrigation system designers and others.

Participants in the workshops were asked to evaluate both the design program and the user's manual at the end of their workshop. No formal comparison of the design program to other methods of designing irrigation systems was undertaken, however.

\subsection{TECHNICAL PERFORMANCE RESULTS}

All workshop participants were able to complete their own sample problem for a trickle, a permanent solid set sprinkle and a center-pivot pipe network design project within the three-day time period in which the workshops were 
conducted. On the basis of these results, it was concluded that the user's manual is a useful teaching tool.

Most workshop participants felt that the program would enhance their design capabilities and simplify and streamline their operations. The program was judged to be a useful design tool; however, a need was perceived to get designers to accept the computer as a design tool and the program as a design strategy.

The economic benefits of using the design program will depend on the accuracy gained in the optimal sizing of pipes and on the time saved in the design process. No quantitative estimates of these benefits were developed. However, the cost of computer time for an individual design run is generally less than $\$ 15$. Thus, if access to a computer is available, the improvement in the accuracy and speed of the design process need not be large for the use of the program to result in net economic benefits. 
.

. 


\subsection{REDUCED-PRESSURE CENTER-PIVOT SYSTEM}

Conventional high-pressure center-pivot irrigation systems were developed at a time when energy prices were relatively low. Consequently, little attention was paid to incorporating energy-saving features into the design of center-pivot systems.

Recently, a number of alternative designs have been developed in an effort to reduce the energy usage of center-pivots. These alternative designs apply water at lower operating pressures than do conventional center-pivots. Some of these reduced pressure center-pivots are already being marketed by private irrigation manufacturers.

Farmers are unlikely to invest in these new reduced-pressure systems until the performance of these systems relative to conventional center-pivot systems is tested and proved. Additional water management problems that are often of concern in relation to using reduced-pressure systems are: 1) increased water runoff and soil erosion, 2) lower uniformity of water distribution, and 3) system operation and management problems. A11 of these problems are associated with the higher water flow rates and smaller water distribution patterns of reduced-pressure systems compared to conventional high-pressure systems.

Two methods of reduced-pressure water application and a conventional method of high-pressure water application were incorporated into the design of an experimental center-pivot system as part of the University of Nebraska study. The primary purpose of this study was to compare the performance of reducedpressure water application methods to the performance of conventional highpressure methods under a variety of conditions including soil type, soil surface, topography and cultural practices.

\subsection{TECHNOLOGY DESCRIPTION}

Three water application systems were mounted on one center-pivot as a means of comparing the performance of reduced-pressure application methods to high pressure application. A sprinkler arrangement for the experimental center- 
pivot is illustrated in Figure 8.1. Specific application systems evaluated included:

- reduced-pressure impact sprinklers

- reduced-pressure spray nozzles

- high-pressure impact sprinklers.

Each of the application systems incorporated into the experimental centerpivot are described in detail below.

\subsubsection{Reduced-Pressure Impact Sprinkler Heads}

Similar to conventional high-pressure impact sprinklers, reduced-pressure impact sprinklers apply water through the rotational movement of a jet stream of water. However, the jet stream of a reduced-pressure impact sprinkler does not have as much force behind it. Consequently, the distance that the water

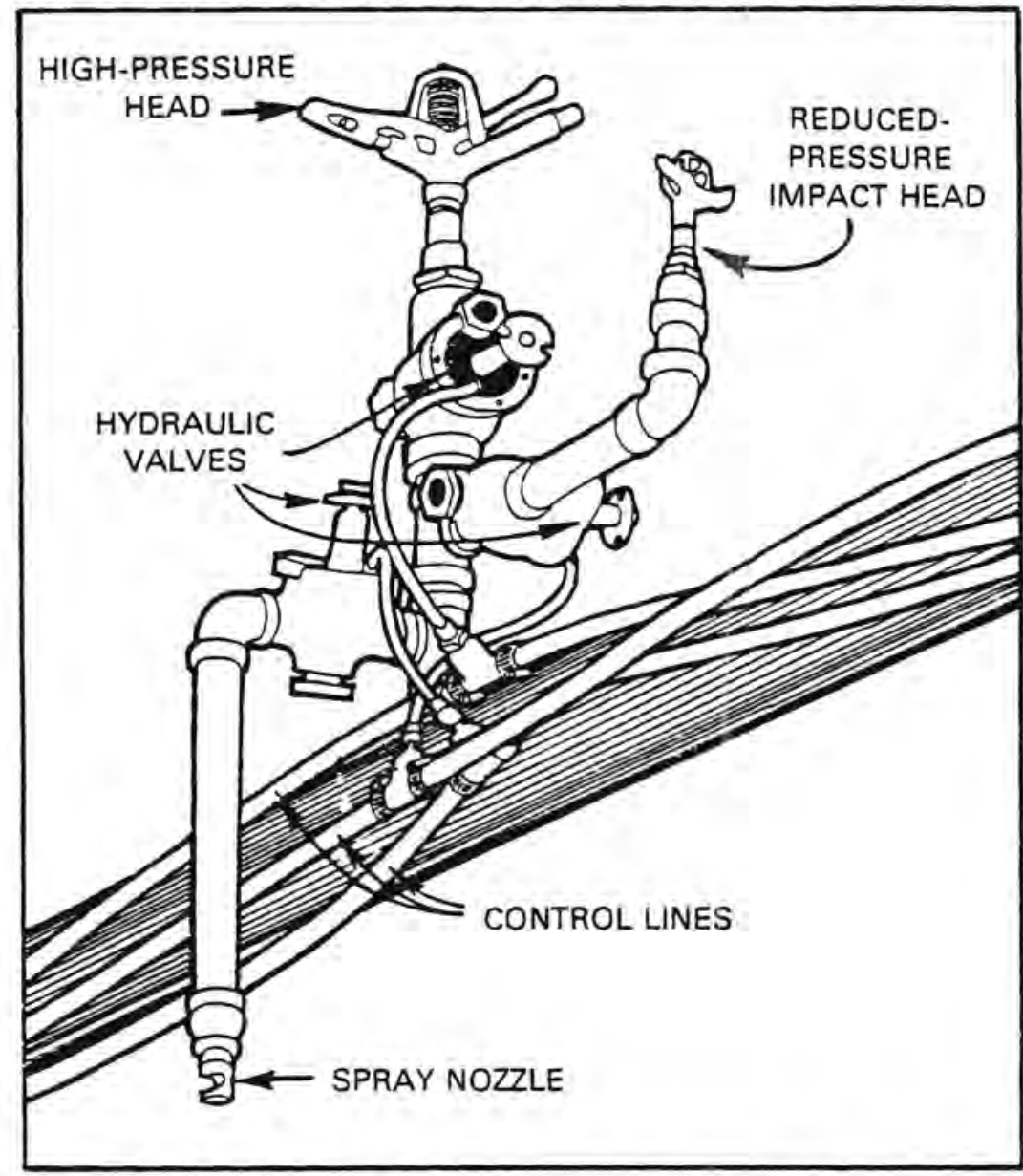

FIGURE 8.1. Sprinkler Arrangement on the Experimental Center-Pivot Irrigation System 
from an individual sprinkler head will travel is reduced and water droplet size is increased because of less pulverization of the jet stream.

Because of the smaller distribution patterns of reduced-pressure impact sprinklers, sprinkler heads must be spaced closer together along the centerpivot mainline. To simulate this requirement, the reduced-pressure impact sprinklers and spray nozzles were spaced approximately four times closer to each other along the experimental center-pivot mainline than were the conventional high-pressure sprinklers. This design is illustrated in Figure 8.2 .

The water pressure for the reduced-pressure impact sprinklers at the end of the experimental center-pivot was designed to be $140 \mathrm{kPa}$, which corresponds to approximately $20 \mathrm{psi}$. Water pressure at the center-pivot pad was designed to be $210 \mathrm{kPa}$ or approximately $30 \mathrm{psi}$.

\subsubsection{Reduced-Pressure Spray Nozzles}

The reduced-pressure spray nozzles used in this study were designed to operate at the same water pressures as the reduced-pressure impact sprinklers.

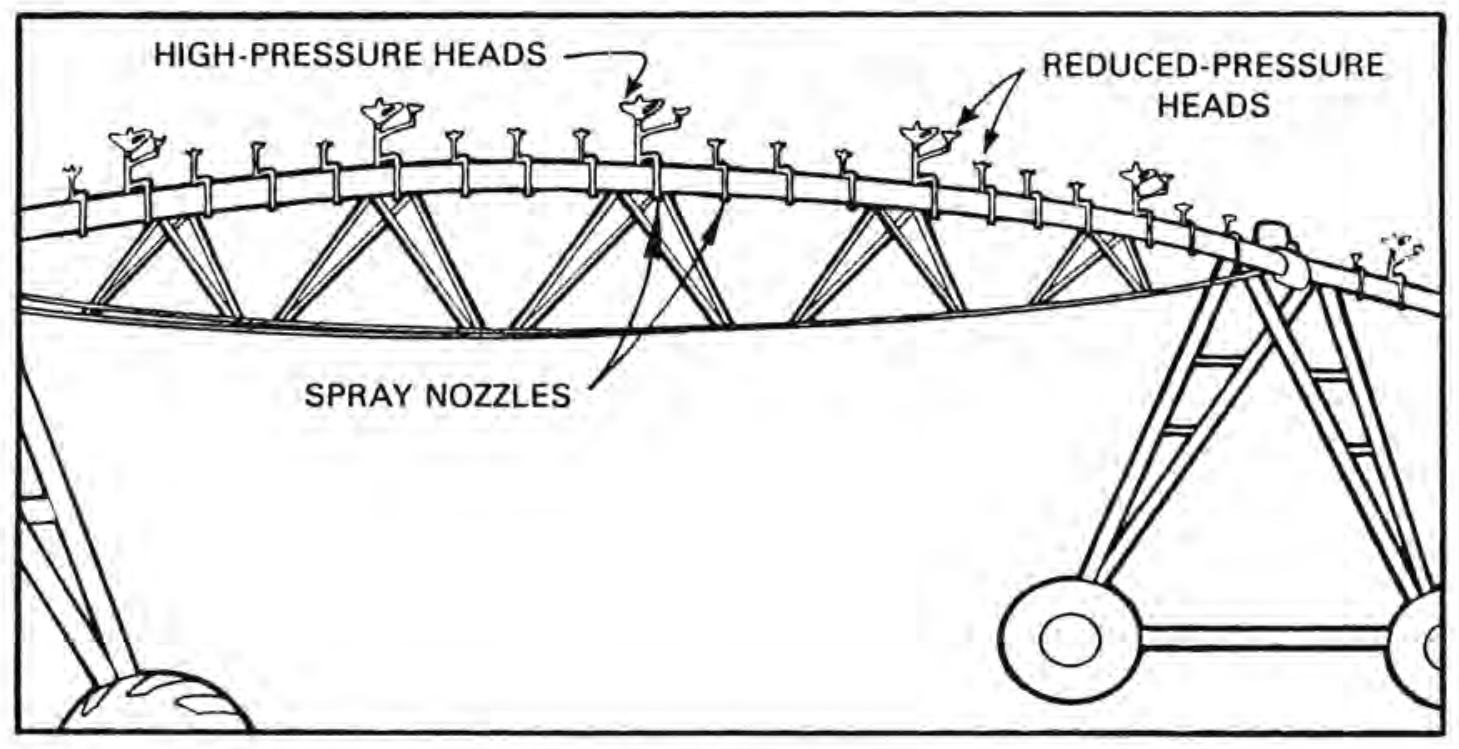

FIGURE 8.2, Organization of Sprinklers on the Experimental Center-Pivot Mainline 
The method of water application is quite different, however, since water is sprayed downward in a circular pattern from the spray nozzles while the centerpivot system moves around the field. Spray from the nozzles resembles a mist.

Water application rates for the spray-nozzle system used in the project were much faster than those of either reduced-pressure impact sprinklers or conventional high-pressure sprinklers. Typical water application rates for the three water application methods are illustrated in Figure 8.3.

Potential runoff occurs whenever the rate of water application exceeds the theoretical soil intake rate. Areas of potential water runoff are identified by the cross-hatched areas in Figure 8.3. Note from Figure 8.3 that the potential for runoff is much greater for the spray-nozzle system than for the other application systems. However, potential runoff does not necessarily equal actual runoff, since a number of techniques, including appropriate

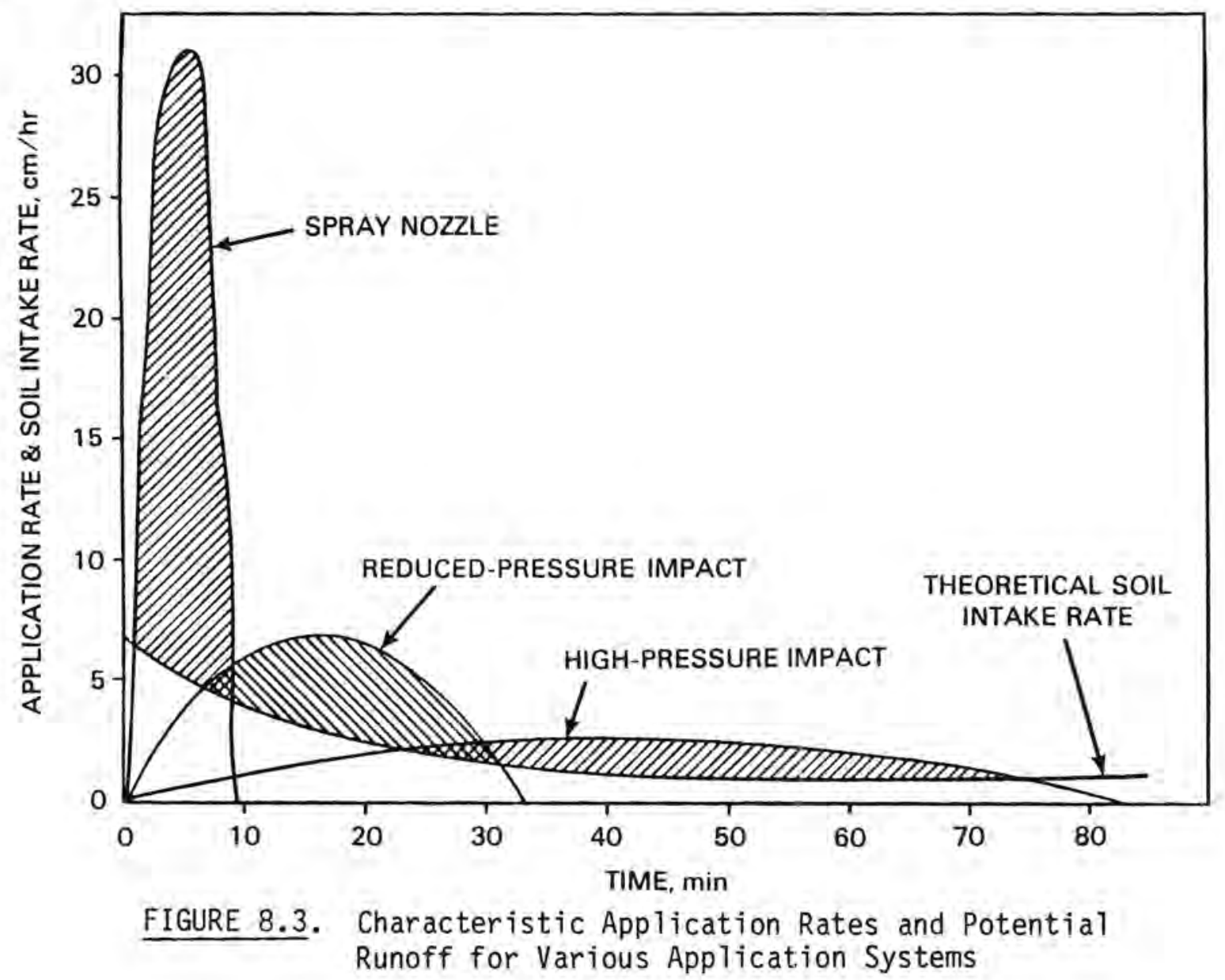


cultivation practices and increased center-pivot rotation speed, can be used to reduce runoff potential.

\subsubsection{High-Pressure Impact Sprinklers}

High-pressure impact sprinklers are the type that have traditionally been used since the development of the center-pivot system. The high-pressure impact sprinklers used on the experimental center-pivot were designed to operate at a water pressure of $410 \mathrm{kPa}$ (approximately $60 \mathrm{psi}$ ) at the end of the center-pivot system and approximately $480 \mathrm{kPa}(70 \mathrm{psi})$ at the center-pivot point.

\subsection{METHOD OF TESTING}

The three methods of water application were tested using the following methods:

- design of an experimental plot that incorporates the three water application methods with various tillage treatments and water applications amounts

- design of a switching system to activate each water application system at the appropriate location within the test plot

- development of mathematical models to analyze center-pivot water application processes and evaluate and select locations where reducedpressure systems can appropriately be used

- computation of various types of performance measurements, including uniformity of water application, water runoff, and crop yields.

\subsubsection{Experimental Plot Design}

The design of the experimental field plot is illustrated in Figure 8.4. Identification of the areas of the experimental plot where each application system was used from Figure 8.4 is straightforward. As illustrated in Figure 8.4, the letters $N, D$, and $C$ correspond to three different tillage methods that were used in different areas of the experimental plot. 


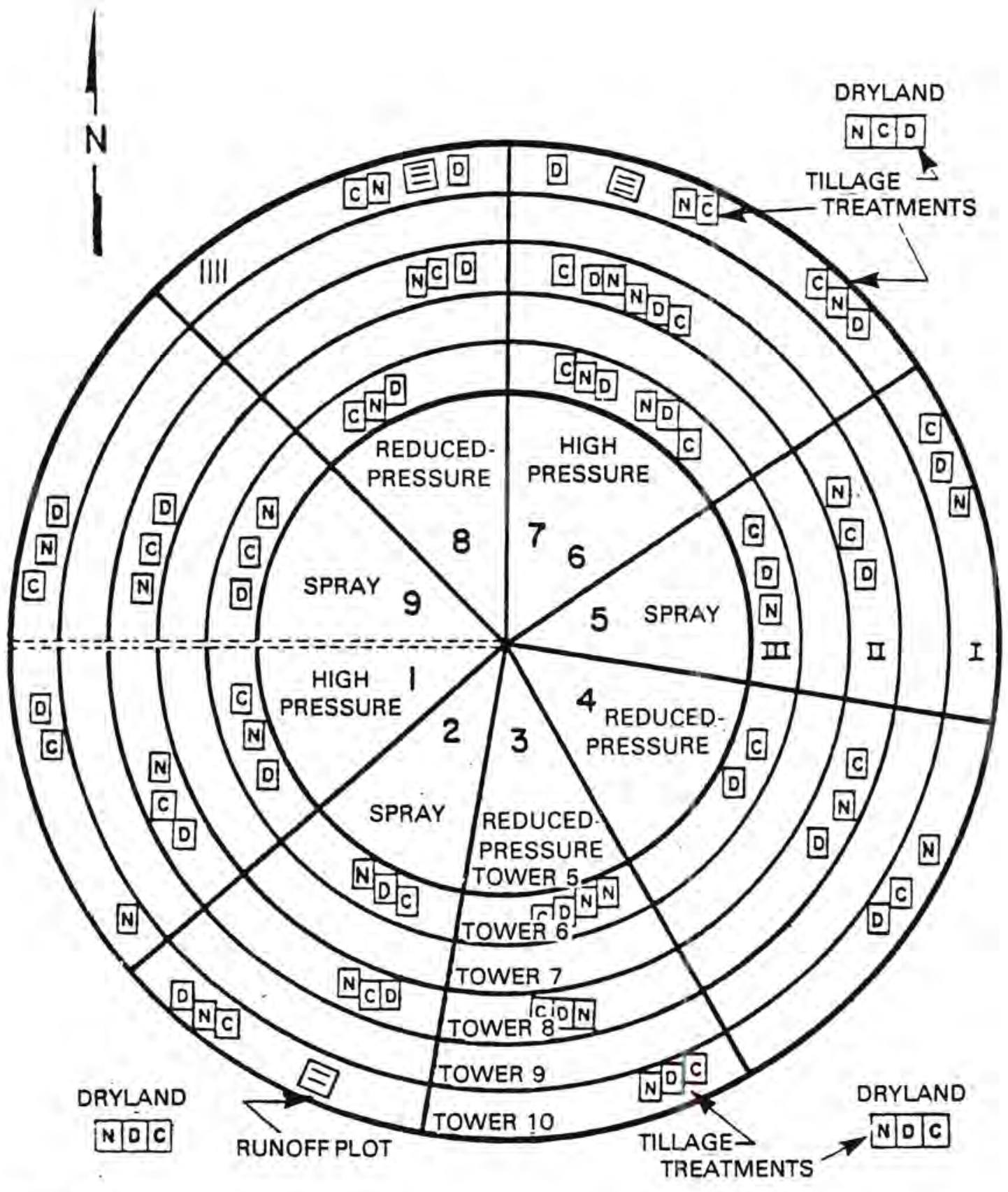

TILLAGE TREATMENT KEY:

$\mathbb{N}=$ CHOP STALKS IN SPRING, TILL PLANT AND CULTIVATE

D = TWO DISKINGS IN SPRING, PLANT AND CULTIVATE

C] = CHOP STALKS IN THE SPRING, TILL PLANT, CULTIVATE AND SUBSOIL

FIGURE 8.4. Layout of Experimental Center-Pivot Test Plot 
The sprinklers and spray nozzles at the outer-end of the center-pivot (Area I in Figure 8.4) were designed to supply a discharge to meet $100 \%$ of the evapotranspiration requirements of eastern Nebraska. The sprinklers and spray nozzles within circular areas II and III in Figure 8.4 were designed to apply 75 and $50 \%$, respectively, of the amount of water applied in Area I.

\subsubsection{Switching-System Design}

The angular location of the experimental center-pivot activates one of three switches within a switching cam. The activated switch provides an electronic signal to the appropriate 3-way solonoid valve, releasing water pressure to the proper sprinkler control line and allowing only one type of application system to operate.

\subsubsection{Mathematical Models}

The mathematical models developed in the project provide selection criteria for choosing an appropriate water application system (reduced-pressure impact, spray, or high-pressure impact) based on water application rates, soil surface storage capabilities and soil types.

\subsubsection{Performance Measurements}

The uniformity of water application for each system was evaluated using measurements 1) of the average depth of water applied by each irrigation system, 2) the average radial deviation from the average water depth across the experimental plots, and 3 ) the average rotational deviation from the average depth along the center-pivots arch. Water depth was measured by rain gauges located at various points in the experimental plots.

Water runoff evaluations for each system were made on the basis of runoff as a percentage of total irrigation water applied. Volume of runoff water was measured by placing water collection flumes at the outer edge of the centerpivot.

Bulk density is a measure of soil compaction and it was also evaluated for each system. These bulk density measurements indicate whether the use of a particular irrigation method will cause a soil crust to form that will inhibit 
water infiltration and plant growth.

Plant response to the three application methods was evaluated on the basis of corn yields, net moisture assimilation-rates, relative plant growth rates, leaf area indexes, leaf area durations, seedling emergence dates, and days to flowering and maturity. Corn yields for each system were recorded relative to the mean-yield for the entire test plot, because water application amounts were not held constant over the 3-year study period.

Energy savings estimates were developed under various assumptions regarding lift-to-pressure ratios, water irrigation efficiencies and changes in water pressure resulting from conversion to reduced pressure systems. Diesel fuel savings estimates resulting from reduced pressure application with a generic center-pivot were also calculated.

\subsection{TECHNICAL PERFORMANCE RESULTS}

The results of the field measurements revealed that the largest application depth deviations, and thus, the lowest moisture distribution uniformities were associated with the spray nozzle application system. The application depth deviations of the reduced-pressure impact and high-pressure impact systems were nearly equal. Variation in pressure caused by changes in field elevation was more critical for reduced-pressure systems, but, it is believed that pressure regulators or flow control nozzles, which were not installed on the experimental center-pivot, could have reduced this discharge variation significant ly.

Runoff test results from the field plots in 1978, 1979, and 1980 found that runoff was a significant problem only for the spray nozzle system. This system yielded runoff measurements of as high as $12.8 \%$ of total water applied for a single irrigation, and runoff amounts greater than $2 \%$ were recorded for many of the irrigations. In addition, the soil seemed to compact and crust more when the spray system was used. Runoff amounts for the reduced-pressure impact system and high-pressure system were less than $1 \%$ for almost every irrigation, and, in many cases, no runoff at all was recorded.

Runoff amounts were significantly affected by cultivation method. The chisel treatment was superior to the other cultivation methods for reducing 
runoff. Even for the spray system, runoff was generally less than $1 \%$ for plots cultivated with the chisel treatment. Disking cultivation methods produced the greatest water runoff, while runoff on the reduced-tillage plots was between the two extremes.

Soil bulk density was slightly higher for the reduced-pressure application methods indicating that some soil compaction does take place when reducedpressure irrigation methods are used. Visual inspection revealed the formation of a thicker soil crust on the plots irrigated with the reducedpressure spray system.

No significant differences in plant response or corn crop yields among the three types of application systems were discovered. This is a significant finding, since it indicates that reduced-pressure systems can be utilized without reducing yields, except in situations where very large amounts of water runoff occur.

Allowable irrigation amounts to produce zero runoff for different application systems in different soil types are presented in Table 8.1. These numbers provide guidance on which systems can be used in which soils. For example, low-spray systems should generally not be used in 0.1 or 0.3 soil intake families, because allowable irrigation amounts are too small.

\subsection{ENERGY SAVINGS RESULTS}

Energy savings analyses indicate that the lift-to-pressure ratio is an important determinant of the percentage energy savings obtainable from reduced pressure application, while changes in application efficiency and water

pressure are important determinants of both the absolute and percentage energy savings attributable to reduced pressure.

The fuel saved for various levels of water pressure reductions, assuming no change in irrigation efficiency, are presented in Table 8.2.

The estimated diesel fuel savings resulting from a change to a reducedpressure application system (assuming various levels of irrigation efficiency) are presented in Table 8.3. Note that large reductions in irrigation efficiency would be necessary in order for the change to reducedpressure to result in negative energy savings. The potential aggregate energy 
TABLE 8.1. Allowable Irrigation Amounts for Different Soil and Center-Pivot Types for Various Values of Soil Surface Storage

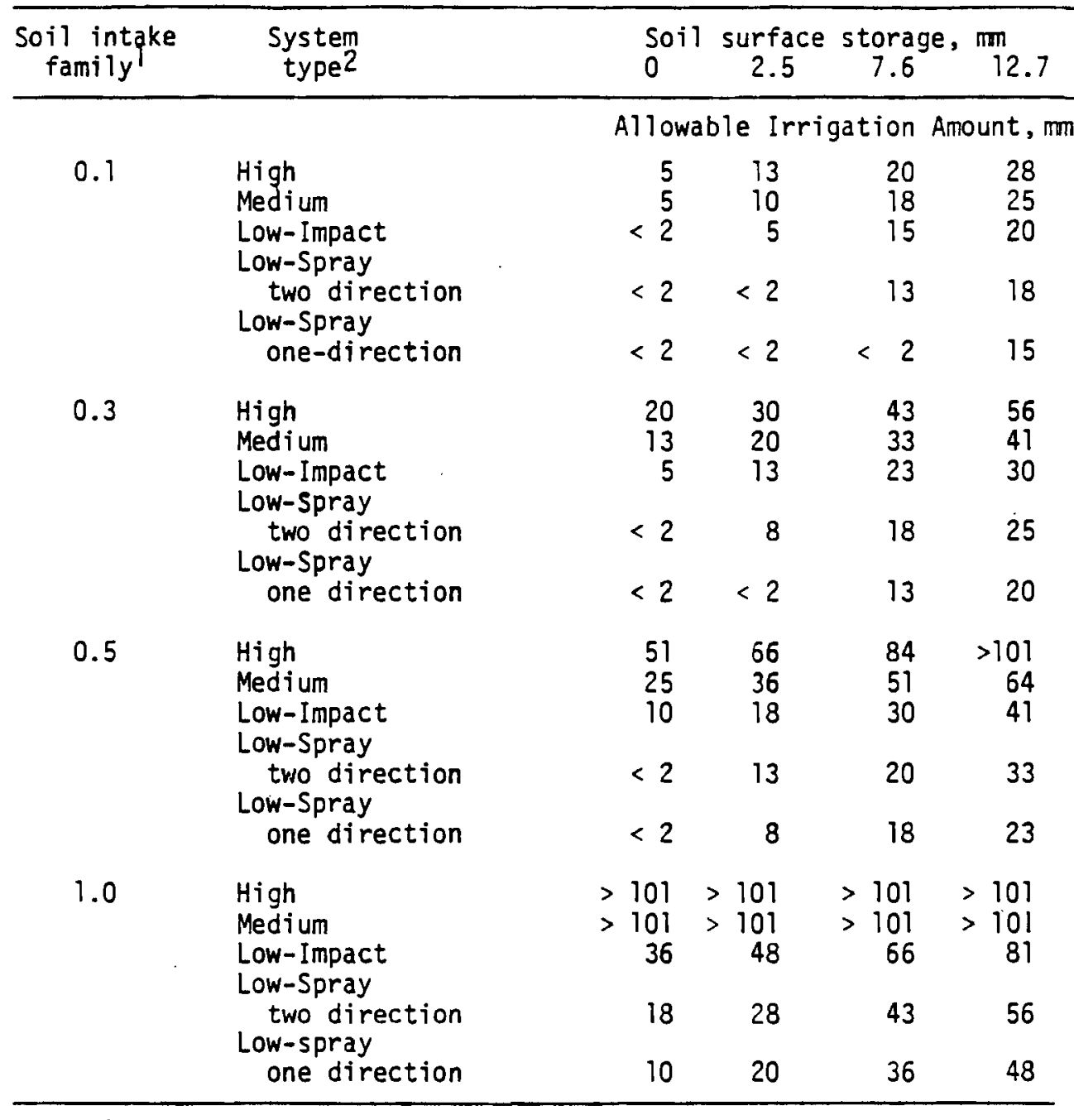

1. Soil Intake Families are defined by the Soil Conservation Service, USDA (1964).

2. All systems are 400 meters in length.

Typical high pressure system with a peak application rate of $25 \mathrm{~mm} / \mathrm{hr}$.

Typical medium pressure system with a peak application rate of $38 \mathrm{~mm} / \mathrm{hr}$.

Typical low pressure impact sprinkler system with a peak application rate of $64 \mathrm{~mm} / \mathrm{hr}$.

Typical low pressure spray nozzle system, spraying in two directions with a peak application rate of $89 \mathrm{~mm} / \mathrm{hr}$.

Typical low pressure spray nozzle system spraying in only one direction with a peak application rate of $152 \mathrm{~mm} / \mathrm{hr}$. 
TABLE 8.2. Fuel Saved Through Pressure Reduction with No Decrease in Irrigation Efficiency.

\begin{tabular}{ccccc}
\hline $\begin{array}{c}\text { Pressure } \\
\text { Reduction } \\
(\mathrm{kPa})\end{array}$ & $\begin{array}{c}\text { Diese }) \\
(\mathrm{L} / \mathrm{ha-cm})\end{array}$ & $\begin{array}{c}\text { Electric } \\
(\mathrm{kWh} / \mathrm{ha}-\mathrm{cm})\end{array}$ & $\begin{array}{c}\text { Propane } \\
(\mathrm{L} / \mathrm{ha}-\mathrm{cm})\end{array}$ & $\begin{array}{c}\text { Naţural Gas } \\
(\mathrm{M} / \mathrm{ha}-\mathrm{cm})\end{array}$ \\
\hline 70 & 0.88 & 2.86 & 1.43 & 1.11 \\
140 & 1.76 & 5.71 & 2.86 & 2.21 \\
210 & 2.65 & 8.57 & 4.28 & 3.32 \\
280 & 3.53 & 11.42 & 5.71 & 4.42 \\
\hline
\end{tabular}

$\mathrm{L} / \mathrm{ha}-\mathrm{cm}=$ Liters per hectare-centimeter of irrigation water applied. $\mathrm{kWh} / \mathrm{ha}-\mathrm{cm}=\mathrm{Kilowatt}$ hours per hectare-centimeter of irrigation water applied. $\mathrm{M}^{3} / \mathrm{ha-cm}=$ Cubic meters per hectare-centimeter of irrigation water applied.

TABLE 8.3. Diesel Fuel Savings with a Reduced-Pressure Center-Pivot System Operating at 40 psi Compared with a High Pressure System of 80 psi with Both Systems Having a Lift of 300 Feet.

\begin{tabular}{ccc}
\hline $\begin{array}{l}\text { Irrigation efficiency } \\
\text { under reduced pressure } \\
\text { (percent) }\end{array}$ & $\begin{array}{c}\text { Diese } \\
\text { fue } \begin{array}{c}\text { I savings } \\
(\mathrm{L} / \mathrm{ha}-\mathrm{cm})\end{array}\end{array}$ & $\begin{array}{c}\text { Diesel } \\
\text { fuel savings } \\
\text { (percent) }\end{array}$ \\
\hline 85 & 3.47 & 18.0 \\
80 & 2.48 & 12.8 \\
75 & 1.36 & 7.0 \\
70 & 0.08 & 0.4 \\
65 & -1.40 & -7.3 \\
\hline
\end{tabular}


savings of using reduced pressure center-pivots in the 17 largest irrigation states were estimated in a companion volume (Wilfert et al. 1982) to equal nearly 40 trillion Btu.

\subsection{COST SAVINGS RESULTS}

The initial costs of new reduced-pressure systems are almost identical to those for new conventional high-pressure systems. If the reduced-pressure systems are properly designed for the field in which they will operate, no change in crop yields should result from using reduced pressure. Thus, the economic benefits of using reduced-pressure irrigation will depend on the changes in system operating costs that occur as a result of the energy saving characteristics of reduced-pressure application systems.

In a companion study (Patton, et al. 1982), the annual levelized after-tax economic benefits of using reduced-pressure water application systems instead of high-pressure systems on 130 acres were estimated to range from $\$ 861$ to $\$ 5626$ in the 17 largest irrigation states. 


\subsection{LOW-ENERGY PRECISION APPLICATION}

It has long been known that drip irrigation systems require less water and energy to irrigate crops than most other types of irrigation systems. However, the drawbacks of using conventional drip irrigation systems, including high labor costs and unreliable performance, have generally inhibited the widespread use of these systems. Less labor intensive systems, such as center-pivots, have seen a rapid expansion in the number of acres irrigated, despite the relatively high energy intensiveness of these systems.

The low-energy precision application system (LEPA) represents an attempt to combine the desirable labor saving characteristics of mobile center-pivot and latera1 move irrigation systems with the energy and water saving features of drip irrigation systems. The mobile LEPA system, developed at Texas A \& $M$, is designed to operate at lower operating pressures than both conventional highpressure center pivots and the reduced-pressure center-pivot systems currently being marketed by irrigation manufacturers. It appears to represent a significant step in the development of energy and water saving irrigation technologies.

\subsection{TECHNOLOGY DESCRIPTION}

An illustation of an operating LEPA irrigation system is presented in Figure 9.1. Note that the structural skeleton of the LEPA system is very similar to that of a conventional center-pivot or lateral move irrigation system.

The major difference between the LEPA system and conventional irrigation technologies is in the method of water application. As illustrated in Figure 9.1, the LEPA system utilizes the force of gravity to apply water directly to the growing crop. Water is pumped through the system at very low pressures and then applied to the crop through a "drop tube" system. This feature allows for more direct water application to the growing crop and lower consumption of both water and energy. A closer view of the driving mechanism and water application method of the LEPA system is presented in Figure 9.2. 


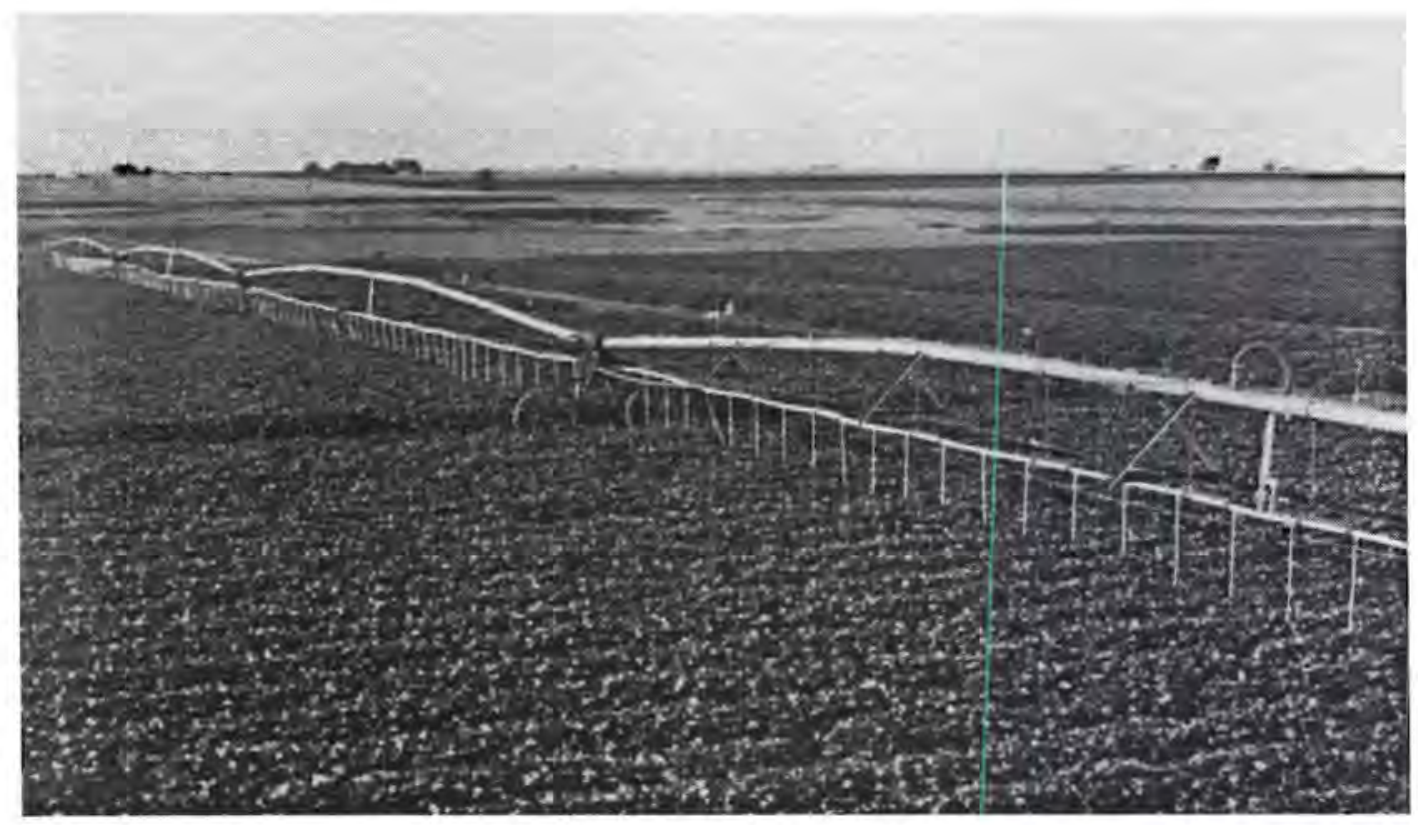

FIGURE 9.1. Operating LEPA System

\section{LOW-PRESSURE APPLICATION SYSTEM}

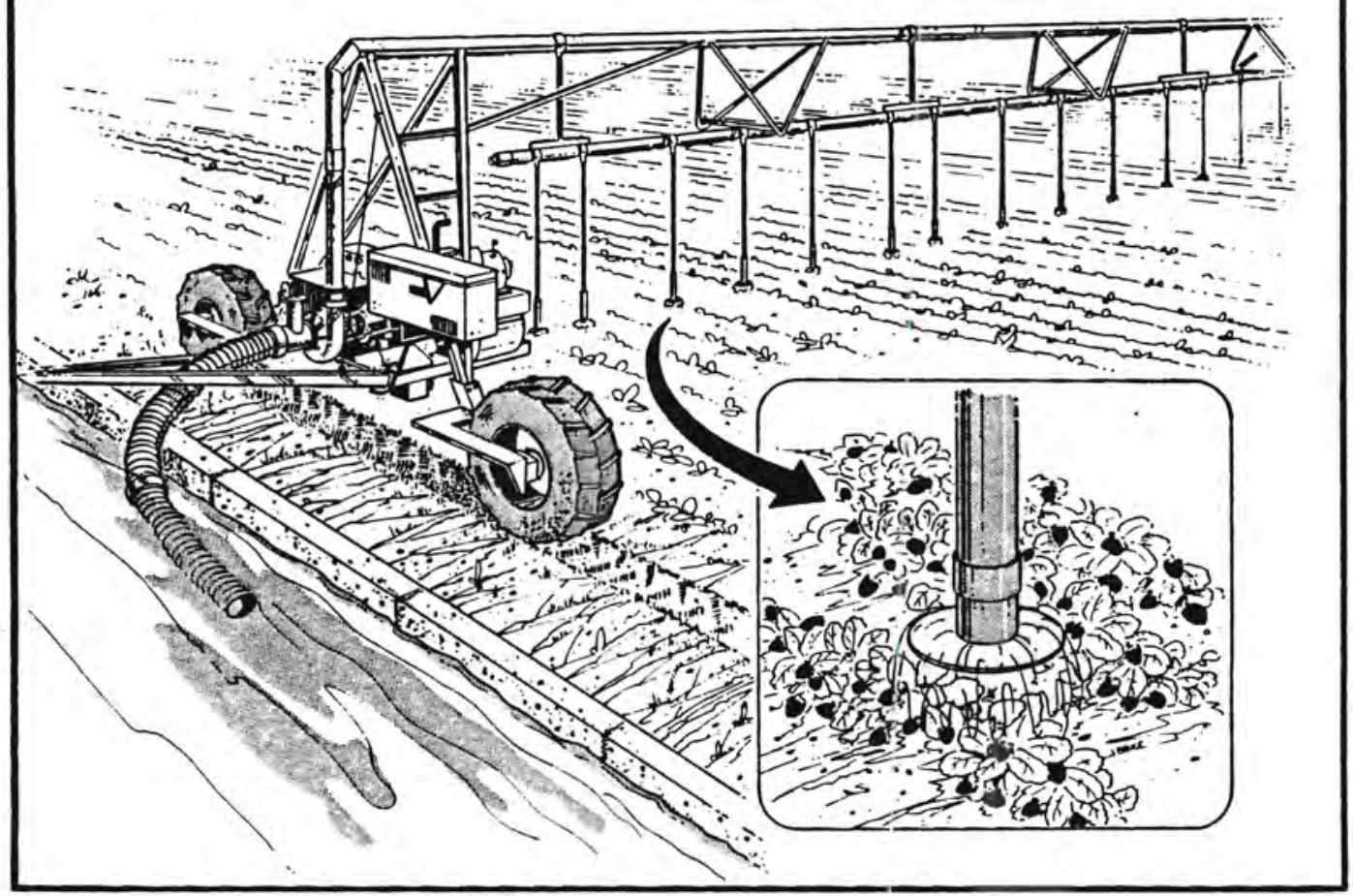

FIGURE 9.2. A Close-Up View of LEPA in Operation 
The major components of the LEPA system are illustrated in Figure 9.3 and include the following:

- an intermediate pressure system to maintain desired water pressure

- a specialized hydraulic design for uniform water distribution

- a "drop tube" system for water application

- a variable speed drive and alignment system

- a guidance system

- a conveyance system.

Basin tillage techniques, which are not necessary for the operation of the LEPA system but which do improve system performance, are recommended for use in conjunction with the LEPA system.

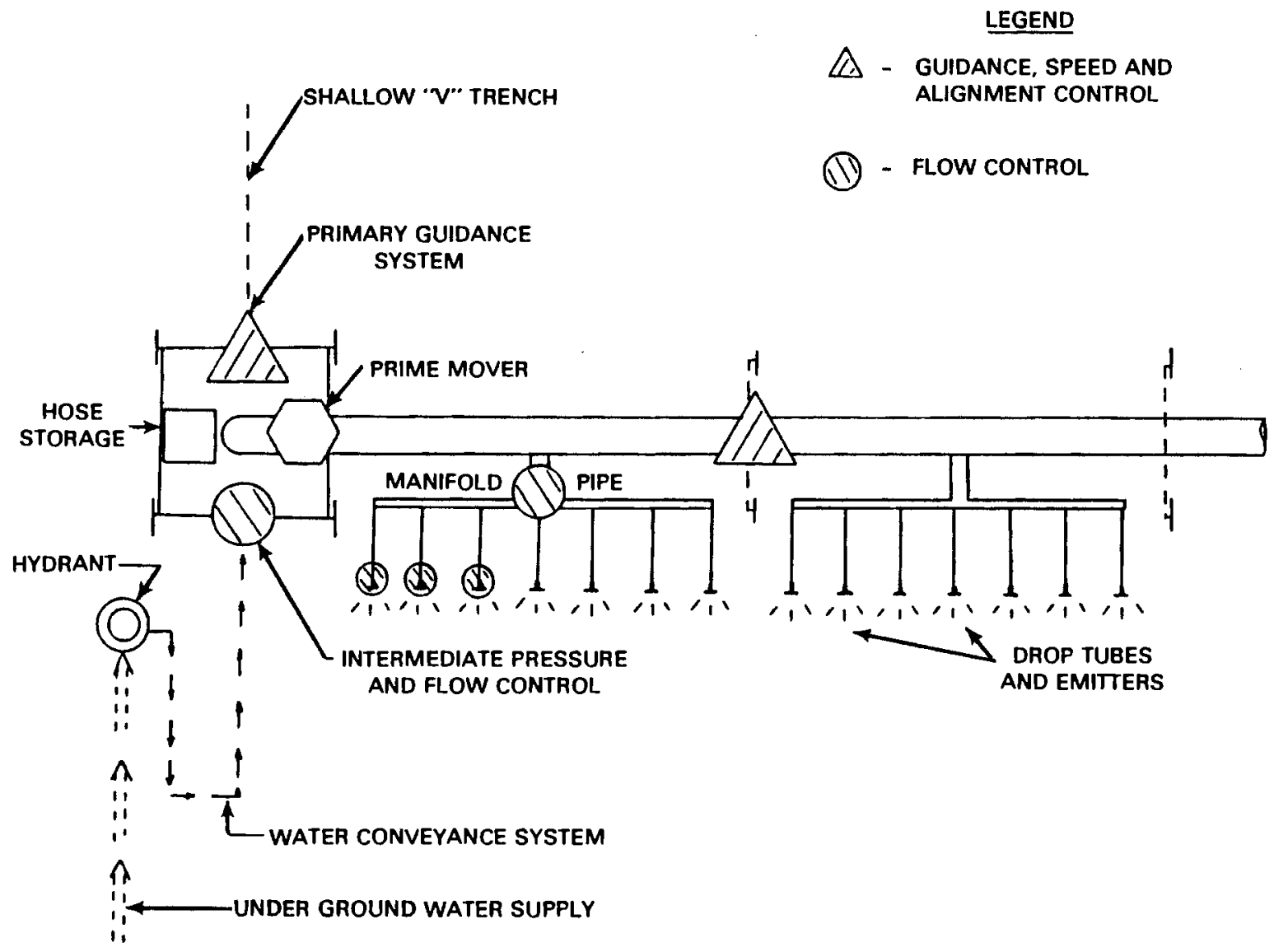

FIGURE 9.3. Schematic Diagram of a LEPA System 


\subsubsection{Intermediate Pressure System}

The LEPA system is designed to take water from low head underground pipelines or open ditches. An intermediate pressure system is necessary to supply a low operating water pressure for the LEPA system and must match its flow rate with that being supplied by the supply pipeline. Negative pressure, which would cause the supply hose for the LEPA system to collapse, must also be prevented.

The pressurization system incorporates a small centrifugal pump, a ball type air relief valve, and a diaphragm-activated surge control valve that is sensitive to retained air. Operation of the LEPA system requires that the RPM of the pressurization pump be adjusted so that about two feet of head is available on the intake side of the pump at all times. When head is reduced below the atmospheric pressure level, air is introduced into the pressurization system through an air relief valve. This air is trapped in an accumulator where a flap valve opens and activates a diaphragm-controlled butterfly valve. This action throttles the pump flow rate slightly until a positive pressure is aga in achieved.

Estimated operating pressure requirements for the LEPA system at various system lengths and flow rates are presented in Table 9.1. These operating pressures are significantly lower than those of other types of mobile irrigation systems.

\subsubsection{Hydraulic Design}

The prototype LEPA system is designed with a manifold distribution system. Manifolds containing drop tubes and emitters are suspended from the main pipe of the LEPA system by a track and trolly arrangement that allows for a 35-inch horizontal adjustment in drop tube location. Because the drop tubes can be horizontally adjusted, the emitters can be centered over the irrigation furrow or plant bed. A portion of the manifold distribution system is illustrated in Figure 9.4. Water is taken out of the main pipeline where it enters the manifold distribution pipe by a 2-1/2 inch hose, and water flow is controlled by either. a manually operated flow control valve or an automatic pressure regulating valve. 
TABLE 9.1. Predicted Pressure Requirements for LEPA Systems

\begin{tabular}{|c|c|c|c|c|c|c|c|}
\hline \multirow{2}{*}{$\begin{array}{l}\text { Flow } \\
\text { Rate } \\
\text { (gpm) }\end{array}$} & \multicolumn{2}{|c|}{$\begin{array}{c}\text { Pressure } \\
\text { Regulation }\end{array}$} & \multirow{2}{*}{$\begin{array}{l}\text { Orifice } \\
\text { Size } \\
\text { (in) }\end{array}$} & \multicolumn{2}{|c|}{ Predicted Pressure } & at Pivot Pad & \multirow{2}{*}{$\frac{(\mathrm{PSI}) \frac{1 /}{10 \text { Tower }}}{(1320 \mathrm{ft})}$} \\
\hline & $\frac{\text { Regul }}{\text { Yes }}$ & $\frac{\text { tion }}{\text { No }}$ & & $\begin{array}{l}4 \text { Towers } \\
(530 \mathrm{ft})\end{array}$ & $\begin{array}{l}6 \text { Towers } \\
(790 \mathrm{ft})\end{array}$ & $\begin{array}{l}8 \text { Towers } \\
(1060 \mathrm{ft})\end{array}$ & \\
\hline \multirow[t]{2}{*}{10021} & $x$ & & $3 / 32$ & 9.3 & 9.3 & 9.3 & 9.4 \\
\hline & & $x$ & & 4.3 & 4.3 & 4.3 & 4.4 \\
\hline \multirow[t]{2}{*}{200} & $x$ & & $1 / 8$ & 9.7 & 9.8 & 10.0 & 10.1 \\
\hline & & $x$ & & 4.7 & 4.8 & 5.0 & 5.1 \\
\hline \multirow[t]{2}{*}{300} & $x$ & & $5 / 32$ & 10.4 & 10.6 & 11.0 & 11.3 \\
\hline & & $x$ & & 5.4 & 5.6 & 6.0 & 6.3 \\
\hline \multirow[t]{2}{*}{400} & $\mathrm{x}$ & & $11 / 64$ & 11.4 & 11.7 & 12.4 & 12.9 \\
\hline & & $x$ & & 6.4 & 6.7 & 7.4 & 7.9 \\
\hline \multirow[t]{2}{*}{500} & $x$ & & $13 / 64$ & 12.7 & 13.2 & 14.2 & 14.9 \\
\hline & & $x$ & & 7.7 & 8.2 & 9.2 & 9.9 \\
\hline \multirow[t]{2}{*}{$6003 /$} & $x$ & & $7 / 32$ & 12,4 & 12.7 & 13.3 & 13.7 \\
\hline & & $\mathrm{x}$ & & 7.4 & 7.7 & 8.3 & 8.7 \\
\hline \multirow[t]{2}{*}{700} & $x$ & & $15 / 64$ & 13.6 & 13.9 & 14.8 & 15.4 \\
\hline & & $\mathrm{x}$ & & 8.6 & 8.9 & 9.8 & 10.4 \\
\hline \multirow[t]{2}{*}{800} & $x$ & & $1 / 4$ & -- & 15.4 & 16.4 & 17.2 \\
\hline & & $x$ & & -- & 10.4 & 11.4 & 12.2 \\
\hline \multirow[t]{2}{*}{900} & $x$ & & $17 / 64$ & $-\infty$ & 17.1 & 18.3 & 19.3 \\
\hline & & $x$ & & -- & 12.1 & 13.3 & 14.3 \\
\hline \multirow[t]{2}{*}{1000} & $x$ & & $9 / 32$ & - & 18.9 & 20.5 & 21.7 \\
\hline & & $x$ & & -- & 13.9 & 15.5 & 16.7 \\
\hline
\end{tabular}




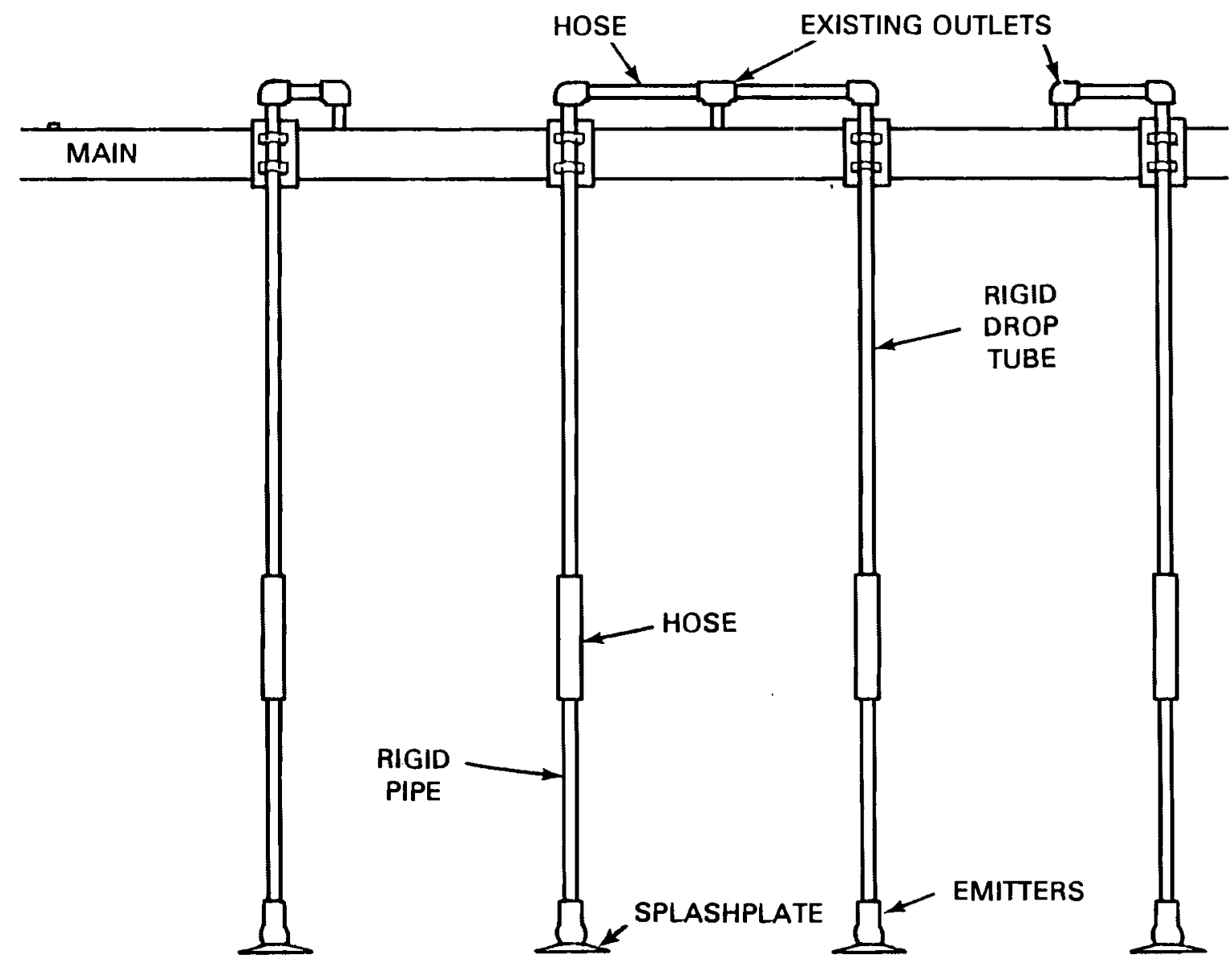

FIGURE 9.4. Arrangement of Manifold Drop Tube Distribution System

\subsubsection{Drop Tube Package}

The drop tube package used for water distribution in the LEPA system contains two primary elements - drop tubes and emitters. Drop tubes are simply pieces of plastic pipe that are suspended from the system manifolds. Water flows down the drop tubes to the emitters, where it makes contact with a splash plate. The water is deflected off the splash plate and, when operated at a height of three to four inches above the furrow, the water falls from the splash plate in a manner similar to gentle rainfall. The outlets are designed to discharge water in all directions over a 12 to 14 square-inch area. A discharging emitter is illustrated in Figure 9.5. 


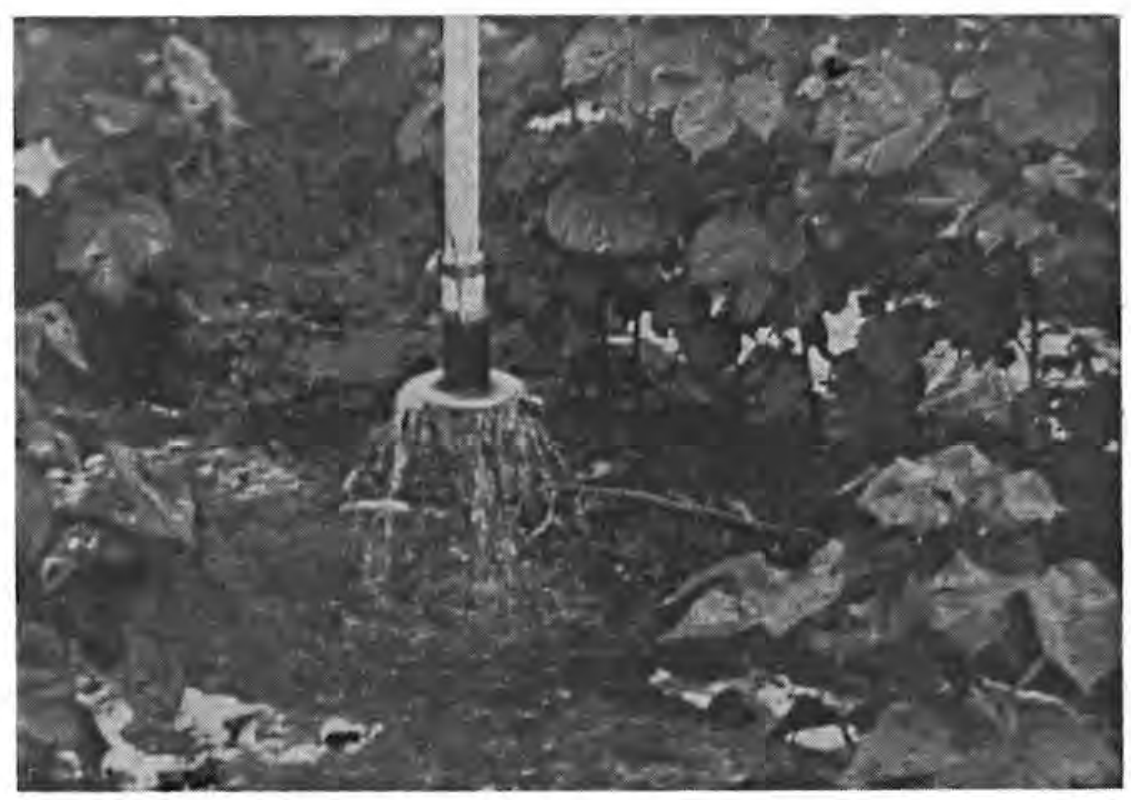

FIGURE 9.5. A Discharging Emitter

The outlets are designed to operate in the 1 to 5 psi range with water discharge from the emitters controlled by orifices. The size of the orifices along each manifold may be varied to compensate for friction losses within the manifold. However, the size of all orifices is larger than the size of discharge openings on conventional drip irrigation systems, which eliminates many of the clogging problems associated with conventional drip irrigation systems.

\subsubsection{Variable Speed Drive and Alignment}

In this experimental design, compressed air and an air hydraulic drive propel the LEPA system. Its operation is similar to that of a conventional center-pivot or lateral move system. Variable air flow dividers and air flow control valves are incorporated for speed control of the command platform and alignment of the pipe system. A mechanical torsion arm and cam arrangement is located at the pivot pad (in the case of a center-pivot system) and is 
responsible for keeping the main pipeline and towers perpendicular to the direction of travel of the pivot pad and command platform.

A change in the angle between the command platform and the main pipeline controls the movement of the end tower. The middle towers then align themselves between the command platform and the end tower by other cam-actuated valves controlling the hydraulic cylinders. The prime mover is an 18horsepower gasoline engine.

\subsubsection{Guidance System}

The guidance system utilizes a mechanical sensing element to activate a pneumatic direction control circuit. A double disk guide, which is attached to a direction sensing arm, follows a shallow trench or furrow. The movement of the sensing arm triggers a four-way air valve that directs compressed air to the appropriate wheels. Direction is maintained by application of differential power to the various wheels.

\subsubsection{Conveyance System}

Flexible lay-flat irrigation hose is used to convey water to a lateral move LEPA system. The hose operates at lower than normal design pressure, and therefore, specially designed hose carts are used to maintain an adequate bend radius and aid in maintaining the internal diameter of the hose at low pressure.

\subsubsection{Basin Tillage Techniques}

Basin tillage techniques are used to improve water distribution and retention within the irrigation furrow. The system utilizes a series of irrigation microbasins to hold water and prevent runoff. These microbasins are created by plowing wide shallow irrigation furrows with equally spaced soil barriers. Figure 9.6 illustrates a LEPA system working in conjunction with a microbasin tillage arrangement.

Some special tillage equipment is needed in order to cultivate using microbasin tillage techniques. The attachment for constructing the soil 


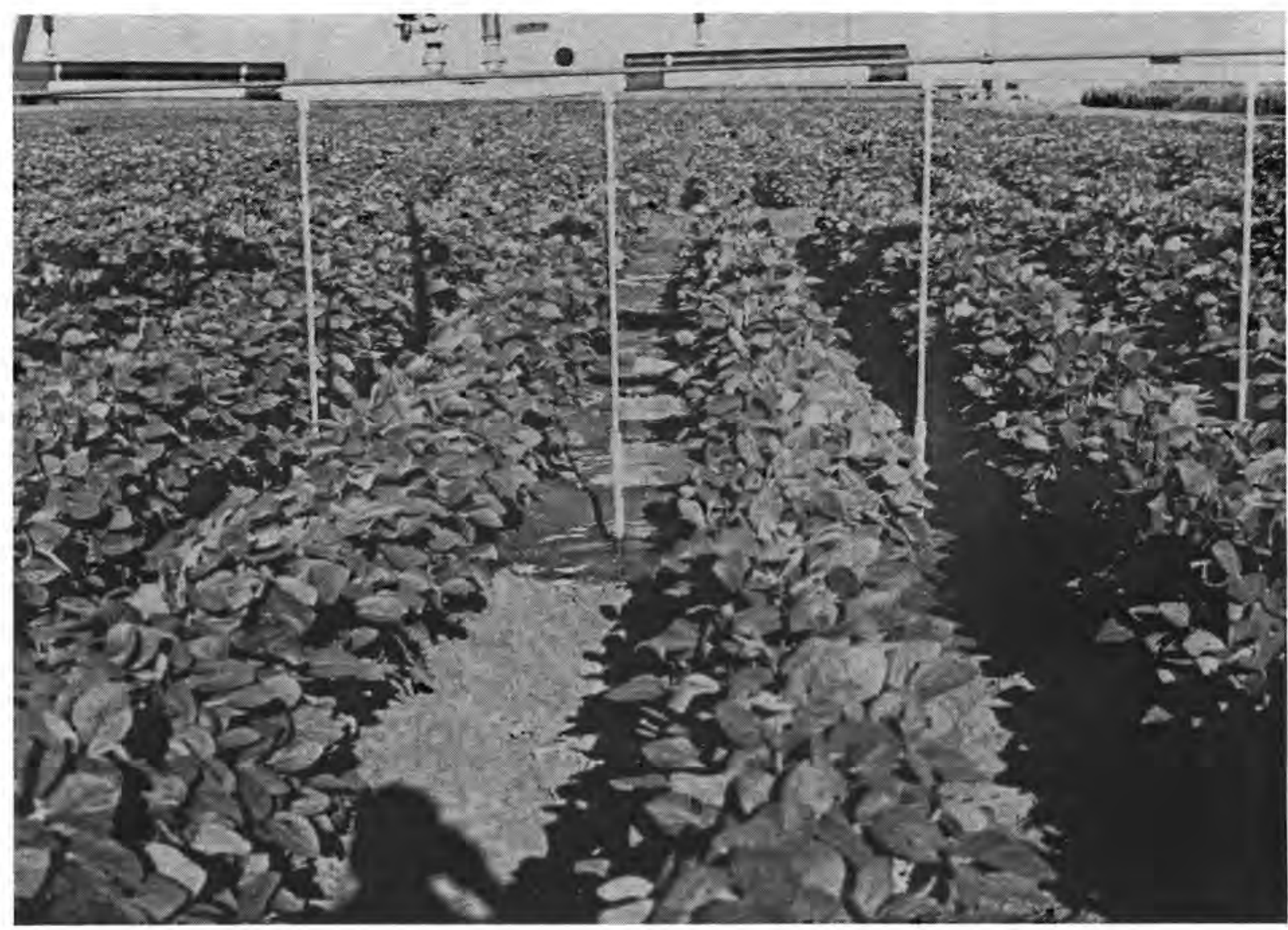

FIGURE 9.6. Close-Up View of Microbasins

barriers within the irrigation furrows is shown in Figure 9.7. A set of blades must also be mounted on the front of the tractor for plowing out dikes. The microbasin tillage implement shown in Figure 9.7 was designed to be attached to equipment such as bedders, planters, and cultivators, currently being used in row crop production. It can be adjusted for various dike spacings and heights so that microbasin size can be regulated.

\subsection{METHOD OF TESTING}

To test the performance of the LEPA system, the following methods were used:

- field testing of the performance of the LEPA system versus the performance of sprinkler and furrow irrigation systems 


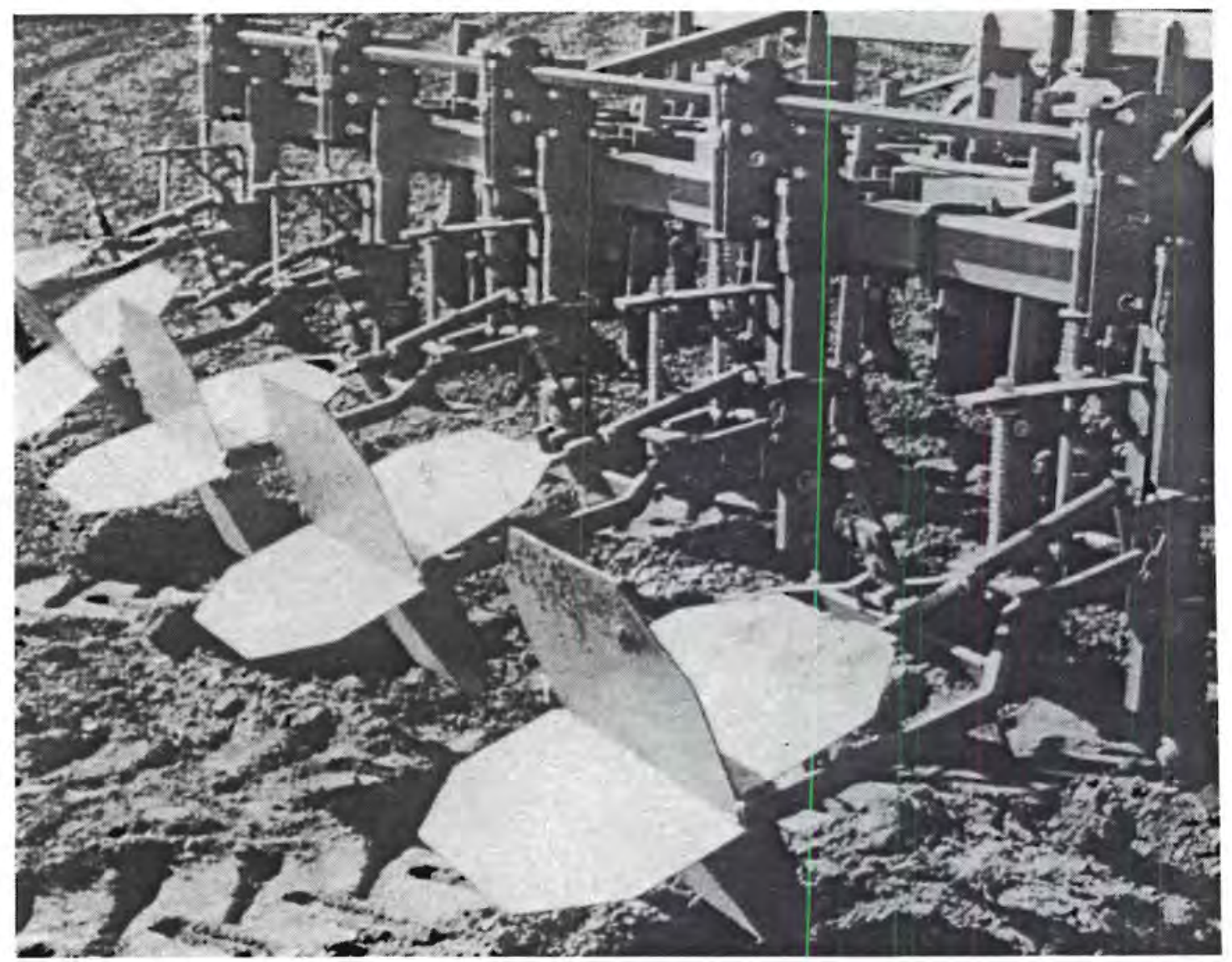

FIGURE 9.7. Hydraulically Operated Basin Tillage Implement

- testing of the interaction of basin tillage with LEPA, sprinkler and furrow irrigation

- measurement of water application efficiencies, water distribution efficiencies, and energy and water use for the three types of irrigation methods

- economic analysis of the LEPA system versus other irrigation systems.

A11 field tests were performed on fields located near Lubbock, Texas.

\subsubsection{Field Tests}

To evaluate the performance of the LEPA system versus conventional highpressure sprinkler irrigation, high-pressure sprinkler heads were attached to an operating LEPA system. These sprinklers were attached between the wheels of 
two lengths of the LEPA mainline. Two other lengths of the mainline were shut off and furrow irrigation was implemented. Border areas were designated between the irrigation system test plots.

Equal quantities of water were applied to all irrigated plots. Flow rates for the LEPA and sprinkler systems were measured by water catchment cans. Flow rates for the furrow system were calculated as a percentage of the nonerosive furrow stream flow rate and the slope of the furrow. Trapezoidal flumes with water level recorders were used to measure water runoff, and neutron tubes and tensiometers were used to obtain soil moisture level measurements. Cotton was used as the test crop in 1979 and soybeans in 1980.

\subsubsection{Basin Tillage Testing}

The effects of microbasin tillage were tested by cultivating several plots in the test field with microbas in tillage methods and cultivating several other plots with conventional tillage methods. Sprinkler and LEPA irrigation system test plots were divided into two areas - a microbasin tillage plot and a conventional tillage plot. Nonirrigated plots with microbasin and conventional tillage were also designated to separate the effects of retained rainfall on yields and the soil moisture budget.

\subsubsection{Performance Measurements}

Water application efficiency is the ratio of water stored in the root zone to water delivered. Water stored in the soil is equal to water delivered minus evaporative losses, deep percolation below the root zone, and runoff. Water distribution efficiency is to measure the uniformity of irrigation and is calculated as a function of the average depth of irrigation and the average deviation from this depth at various locations in the field. An energy coefficient is the ratio of irrigation head to the product of application efficiency and distribution efficiency. All of these measurements were calculated and used to evaluate the performance of the LEPA versus conventional sprinkler and gravity flow systems.

Other performance measurements used to evaluate the LEPA system were the energy use and water use per unit of crop yield. These measurements are 
calculated simply by dividing crop yields per acre by gross amounts of energy and water used in producing this yield.

\subsubsection{Economic Analys is}

The costs of converting to LEPA from a high-pressure impact sprinkler system, a low-pressure spray nozzle system, and a furrow system were compared to the energy cost savings that could result from such conversion as a means of analyzing the economics of LEPA use. Four LEPA conversion options were analyzed for each of the conventional systems: LEPA linear move with and without pressure regulators, and LEPA center-pivot with and without pressure regulators. A cost payback period for the LEPA system was also calculated.

Energy costs for LEPA and high-pressure sprinkler systems were estimated based on energy efficiency data obtained in the field tests. Efficiency data for furrow and low-pressure spray systems were obtained from the results of other studies performed in Texas by the High Plains Underground Water Conservation District.

\subsection{TECHNICAL PERFORMANCE RESULTS}

The LEPA system achieved superior performance compared to the other irrigation systems in most performance measurement categories. However, in some cases, use of microbasin tillage in conjunction with the LEPA system was essential to the superior performance of the LEPA system.

A sumary of the results of the tests of water distribution efficiencies, water application efficiencies and total system energy coefficients is presented in Table 9.2. Note from Table 9.2 the significantly higher application efficiencies for the LEPA system compared to sprinkler systems and the significantly higher distribution efficiencies for the LEPA system compared to gravity flow furrow systems. The energy coefficients demonstrate that the LEPA system is much more efficient in its use of energy than the other systems. However, it should be noted that LEPA has only been successfully used to irrigate row crops, and that further testing is necessary to determine if LEPA can be used to irrigate non-row crops. 
TABLE 9.2. Total System Energy Coefficients, 1979-1980

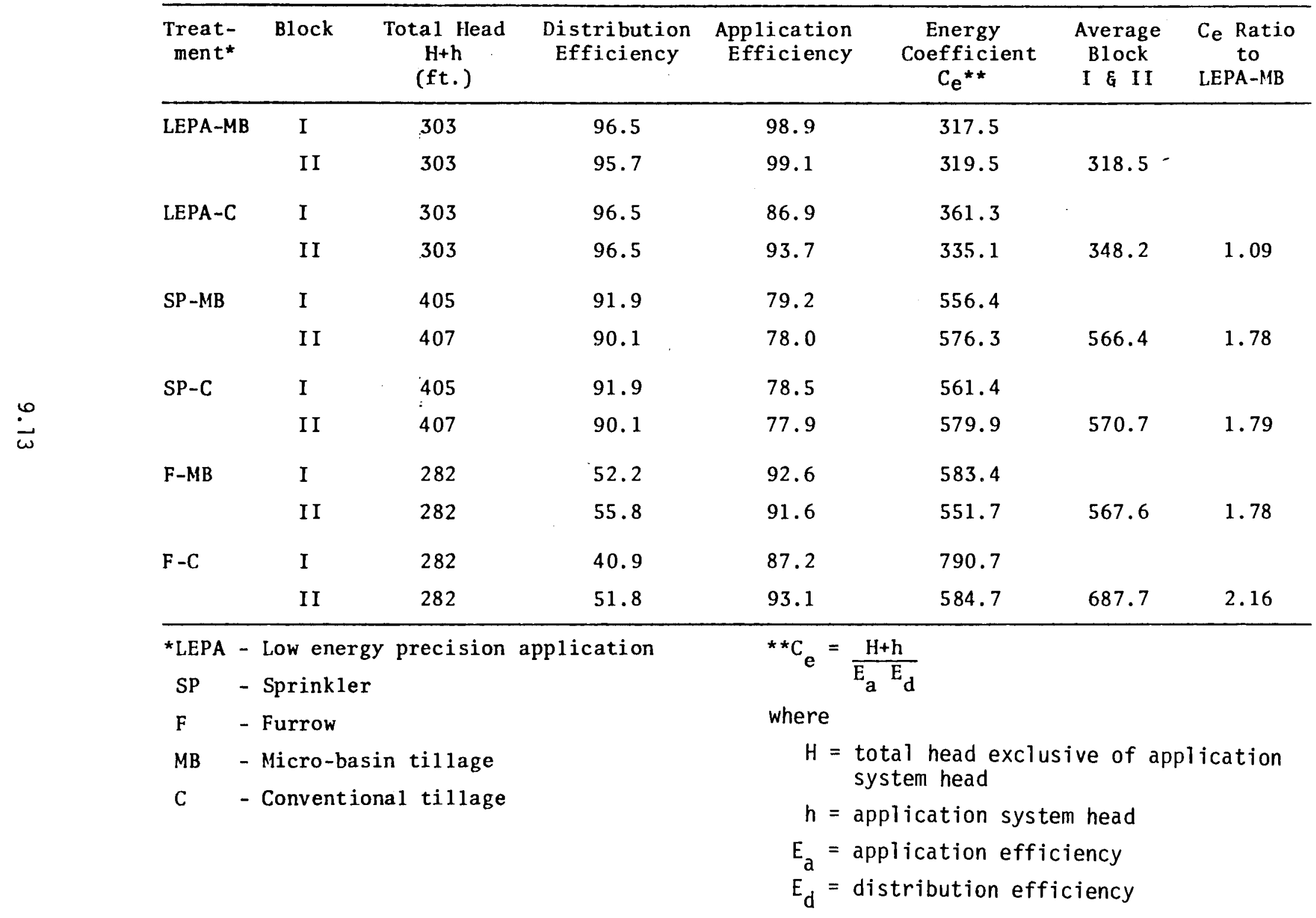




\subsection{ENERGY SAVINGS RESULTS}

Water and energy use per unit of yield for soybeans obtained in the 1980 field tests are shown in Table 9.3. LEPA system performance was generally superior to that of other systems, but the use of microbasin tillage was an important element in LEPA's successful performance, particularly for water use efficiency measurements. Note that a high-pressure sprinkler system with conventional tillage uses nearly twice as much energy per unit of yield than does the LEPA system with microbasin tillage. Water and energy use per unit of yield were not measured for the cotton crop in 1979 because an abnormally large amount of rainfall during the growing season of that year caused any analys is of the effects of irrigation on crop yields to be useless. In a companion study to this one (Wilfert, et al. 1982) it was estimated that a potential aggregate energy savings of nearly 40 trillion Btu could result from using LEPA center-pivot and lateral move systems rather than conventional highpressure mobile sprinkler systems.

\subsection{COST SAVINGS RESULTS}

The estimated costs of converting various types of irrigation systems to LEPA are presented in Table 9.4. An analysis of the payback periods for returning these costs, using ranges in applied water of one to four acre feet, ranges in pumping lift of 50 to 400 feet, power costs of $\$ 0.08$ per $\mathrm{kWh}$, a $15 \%$

TABLE 9.3. Average Water and Energy Use Per Unit of Crop Yield for LEPA, Sprinkler, and Gravity Flow Irrigation Systems

Basin Tillage
LEPA SPRINKLER FURROW

Conventional Tillage LEPA SPRINKLER FURROW

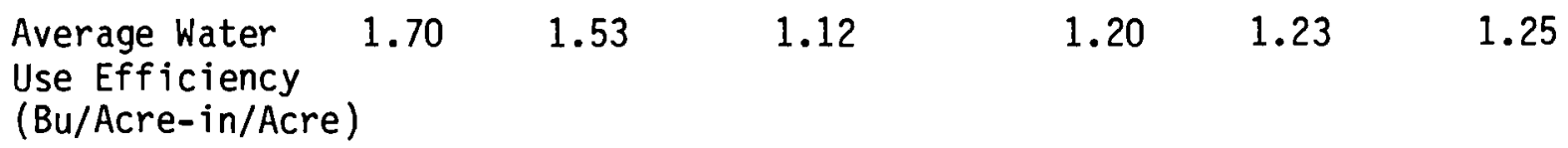

Energy Ratio .050 .033 .035 .035 .027 
TABLE 9.4. Estimated Costs of Converting Irrigation Systems to LEPA $(\$ 1980)$

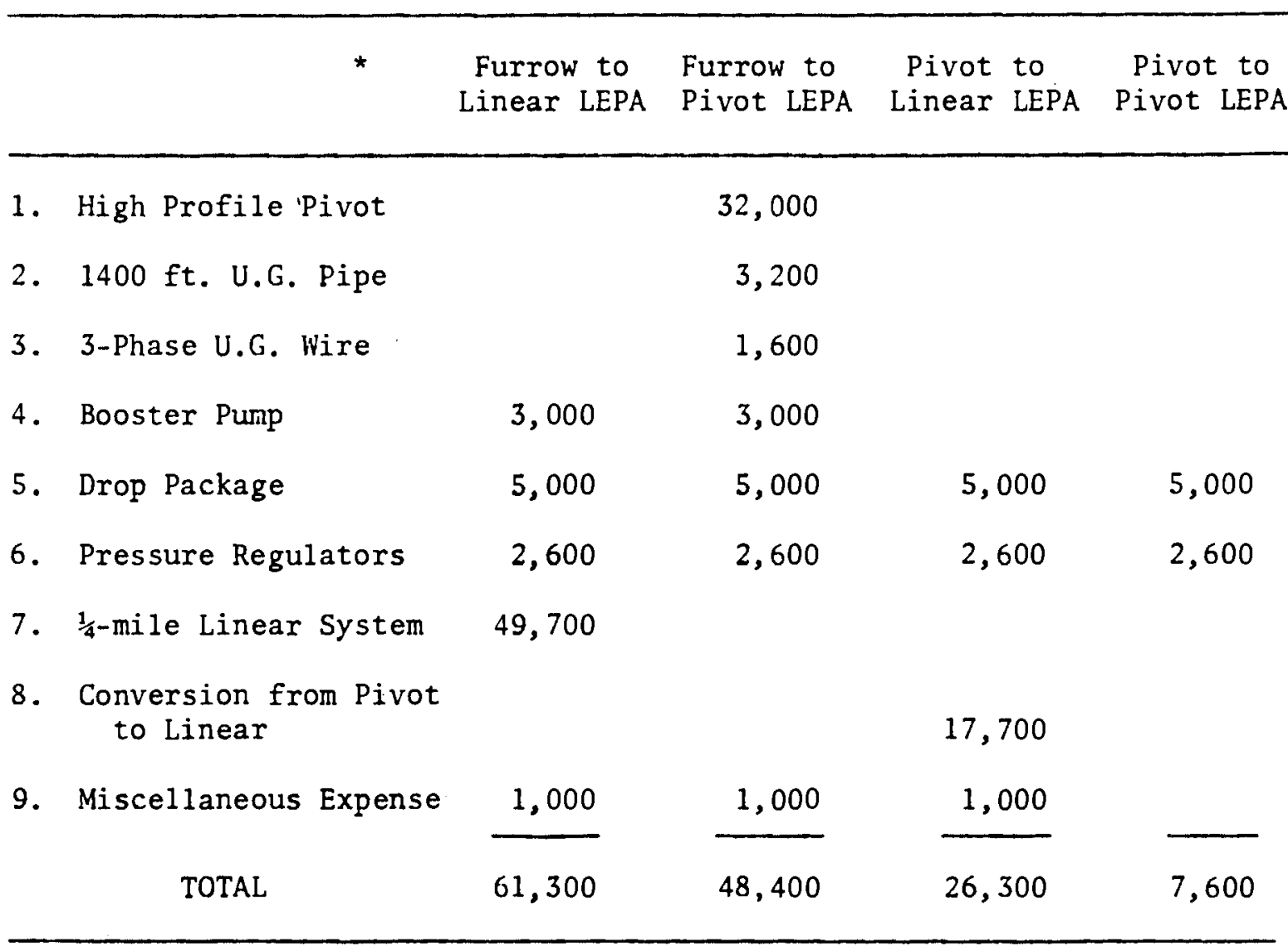

* Cost information based on 1980 prices obtained from Christian Irrigation of Plainview, Texas, Vali Irrigation of Olton, Texas, and Texas Agricultural Experiment Station records.

interest rate on the initial cost of the LEPA system, and various other assumptions, found that the energy cost savings of converting from either a conventional high-pressure sprinkler system or a low-pressure spray system to LEPA would generally return the initial costs of conversion in less than two years. However, the payback period for converting from a gravity flow furrow system to LEPA would be at least five years, based on energy cost savings alone. If the potential labor and water cost savings resulting from the use of the mobile LEPA system rather than a furrow system were included in the analysis, it is believed that conversion of a gravity flow furrow irrigation system to LEPA would also have a short payback period. 
An economic analysis of the annual levelized costs of using LEPA lateral move and center-pivot systems performed in a companion study (Patton, et al. 1982) found that the levelized lifetime costs of LEPA systems are substantially less than conventional center-pivot and lateral move irrigation systems. The annual after-tax benefits of using the LEPA lateral move system rather than a conventional system on 160 acres in the 17 largest irrigation states ranged from $\$ 250$ for certain surface water irrigation situations to $\$ 11,027$ for certain groundwater irrigation situations. The annual after-tax benefits for using the LEPA center-pivot system rather than a conventional center-pivot on 130 acres were estimated to range from $\$ 220$ for some surface water applications to $\$ 9709$ in some groundwater applications. Annual after-tax benefits for using the LEPA system were realized in all of the states analyzed. 


\subsection{AUTOMATED GATED-PIPE SYSTEM}

Conventional gravity flow irrigation systems use large amounts of labor and water. Consequently, many farmers have switched from gravity flow systems to center-pivot systems, which require less labor and water but which use large amounts of energy per unit of water delivered.

An automated gated-pipe system was recently developed in an attempt to reduce the labor and water usage associated with gravity flow irrigation. Automation facilitates the moving of water from one part of a field to another. This reduces labor requirements and also allows for more precise water application. More precise water application reduces total water usage and energy consumption.

The automated system developed at Kansas State University uses radio controls to automatically activate flow-control valves which initiate the flow of water through the gates of the gated-pipe system. Either irrigation controllers or a micro-computer can be used to schedule the operation of the radio controls. An illustration of the automated system in operation is presented in Figure 10.1.

\subsection{TECHNOLOGY DESCRIPTION}

The primary components of the automated gated-pipe system developed in this project are the following:

- irrigation controllers and a mini-computer that are used to control the timing and pattern of irrigation settings

- radio equipment used to transmit and receive the radio signals that control the operation of water flow valves

- radio-controlled servos, which translate radio signals into mechanical action

- three-way pilot valves operated by the servos

- water flow-control valves that control water flow from the gated-pipe to the irrigation furrows 


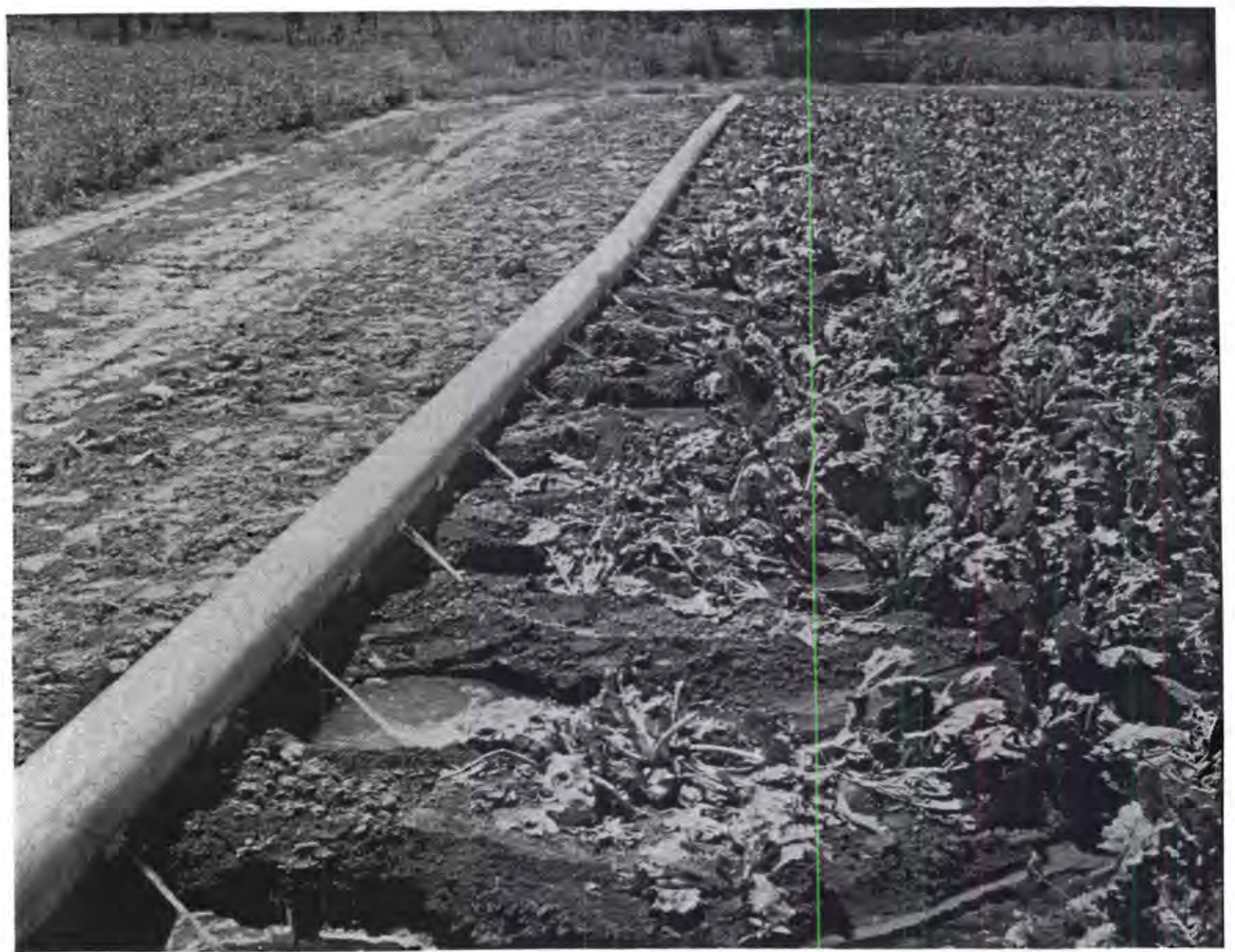

FIGURE 10.1. Operating Automated Gated-P ipe Irrigation System

- a safety hose to prevent the underground pipeline from bursting in the event the radio system malfunctions.

A schematic diagram of the automated gated-pipe system is presented in Figure 10.2. When the automated system is operating, radio signals are transmitted to receivers mounted near the flow-control valves. These radio signals are translated into mechanical action and water flow is initiated at the appropriate flow-control valves.

\subsubsection{Irrigation Controllers and Mini-Computer}

The irrigation controllers of the system utilize direct mechanical time controls to determine the timing and location of irrigation applications. The controllers used in the initial development of the automated system in 1979 were Rain Bird Model AG-7s. The AG-7 is a seven-station automatic controller 


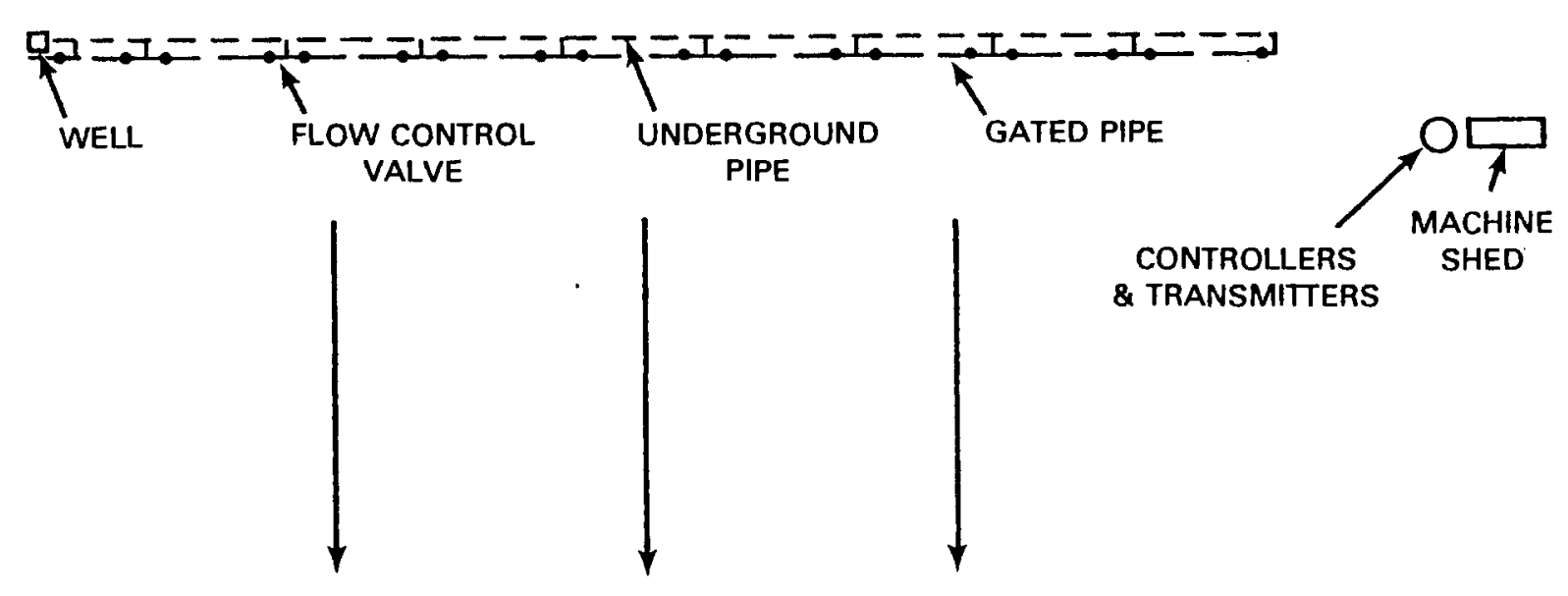

DIRECTION OF IRRIGATION

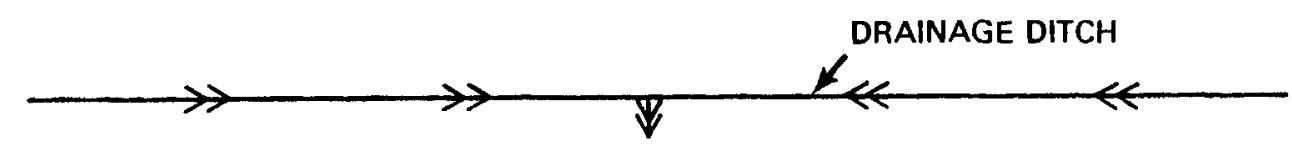

FIGURE 10.2. Schematic of Automated Gated-Pipe System

that can be set to start up operation of the radio controls at any preset time within a 14-day interval. Three AG-7s were wired together to allow for continuous programming. The seventh channel on each controller was dedicated for switching to the next controller, thus, a total of 18 channels were available for directing the radio transmitters. Each channel can be operated for pre-set lengths of time between 1.2 and 24 hours in 24-minute increments.

In the second year of testing the automated system (1980), the irrigation controllers were replaced with a mini-computer. The mini-computer that was used was a SYM-1 single-board computer manufactured by Synerteck Systems Corporation. A program to operate the radio controls was written with an Apple II computer assembler and then fed into the SYM-1 by cassette tape.

The SYM-1, as programmed, had complete control of radio transmitter operation. One to four of the water flow valves could be open at any time and duration of flow could be set for one to 99 hours at one-hour increments. The status of each of the flow-control valves could be continuously monitored using a display capacity that would show the valve number, whether it was opened or closed, and the duration of the flow programned for the valve. 


\subsubsection{Radio Transmitters and Receivers}

Radio transmitters communicated with radio-control receivers to operate the system. The radio transmitters and receivers used in the initial development of the automated system were originally designed for use in radio-controlled model airplanes. The transmitters used were Heathkit Model GDA-1205-D and the receivers were Heathk it Model GDA-1205-2.

The radio transmitters used in the system are solid-state units that use digital techniques to provide simultaneous control for eight channels on the same frequency. A transmitter was connected to one of the three controllers and, because each controller had six channels, only six of the eight channels on each transmitter were utilized. A separate power supply was provided for the transmitters because the original batteries for the transmitters were only able to operate continuously for five hours and could not be recharged while a transmitter was in operation. Plug-in radio frequency (RF) modules of 72.16 , 72.32 , and $72.96 \mathrm{MHz}$ were used in the three transmitters. A Class $\mathrm{C}$ operator's license from the Federal Communications Commission is required to operate transmitters on the $72 \mathrm{MHz}$ band.

Similar plug-in RF modules were used in the radio receivers, to insure that the receivers were kept on the same radio frequency as the transmitters. The radio receivers were initialiy mounted under a small platform erected eight feet above the ground surface but were later lowered to near gound level. A rigid aluminum rod, 40 inches long, was connected to the receiver platform and served as an antenna in the initial year of system development. This rigid antenna was replaced by a whip-like antenna in the second year of system development. One receiver was installed on each riser on the underground pipeline and, although each receiver is capable of operating up to eight servos, only one or two servos was operated by each receiver.

In the original design of the automated system (1979) a solar panel was constructed to provide power for the radio receivers and servos. In the second year of development (1980), however, the solar panel was abandoned and its function was replaced by battery packs that had to be recharged about once during the irrigation season. 


\subsubsection{Radio-Controlled Servos}

Servos are devices that transform radio signals into useful mechanical output. Heathkit Model GDA-1205-8 High Torque Digital Proportional Servos were used to turn pilot valves on the flow-control valves of the automated system. Each servo operated one or two water flow-control valves.

The servos that were originally installed with the automated gated-pipe system in the spring of 1979 were later modified by replacing the original circuit board of the servos with a new circuit board designed and built in the Kansas State Agricultural Engineering Department. The new circuit compared the incoming radio signal pulse with a standard pulse and directed the servo motor to turn the servo arm in the correct direction. The control that communicated the position of the servo arm to the circuit was also modified so that once the servo arm reached the end of its rotation, the control sent a signal to the circuit which shut off the servo motor and stopped movement of the arm.

\subsubsection{Three-Way Pilot Valves}

Three-way pilot valves control the operation of the water flow-control valves. When the servos are commanded by radio signal to turn the rod of the pilot valve to the down position, water flows from a tube in the pilot valve to the flow-control valve diaphragm, causing the flow-control valve to close. When the servos raise the rod of the pilot valve 0.5 inches, water flows from the flow-control valve diaphragm and the flow-control valve is opened.

Brass three-way pilot valves were originally installed in the automated system, but it was discovered that the servos did not develop sufficient torque to operate them. In 1979, these valves were replaced by a slide valve made out of aluminum and Teflon, and in 1980 , by a modified brass two-way gas valve. Leakage and other operational problems were incurred in using the slide valve. The two-way gas valves performed well, however, and these valves were used throughout the majority of the system's testing period. These valves are equipped with a stopcock that can be tightened or loosened with a spring loaded screw to insure proper valve operation without water leakage.

\footnotetext{
- Registered trademark of E. I. duPont and Company.
} 


\subsubsection{Flow-Control Valves}

Water flow from the automated system is controlled by rubber diaphragms within flow-control valves. When the rubber diaphragms are inflated by water (pilot value in the down position) the flow-control valves are closed and water flow through the holes in the gated-pipe is prevented. When the rubber diaphragms are deflated by draining the water out (pilot valve in the raised position) the flow-control valves are opened and water flow is initiated. Each valve has a small reservoir for storing water to inflate the diaphragm during low pipe flows. This reservoir must be filled from a water tank at the beginning of the irrigation season, but thereafter is refilled when water flows through the control valve during irrigations. Each flow-control valve was attached to a riser on the underground pipeline and each valve controlled water application to several furrows.

A close-up view of the valve system in operation is presented in Figure 10.3. The aluminum box that houses the radio servo is denoted by Point $A$, a pilot valve by Point $B$, and a flow-control valve by Point $C$.

\subsubsection{Safety Hose}

A safety hose, installed to prevent damage to the underground water pipline when all flow-control valves close because of a malfunction in radio controls, is attached at a flow-control valve. It consists of a long plastic hose connected by a tee to the hose connecting the three-way pilot valve to the diaphragm of the flow-control valve. When the pressure at the flowcontrol valve exceeds the height of the high point of the safety hose, water is drained from the diaphragm of the flow-control valve, the flow-control valve is opened, and water flow is initiated through the gated-pipe connected to the flow-control valve containing the safety hose. This continues until the malfunction is corrected and radio control of the system is resumed.

\subsection{METHOD OF TESTING}

Testing the automated gated-pipe system consisted of the following elements: 


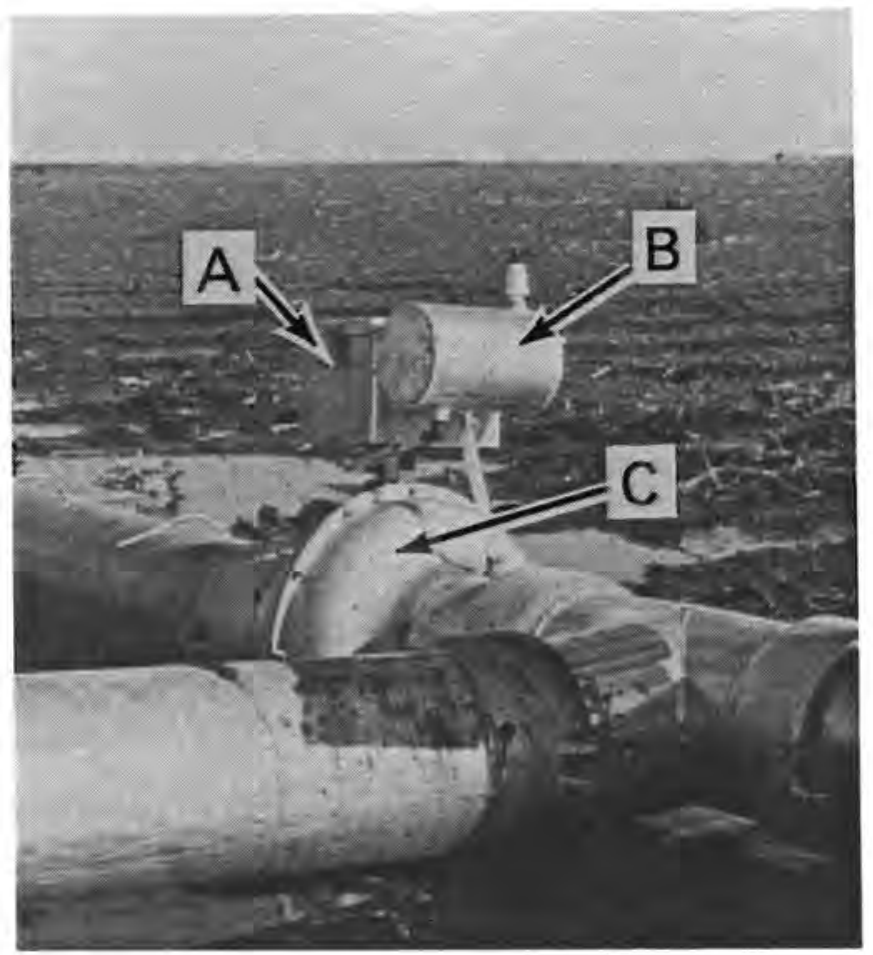

FIGURE 10.3. Radio Servo (A), Pilot Valve (B), and FlowControl Valve (C) of the Automated-Gated Pipe System

- irrigation of 150 acres of corn during the 1979 growing season using the automated system

- based on the results of 1979 irrigation testing, redesign of the automated system and reuse of the system to irrigate 150 acres of corn during the 1980 growing season.

A11 irrigation tests were conducted on land belonging to a commercial farmer in Haske11 County, Kansas.

\subsubsection{Irrigation Testing}

The automated gated-pipe system was installed and used to preirrigate the 150 -acre corn field before planting. Furrows in the test field were $2600 \mathrm{ft}$ long and each set of furrows was watered for 24 hours during preirrigation. The modified radio-controlled system was reinstalled after corn was planted. The system was used to irrigate the field six times in sets of 12 hours during the summer. 


\subsubsection{Irrigation Testing}

The automated system was not used to preirrigate in 1980 because sufficient rainfall fell to replenish soil moisture in the corn root zone. The system was laid out in June, and six irrigations of 12-hour duration were applied to the field.

\subsection{TECHNICAL PERFORMANCE RESULTS}

The automated gated-pipe system was able to succesfully irrigate the corn field during the 1979 and 1980 growing seasons. The irrigation controllers and the SM-1 computer were both able to control irrigation timing and amounts correctly, although some power outages caused the temporary loss of the SYM-1 control program. When the SMM-1 lost power, some of the servos were false triggered causing the flow-control valves to open. A backup battery system or alternating current generator is suggested by the system developers as a means of reducing this problem.

Although the radio controls generally operated correctly, a number of technical problems were incurred. Chattering, a continued back and forth movement, was observed at many of the servos. This chattering caused excessive wear on the servos and a large drain on the batteries. Chattering increased as distance from the servo to the transmitter increased. In addition, false triggering of servos occurred when motor vehicles passed within 50 feet or people stood near the receivers. Chattering was reduced, but not eliminated, by placing individual timers on the servos which chattered, by installing a shielded cable to link the servos and batteries to their receivers, and by using plexiglas to insulate the system antennas from their support brackets. More powerful transmitters are suggested by the system developer as an additional method for reducing chattering.

Thunderstorms caused electrical damage to the servos and receivers. Part of the blame for this damage was attributed to the solar panels that were originally installed with the system and, consequently, these panels were eliminated from the system in favor of battery packs and coils. 
Minor problems were incurred in both the pilot valves and the flow-control valves. The aluminum and Teflon pilot valves leaked, and leakage was increased during cold weather because the valves contracted. The modified brass pilot valves operated without leakage. In several cases, the clamp that held the diaphragm of the flow-control valves in place slipped, and the valves would not close. Algae growth in the plastic hose connecting the pilot hose to the flow-control valve diaphragm caused difficulty in opening and closing the valves. Several diaphragms ruptured in their second year of operation.

The technical problems suggest a need for additional research before an automated gated-pipe system can be manufactured for widespread use. First, improved methods must be designed for controlling the system. Development of radio controls specifically designed for use in irrigation systems or hardwiring of control mechanisms are two possible methods of improving the automated system. Another suggested improvement is the replacement of brass pilot valves with latching solonoid valves which will not corrode as rapidly over time.

Water distribution efficiency averaged $64 \%$ for the automated system while water-application eff ic iency averaged $74 \%$. This compares to typical application efficiencies of $50 \%$ to $60 \%$ for conventional gated-pipe systems. This implies that water use can be reduced by between $14 \%$ and $24 \%$ by using the automated gated-pipe system rather than a conventional gated-pipe system.

\subsection{ENERGY AND LABOR SAVINGS RESULTS}

The annual labor requirements for irrigating 150 acres using conventional and automated gated-pipe systems and a center-pivot system are shown in Table 10.1. Note that eliminating the need to open and close pipe gates through automation does reduce labor requirements substantially.

Estimates of the annual energy use for the three systems are presented in Table 10.2 for four fuel types on a well with a dynamic pumping head of approximately 300 feet. As a result of better water application efficiency, the automated gated-pipe system uses 15\% less energy than the conventional gated-pipe system. Reduced energy use compared to the center-pivot results from the lower pressure requirements for gated-pipe application. 
TABLE 10.1. Estimated Annual Labor Requirements for Irrigating 150 Acres

$\frac{\text { System }}{\text { Conventional Gated-Pipe }}$

2600-ft run

1300-ft run

Automated Gated-Pipe

2600-ft run

1300-ft run

Center-Pivot

\begin{tabular}{ccccc}
$\begin{array}{c}\text { Preparation } \\
\mathrm{hr}\end{array}$ & $\begin{array}{c}\text { Operation } \\
\mathrm{hr}\end{array}$ & $\begin{array}{c}\text { Total } \\
\mathrm{hr}\end{array}$ & $\begin{array}{c}\text { Rate } \\
\mathrm{hr} / \mathrm{ac}\end{array}$ \\
\cline { 5 - 5 } 64 & 114 & & 178 & 1.2 \\
128 & 114 & 242 & 1.6 \\
& & & & \\
80 & 57 & 137 & 0.9 \\
144 & 57 & 201 & 1.3 \\
16 & 57 & 73 & 0.5
\end{tabular}

TABLE 10.2. Estimated Annual Energy Requirements for Irrigating 150 Acres of Corn 1

\begin{tabular}{|c|c|c|c|c|}
\hline System & $\begin{array}{c}\text { Electricity } \\
\mathrm{kWh}\end{array}$ & $\begin{array}{c}\text { Diesel } \\
\text { gal }\end{array}$ & $\begin{array}{c}\text { Natural Gas } \\
\text { Mcf }\end{array}$ & $\begin{array}{l}\text { Propane } \\
\text { gal }\end{array}$ \\
\hline Conventional Gated-Pipe & 216,121 & 17,483 & 3,277 & 31,726 \\
\hline Automated Gated-Pipe & 168,154 & 13,603 & 2,550 & 24,684 \\
\hline Center-Pivot & 210,759 & 17,050 & 3,196 & 30,939 \\
\hline
\end{tabular}

1 Computed by using Nebraska standard energy use numbers (Fischbach and Thompson, 1981) to convert estimated water horsepower requirements to energy use requirements.

Water horsepower per unit of energy is taken as $80 \%$ of the Nebraska standard for electric and diesel pumping plants ard $70 \%$ of the Nebraska standard for natural gas and propane pumping plants to reflect the decline in energy efficiency that can occur as pumping plants age. Note that, for a situation where the dynamic pumping head is 300 feet, the automated system is estimated to consume $22.2 \%$ less energy than conventional gated-pipe and $20.2 \%$ less energy than a center-pivot.

\subsection{COST SAVINGS RESULTS}

Capital costs for three systems are presented in Table 10.3. Note that the cost of the gated pipe and fittings for the automated system are reduced substantially by "purchasing" them from the conventional gated-pipe system at 
TABLE 10.3. Irrigation System Investment Costs for 150 Acres (\$1980)

Cost

Conventional

Gated-Pipe
Automated

Gated-P ipe

$2600 \mathrm{ft} 1300 \mathrm{ft}$

Conversion Cost

Item

Underground $P$ ipeline

Gated Pipe \& Fittings

Controls

Center $P$ ivot.

Added Pump Bowls

$2600 \mathrm{ft} 1300 \mathrm{ft}$

\section{$\frac{\$}{26 \text { hases }}$}

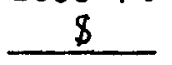

$$
6,680
$$$$
1,330
$$

13,340

$9,400 \quad 18,660$

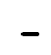

$-$

$-$

$-$

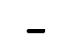

$-$

$-$
21,030

1,330

21,030

$-$

$-$
Items Used in System Conversion

Gated Pipe \& Fittings

Salvage Value ${ }^{1}$<smiles>C1CCCCC1</smiles>

$-\quad-$

$-\quad 3,290$

6,530

0

0

Underground $P$ ipeline

Salvage Value ${ }^{2}$
$-$

$-$

0

0

0

0

Underground $P$ ipeline

Salvage Value ${ }^{1}$

Gated Pipe \& Fittings

Salvage Value ${ }^{2}$

Total Cost

\section{Unused Items in System Conversion}


the salvage value price of $\$ 3290$, rather than buying them new for $\$ 9400$. Costs for the automated gated-pipe system represent costs for a prototype system rather than the costs for a system that is mass produced. Mass production could reduce costs substantiality.

Estimated annual system costs for the three alternative systems are presented in Table 10.4 for the four fuel types. For the conditions existing in Kansas, use of the automated gated-pipe system would result in lower costs compared to a conventional gated-pipe system for relatively expensive fuel types such as propane and diesel, but not for cheaper fuel sources such as natural gas. Another cost analys is conducted in a companion study found that, based on energy cost savings alone, the automated system in its current form would not produce economic benefits when used in place of a conventional gated-pipe system in most areas of the country (Patton et al. 1982). The results listed in Table 10.4 illustrate that, based on energy and labor cost savings, a reliable automated gated-pipe system could produce economic benefits compared to a conventional gated-pipe system for some types of fuels. A reliable automated gated-pipe system could produce substantial cost savings compared to a high-pressure center-pivot when used on land that does not require leveling. 
TABLE 10.4. Total Annual System Costs for 150 Acres (\$1980)

\begin{tabular}{|c|c|c|c|c|c|c|}
\hline \multirow[b]{2}{*}{ I tem } & \multicolumn{2}{|c|}{$\begin{array}{c}\text { Convent ional } \\
\text { Gated-P ipe }\end{array}$} & \multicolumn{2}{|c|}{$\begin{array}{r}\text { Automated } \\
\text { Gated-Pipe }\end{array}$} & \multicolumn{2}{|c|}{ Center-Pivot } \\
\hline & $\begin{array}{r}2600 \mathrm{ft} \\
8\end{array}$ & $\begin{array}{r}1300 \mathrm{ft} \\
\quad 8\end{array}$ & $\begin{array}{r}2600 \mathrm{ft} \\
\quad \mathrm{f}\end{array}$ & $\begin{array}{r}1300 \mathrm{ft} \\
\mathrm{s}\end{array}$ & $\begin{array}{r}2600 \mathrm{ft} \\
\quad \mathrm{f}\end{array}$ & $\begin{array}{r}1300 \mathrm{ft} \\
\quad 8\end{array}$ \\
\hline \multicolumn{7}{|c|}{ Electricity $-\$ 0.06 / \mathrm{kwh}$} \\
\hline Ownership & 2,664 & 5,217 & 5,800 & 7,576 & 8,819 & 8,238 \\
\hline Labor & 1,248 & 1,632 & 912 & 1,296 & 480 & 480 \\
\hline Repairs & 223 & 436 & 1,500 & 1,813 & 2,521 & 2,521 \\
\hline Energy & 12,967 & 12,967 & 10,089 & 10,089 & 12,646 & 12,646 \\
\hline Total & 17,102 & 20,252 & 18,301 & 20,774 & 24,466 & 23,885 \\
\hline \multicolumn{7}{|c|}{ Diese $1-\$ 1.20 / \mathrm{gal}$} \\
\hline Ownership & 2,664 & 5,217 & 5,800 & 7,576 & 8,819 & 8,238 \\
\hline Labor & 1,248 & 1,632 & 912 & 1,296 & 480 & 480 \\
\hline Repairs & 223 & 436 & 1,500 & 1,813 & 2,521 & 2,521 \\
\hline Energy & 20,980 & 20,980 & 16,324 & 16,324 & 20,460 & 20,460 \\
\hline Total & 25,115 & 28,265 & 24,536 & 27,009 & 32,280 & 31,699 \\
\hline \multicolumn{7}{|c|}{ Natural Gas $-\$ 2.50 /$ Mcf } \\
\hline Ownership & 2,664 & 5,217 & 5,800 & 7,576 & 8,819 & 8,238 \\
\hline Labor & 1,248 & 1,632 & 912 & 1,296 & 480 & 480 \\
\hline Repairs & 223 & 436 & 1,500 & 1,813 & 2,521 & 2,521 \\
\hline Energy & 8,193 & 8,193 & 6,375 & 6,375 & 7,990 & 7,990 \\
\hline Total & 12,328 & 15,478 & 14,587 & 17,060 & 19,810 & 19,229 \\
\hline \multicolumn{7}{|c|}{ Propane $-\$ 0.70 \$ / \mathrm{gal}$} \\
\hline Ownership & 2,664 & 5,217 & 5,800 & 7,576 & 8,819 & 8,238 \\
\hline Labor & 1,248 & 1,632 & 912 & 1,296 & 480 & 480 \\
\hline Repairs & 223 & 436 & 1,500 & 1,813 & 2,521 & 2,521 \\
\hline Energy & 22,208 & 22,208 & 17,279 & 17,279 & 21,657 & 21,657 \\
\hline Total & 26,343 & 29,493 & 25,491 & 27,964 & 33,477 & 32,896 \\
\hline
\end{tabular}





\subsection{COMPUTERIZED IRRIGATION SCHEDULING}

Conventional irrigation scheduling has traditionally been based on the subjective judgment of the person doing the scheduling. As a result, it is generally believed that crops have of ten been overwatered because the risks of financial loss from overwatering have been perceived to be less than the risks of financial loss from underwatering. Overwatering of crops has resulted in the excess use of water, energy, and money. In addition, it is possible that overwatering has actually reduced crop yields, especially on crops where the timing of irrigations is as important as the amounts.

Computerized scheduling systems have been developed to apply scientific principles to determining the timing and amounts of irrigation water applications. The project conducted by J. M. Lord was designed to statistically compare the performance of a computerized irrigation scheduling system to the performance of conventional scheduling methods. This comparison is intended to provide information on the potential costs and benefits of using computerized scheduling in irrigation.

\subsection{TECHNOLOGY DESCRIPTION}

The computerized irrigation scheduling system tested in this project is known as the Computerized Predictive Model System (CPMS). Computers have the ability to quickly merge a variety of scheduling information, as is illustrated in Figure 11.1. The CPMS system utilizes the following elements to schedule irrigations:

- field input data obtained from the irrigated area where scheduling is being performed

- the computer program itself

- computer output data.

Each of these elements is described in detail below. 


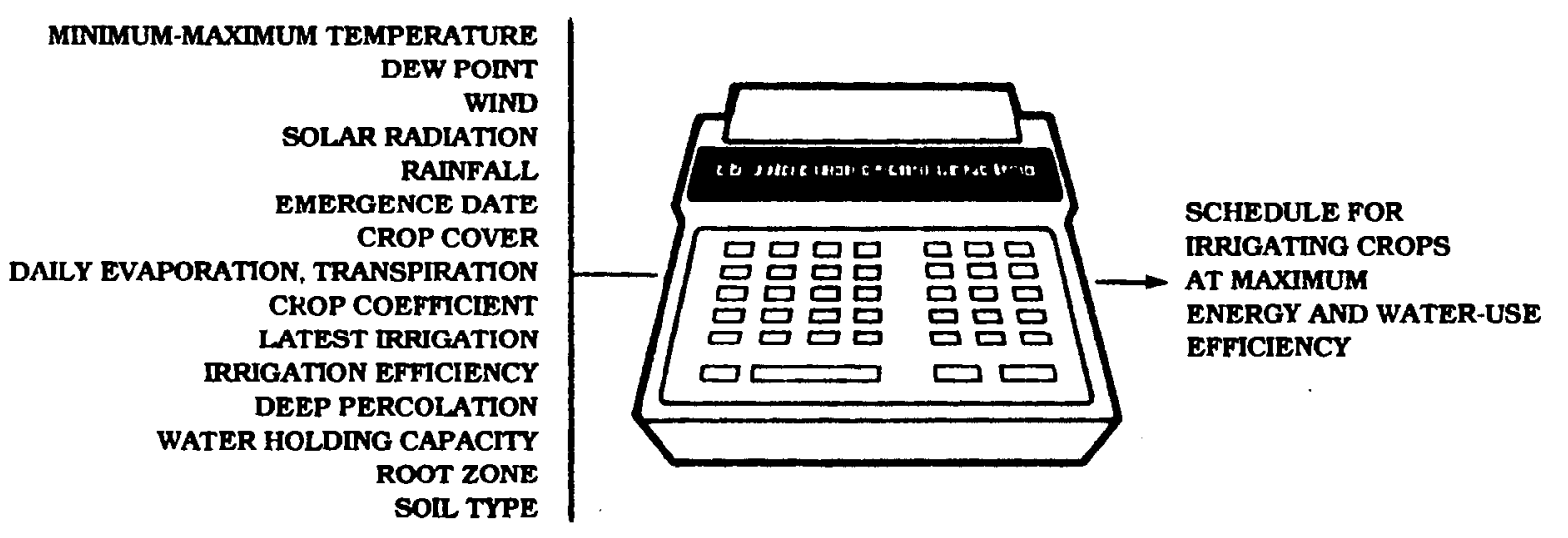

FIGURE 11.1. Computers Can Quickly Convert Collected Input Data into Useful Output Data

\subsubsection{Field Input Data}

obtaining and recording required input data is the most crucial element in utilizing a computerized scheduling system. If "full" scheduling services are used, the firm which has ownership of the computerized scheduling program will dispatch its own personnel to perform data collection. Other variations of scheduling services include those where farmers collect data themselves for input into a computerized program and those where data is collected and provided to farmers so that they can perform their own scheduling. The types of data required by the CPMS program are described in detail below, and a list of the input data is provided in Table 11.1. Photos of a J. M. Lord employee collecting and recording input data are presented in Figures 11.2 and 11.3.

\section{Crop Data}

Crop input data utilized in the program include the type of crop, the emergence date, and the effective cover date. These data are used to place the field on a growth function curve, which is used to calculate crop evapotranspiration. Plant fertility data are also collected. 
TABLE 11.1. Computer Input Summary Sheet Specific Pieces of Data Required for Computerized Scheduling Analysis

\begin{tabular}{|c|c|c|}
\hline Summary Data & Plant Data & Site Data \\
\hline Crop year & Crop type & Field identification \\
\hline Scheduler's name & Crop code & Field code \\
\hline Monitor's name & Emergence date & Climatic zone \\
\hline \multirow[t]{4}{*}{ Date of report } & Cover date & Field size \\
\hline & Final irrigation & \\
\hline & date & \\
\hline & Production hazards & \\
\hline Irrigation Data & Soil Data & Energy Data \\
\hline Prime method & Water-holding & Power source \\
\hline Secondary method & capacities & (electric- \\
\hline Estimated system & Soil type & combustion) \\
\hline efficiency & Soil class & \\
\hline \multicolumn{3}{|l|}{ Calculated system } \\
\hline \multicolumn{3}{|l|}{ efficiency } \\
\hline \multicolumn{3}{|l|}{ Water Data } \\
\hline \multicolumn{3}{|l|}{ Farm water cost } \\
\hline \multicolumn{3}{|c|}{ Crop evapotranspiration } \\
\hline \multicolumn{3}{|l|}{ Prime source } \\
\hline \multicolumn{3}{|l|}{ Secondary source } \\
\hline Total gross app 11 & on amounts & \\
\hline
\end{tabular}




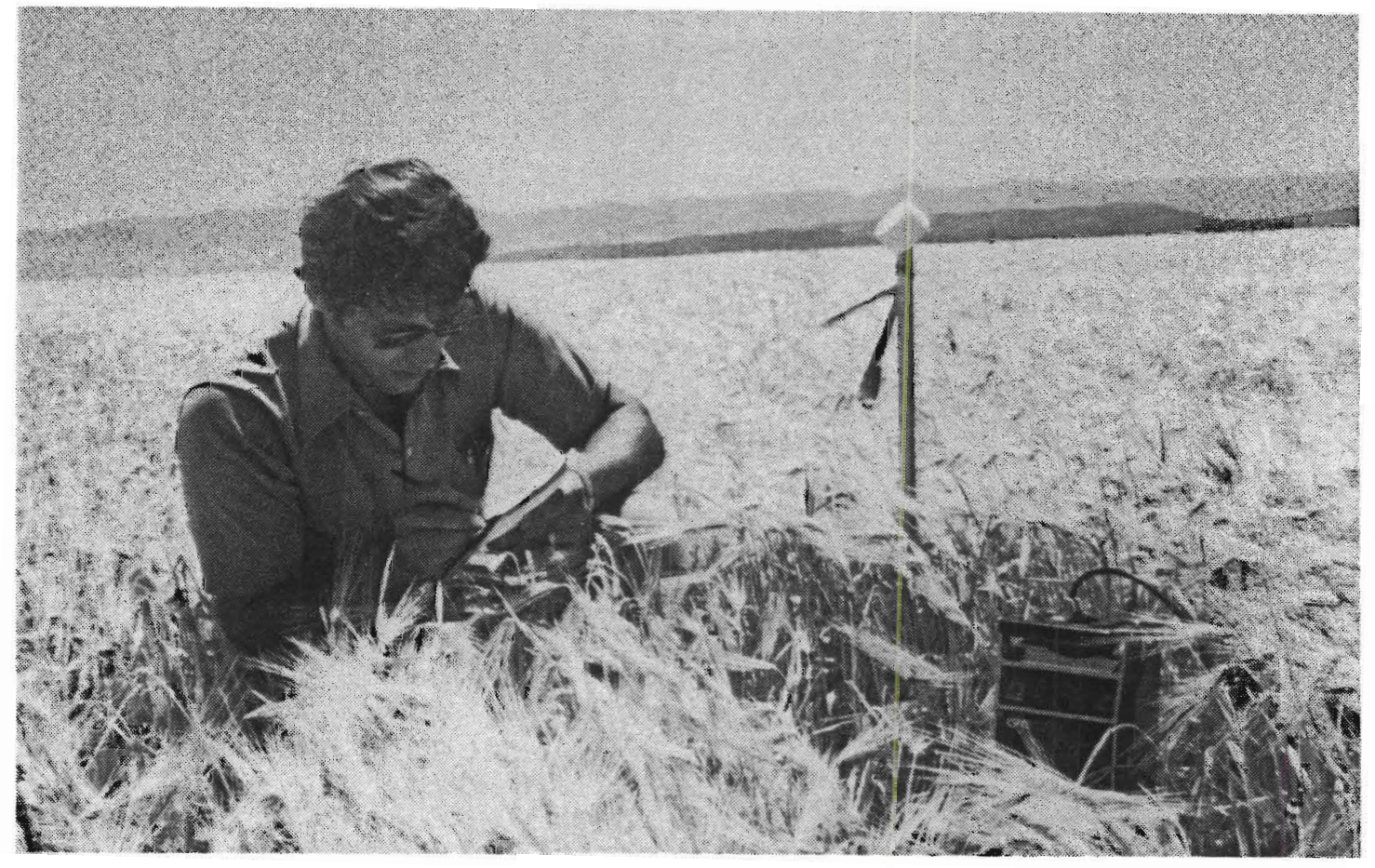

FIGURE 11.2. Collecting Field Input Data

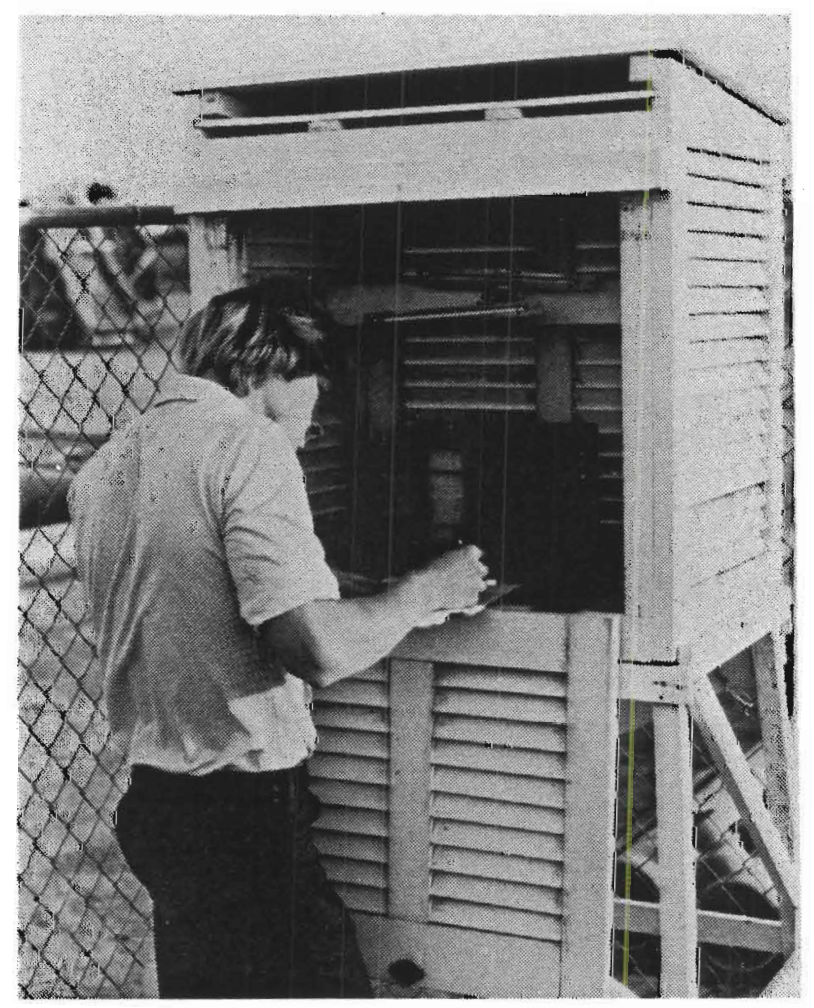

FIGURE 11.3. Recording Field Input Data 


\section{Soil Data}

Soil data used in the program include water-holding capacity, permanent wilting point, field capacity, bulk density and soil texture. Soil texture can be determined by hand texturing or by using the hydrometer method of particle size analysis. Water-holding capacity can be obtained through bulk density samples, pressure plate tests, or by comparison to past physical analysis data.

Soil moisture status must be monitored continually while scheduling is being performed. Soil moisture status measurements may be obtained directly by using a neutron probe or by using experienced personnel to "feel" the soil's moisture status. The CPMS program also has the ability to generate indirect soil moisture status readings based on weather conditions and soil characteristics.

\section{Climatic Data}

Climatic data used in the program are maximum/minimum daily temperature, relative humidity/dewpoint, wind run in miles/day, solar radiation, and rainfall. This information is generally collected on a weekly basis. Evapotranspiration potential is calculated from the weather data using a modified Penman evapotranspiration potential equation.

\section{Water Application Amounts}

In order to determine whether scheduled amounts of irrigation water are actually being applied, some method must be used to measure the amount of water applied. Water district meters and records, pipe flow meters, and partial flumes can all be used to measure water application amounts with varying degrees of precision. Determining the gross amount of water applied through a sprinkler system is not difficult, and can often be done by observation. Determining the amount of water applied through a gravity flow irrigation system is difficult, however, without the aid of partial flumes or other types of water measuring devices.

\subsubsection{The Computer Program}

The computer program used in the CPMS system is written in FORTRAN programming language. It is currently programmed into an HP9825 computer, but 
is compatible with a number of other types of computers. When a cassette tape is used, the CPMS program in its current form requires less than 16,000 words of computer storage space for the main program and data input. Computerized scheduling programs can be designed for use in small home computers. A photo of a J. M. Lord employee operating the computerized scheduling program is presented in Figure 11.4.

\section{Output Data}

The output data generated by the CPMS program is quite simple and its main thrust is to tell the irrigator when to irrigate and how much water to apply.

\subsection{METHOD OF TESTING}

The procedure used to test the performance of computerized scheduling versus conventional scheduling was the following:

- pair crop fields based on common characteristics

- schedule irrigations of half of the paired fields by conventional scheduling methods and the other half by using the CPMS system

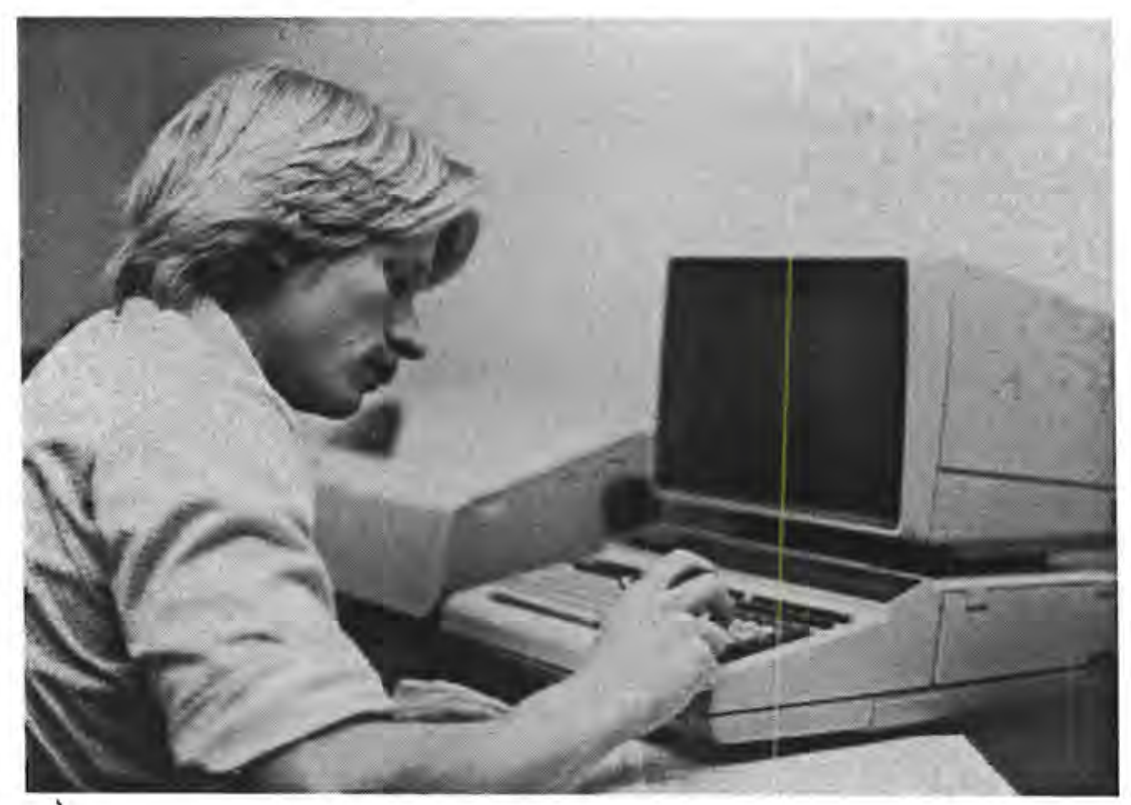

FIGURE 11.4. Operation of the Computerized Irrigation Scheduling Program 
- compare the performance of the two scheduling treatments based on the following performance measurements:

- t-tests for significant differences in yields, applied water use, and energy use per unit of crop yield between the two scheduling methods

- minimum values for water and energy savings necessary to return the costs of scheduling services

- the expected return and benefit/cost ratio for computerized irrigation scheduling at current market prices.

All tests were performed on farms located in the San Joaquin Valley of central California.

\subsubsection{Pairing of Crop Fields}

In order to adequately compare the performance of computerized versus conventional irrigation scheduling, it was necessary to eliminate the factors, other than method of irrigation scheduling, that affect water use and crop yields. This was accomplished by pairing crop fields with similar characteristics.

Before the beginning of the irrigation season, regions of similar potential evapotranspiration were defined and fields were preliminarily paired on the basis of the following factors:

- similar climatic conditions

- presence of perched water table conditions

- easily monitorable water supply

- conventional farming practices

- grower cooperation

- similar soil conditions

- similar water source.

Comparative groups of fields were also defined, with grouping based on type of crop being grown and irrigation method. The impacts of irrigation scheduling method on three crops (small grains, cotton, and tomatoes) and two irrigation methods (sprinkler and surface) were analyzed in the study. Therefore, six comparative groups were defined and a goal was set to obtain 
five field pairs per group to use as the basis for performance comparisons within each group.

Final field pairings were made at the end of the growing season to insure that such elements as fertility and water table levels within each pair were similar throughout the growing season. Secondary data, collected during the growing season, were used in determining the final pairs. These data included crop characteristics, nutrient status, soil characteristics, weather conditions, method of irrigation, and irrigation water quality. If differences in secondary data between pairs were discovered, pairings were either changed or rejected. Secondary and primary data used to evaluate field pairings and scheduling system performance were collected two or three times a week during the growing season by J. M. Lord field personnel.

\subsubsection{Scheduling of Paired Fields}

Individual fields within each of the preliminary pairs were scheduled by either conventional scheduling methods (i.e. the individual irrigator's system) or by the CPMS system. However, certain preliminary pairs were eliminated before the performance data analys is because of differences in secondary data between the fields within the pairs.

Tests were performed on paired fields over a period of two growing seasons in 1979 and 1980. Small grains required relatively little irrigation because of their relatively low water requirements and short growing season. Tomatoes required more irrigation and cotton required the most of the three crops tested. The average water use of the three crops in the two growing seasons and the average rainfall in the San Joaquin Valley are shown in Table 11.2 .

TABLE 11.2. Average Annual Water Requirements and Rainfall for Three Crops Grown in the San Joaquin Valley of California

\begin{tabular}{ccccc} 
Year & Rainfall (inches) & & \multicolumn{3}{c}{ Water Requirements (inches) } \\
1979 & $\frac{\text { SmallGrains }}{1-10}$ & $\frac{\text { Tomatoes }}{22.8}$ & $\frac{\text { Cotton }}{26.6}$ \\
1980 & $7-10$ & 16.5 & 20.7 & 26.7
\end{tabular}




\subsubsection{Performance Measurements}

Performance comparisons were made on the basis of several different types of measurements. Comparisons made on the basis of yields and applied water use from field test data were straightforward. However, the primary basis of comparison between scheduling systems was the energy use per unit of crop yield (EUY) value. Energy use for calculating EUY values was not measured directly in the study, but rather was calculated based on the amount of irrigation water applied. In order to calculate energy use in this manner, it is necessary to know the energy content in a unit of irrigation water.

The majority of the fields used in.the study were located in the Westlands Water District. The district estimates that the energy content of its water is approximately $605 \mathrm{kWh} / \mathrm{ac}-\mathrm{ft}$, and this value was used in the study to measure the energy content of water used in surface irrigation. For sprinkler irrigation, a lift of 140 feet was assumed at an energy rate of $1.8 \mathrm{kWh} / \mathrm{ac}-$ $\mathrm{ft} / \mathrm{ft}$ of lift. The $1.8 \mathrm{kWh} / \mathrm{ac}-\mathrm{ft} / \mathrm{ft}$ was computed from farm pump testing records collected by Pacific Gas and Electric, a large private utility. Thus, the energy used to boost water through the sprinkler system was estimated to equal $252 \mathrm{kWh} / \mathrm{ac}-\mathrm{ft}$ and, when added to the energy content of $605 \mathrm{kWh}$ ac-ft for surface water, a total energy content of $857 \mathrm{kWh} / \mathrm{ac}-\mathrm{ft}$ for sprinkler water was obtained. Energy use per acre for the performance comparisons was calculated simply by multiplying the energy content per acre foot for each application system by the acre feet of water applied on each paired field. EUY values were then calculated by:

$$
\text { EUY }=\frac{\text { kWh Energy/acre }}{\text { Yield/acre }}
$$

EUY $=k$ Wh of energy used in irrigation per unit of crop yield

The student's t-test that was used to compare EUY, yields, and applied water use between conventional and computerized scheduling is a standard measurement used in making statistical comparisons. It was computed as the ratio of the mean of differences between paired fields to the standard deviation of the mean of differences between paired fields. This computed $t$ 
value was then compared to standard $t$ values in a statistical t table to determine the statistical significance of differences between paired fields.

Minimum unit values for water and energy necessary to return the costs of irrigation scheduling were calculated as a means of measuring the economics of investing in computerized irrigation scheduling. If the costs of energy and water or prices received for crops in a given area are higher than these minimum values, then computerized scheduling should be utilized. Crucial parameters for calculating minimum values include the expected change in energy use or crop production as a result of using computerized scheduling and the costs of irrigation scheduling. Minimum values were calculated using the following formula:

$$
M V=-\frac{S C}{U C}+\frac{3 S C}{(U C)(S i g)}
$$

where

MV = minimum unit value of energy, water, or crop yield in dollars;

Sig = significance levels from the t-tests of significant differences between scheduled and nonscheduled fields;

$U C=$ unit change in per-acre energy use, water use or production as a result of computerized scheduling in the field tests.

SC = computerized scheduling cost per acre in dollars.

Expected returns represent the probable net economic returns from computerized scheduling. They are calculated using an equation similar to that used for calculating minimum unit values, i.e.,

$$
E R=(S i g)(U C)(U V)-(S C)-(1-S i g)(S C)
$$

where

$$
\begin{aligned}
& E R=\text { expected returns; } \\
& U V=\text { current unit value of energy, water or crop yield; }
\end{aligned}
$$

Sig, $U C, S C=$ same as in previous equation.

The benefit/cost ratio for computerized scheduling is simply the expected return from this scheduling divided by its cost, i.e.,

$$
B / C \text { ratio }=E R / S C \text {. }
$$




\subsection{TECHNICAL PERFORMANCE RESULTS}

The results of the paired field tests demonstrate that computerized scheduling will lower applied water levels and/or increase yields in some, but not all, agricultural applications. Statistical measurements of differences between the computerized scheduling system and conventional scheduling methods in terms of applied water levels and yield per acre are summarized in Table 11.3.

TABLE 11.3. Yield and Applied Water Results, 1979-1980

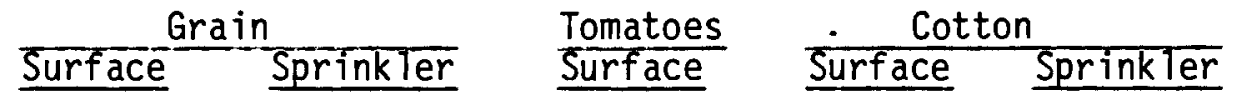

Yield 1

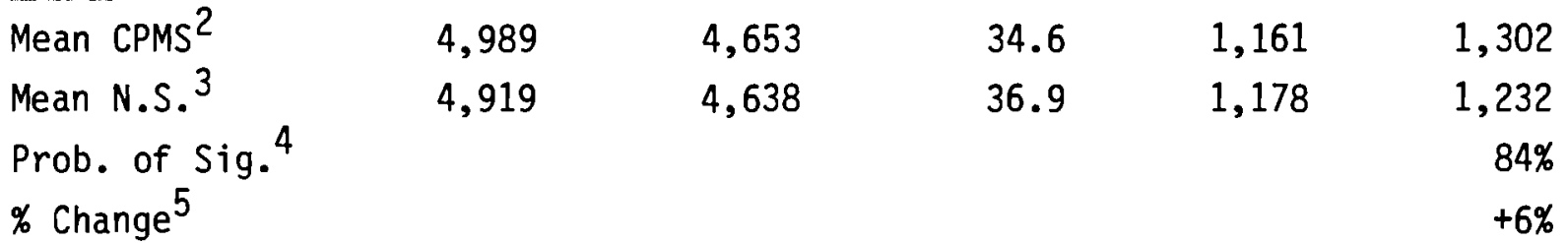

Applied Water (in.)

Mean CPMS

Mean N.S.

Prob. of Sig.

$\%$ Change
14.4

14.1
12.2

17.6

$98 \%$

$-31 \%$
20.6

31.5

$99 \%$

$-35 \%$

1

Yield - in pounds for grain, pounds of lint for cotton and tons for tomatoes.

2 CPMS - Computerized Predictive Model System of irrigation scheduling.

3 N.S. - Not scheduled.

4 Prob. of Sig. - Calculated probability that the differences shown were true differences based on the one-tailed t-test. Shown only for probabilities

5 greater than $80 \%$.

\% Change - based on the mean for the not scheduled fields in those field tests where significant differences were noted. 
No significant differences were found in yields between scheduled and nonscheduled fields, except for sprinkler irrigated cotton fields, where yields on the scheduled fields were significantly higher. These results indicate that the use of computerized scheduling will generally not decrease crop yields, and may even increase yields on crops, such as cotton, where the timing of irrigations is as important as the amounts. Water use was significantly lower on the scheduled sprinkler irrigated grain and tomato plots, while no significant differences were noted for the other cases.

The EUY results for the test fields are presented in Table 11.4. Note that, as a result of computerized scheduling, the EUYs declined sharply on sprinkler irrigated grain and tomato plots that had lower water use and also declined on sprinkler irrigated cotton plots that had higher yields.

\subsection{ENERGY SAVINGS RESULTS}

The total potential aggregate energy savings of using computerized irrigation scheduling in the 17 largest irrigating states, where such use is cost-effective, were estimated in a companion volume (Wilfert, et al. 1982) to be over 25 trillion Btu.

TABLE 11.4. Energy Use Per Unit of Yield Results, 1979-1980.

\begin{tabular}{|c|c|c|}
\hline Grain & Tomatoes & Cotton \\
\hline Sprinkter & Surface & Sprinkter \\
\hline
\end{tabular}

EUY 1

\begin{tabular}{|c|c|c|c|c|}
\hline$\overline{\text { Mean }}$ CPMS $^{2}$ & 0.147 & 0.186 & 33.2 & 1.14 \\
\hline Mean N.S. ${ }^{3}$ & 0.147 & 0.274 & 44.2 & 1.19 \\
\hline Prob. of Sig. ${ }^{4}$ & & $93 \%$ & $99 \%$ & \\
\hline$\%$ Change $^{5}$ & & $-32 \%$ & $-25 \%$ & \\
\hline
\end{tabular}

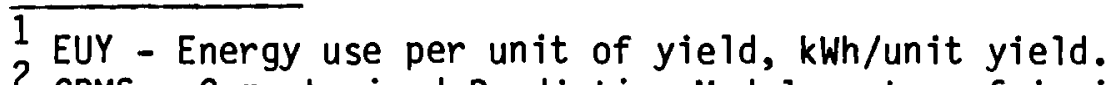

2 CPMS - Computerized Predictive Model system of irrigation scheduling.

3 N.S. - Not scheduled.

4 Prob. of Sig. - Calculated probability that the differences shown were true differences based on the one-tailed t-test. Shown only for

5 probabilities greater than $80 \%$.

5 \% Change - Based on the mean for the N.S. 


\subsection{COST SAVINGS RESULTS}

Minimum crop, water and energy values necessary to return the costs of computerized irrigation scheduling were calculated for all cases where significant differences were noted between computerized and conventionally scheduled plots. These minimum values were calculated based on an assumed cost of five dollars per acre for computerized scheduling. Changes in water use, energy use, crop yields and the probabilities that these changes will actually occur when using computerized scheduling were taken directly from the field test results.

The minimum value for cotton necessary to return a computerized scheduling cost of $\$ 5 /$ acre given a yield increase of $70 \mathrm{lb} / \mathrm{acre}$ and an 84 percent probability of such a yield increase occuring is $\$ 0.18$ per pound. Minimum values necessary to return the five dollar scheduling cost in other situations were the following:

- $\$ 22.90$ per acre foot minimum water value for sprinkler-irrigated grain, assuming a decline in water use of 5.4 acre inches per acre and a 98 percent probability level;

- \$11.28 per acre foot minimum water value for surface irrigated tomatoes assuming a decline in water use of 10.9 acre inches per acre and a 99 percent probability level;

- \$0.027 per kWh minimum energy value for sprinkler irrigated grain when energy use per acre declines by 386 kWhs at a probability of 98 percent;

- \$0.019 per kWh minimum energy value for surface irrigated tomatoes when energy use per acre declines by $545 \mathrm{kWhs}$ at a probability of 99 percent.

Table 11.5 shows the expected returns at (1980 market values) from using computerized irrigation scheduling for those situations where significant differences were noted between computerized and conventionally scheduled plots Benefit/cost ratios based on these expected returns are shown in Table 11.6. Note that for situations analyzed, computerized irrigation scheduling is economically beneficial by all performance measures. All minimum values are less than current market values; all expected returns are positive and all benefit/cost ratios are greater than one. 
TABLE 11.5. Expectation of Return (ER) at Current Market Values

\begin{tabular}{|c|c|c|c|c|c|c|c|c|c|c|}
\hline \multirow{2}{*}{$\begin{array}{l}\text { Analysis } \\
\begin{array}{l}\text { Yield in- } \\
\text { crease }\end{array}\end{array}$} & \multirow{2}{*}{$\begin{array}{l}\text { Crop/Method } \\
\text { Cotton/ } \\
\text { Sprink ler }\end{array}$} & \multirow{2}{*}{$\begin{array}{c}\begin{array}{c}\text { Schedulfing } \\
\text { Cost }\end{array} \\
\$ 5.00\end{array}$} & \multirow{2}{*}{$\frac{\text { Prob. }}{84 \%}$} & \multirow{2}{*}{$\frac{\text { Increase }}{70 \mathrm{lbs} / \mathrm{ac}}$} & \multicolumn{2}{|c|}{ Savings } & \multicolumn{3}{|c|}{ Market Value } & ER \\
\hline & & & & & & & 5.85 & . & & $\$ 44.18 / \mathrm{ac}$ \\
\hline \multirow[t]{2}{*}{$\begin{array}{l}\text { Water } \\
\text { Savings }\end{array}$} & $\begin{array}{l}\text { Grain/ } \\
\text { Sprinkler }\end{array}$ & $\$ 5.00$ & $98 x$ & & $5.4 \mathrm{ac}-\ln / \mathrm{ac}$ & & & $\$ 26.62^{2}$ & & $6.64 / a c$ \\
\hline & $\begin{array}{l}\text { Tomato/ } \\
\text { Surf ace }\end{array}$ & $\$ 5.00$ & 99\% & & $10.8 \mathrm{ac}-\ln / \mathrm{ac}$ & & & $11.50^{3}$ & & $5.20 / a c$ \\
\hline \multirow[t]{2}{*}{$\begin{array}{l}\text { Energy } \\
\text { Savings }\end{array}$} & $\begin{array}{l}\text { Grain/ } \\
\quad \text { Sprinkler }\end{array}$ & $\$ 5.00$ & $98 x$ & & $5.4 \mathrm{ac}-\mathrm{in} / \mathrm{ac}$ & $\begin{array}{l}386 \mathrm{kWh} / \\
\mathrm{ac} \mathrm{c}^{5}\end{array}$ & & & $50.06^{4}$ & $17.60 / \mathrm{ac}$ \\
\hline & $\begin{array}{l}\text { Tomato/ } \\
\text { Surface }\end{array}$ & $\$ 5.00$ & $99 x$ & & $10.8 \mathrm{ac}-\ln / \mathrm{ac}$ & $\begin{array}{l}545 \mathrm{kWh} / \\
\mathrm{ac}^{6}\end{array}$ & & & 0.06 & $27.32 / \mathrm{ac}$ \\
\hline
\end{tabular}

1. Taken from Table 11.3 .

2. Based on $\$ 11.50$ ac- $\mathrm{ft}$ water from Westlands Irrigation District plus energy costs to boost to 60 psi.

3. 1981 West lands priority I water cost.

4. $1980 \mathrm{kHh}$ average charge by PGlE.

5. Calculated by (ac-ft saved) $(605 \mathrm{kWh} / \mathrm{ac}-\mathrm{ft})=$ energy savings; $605 \mathrm{kWh} / \mathrm{ac}-\mathrm{ft}$.

6. Calculated by $(857 \mathrm{kWh} / \mathrm{ac}-\mathrm{ft})(\mathrm{ac}-\mathrm{ft}$ saved) $=$ energy savings; $857 \mathrm{kWh} / \mathrm{ac}-\mathrm{ft}$. 
TABLE 11.6. Benefit/Cost Ratio of Irrigation Scheduling

\begin{tabular}{|c|c|c|c|c|c|}
\hline Analysis & Crop/Method & Prob. (\%) & $\underline{E R^{1}}$ & $\begin{array}{l}\text { Scheduling } \\
\text { Cost (SC) }\end{array}$ & $\begin{array}{c}\text { Benefit/ } \\
\text { Cost Ratio } \\
\text { (ER/SC) } \\
\end{array}$ \\
\hline Yield Increase & Cotton/Sprinkler & 84 & $\$ 44.18$ & $\$ 5.00$ & 8.84 \\
\hline \multirow[t]{2}{*}{ Water Savings } & Grain/Sprinkler & 98 & 6.64 & 5.00 & 1.33 \\
\hline & Tomatoes/Surface & 99 & 5.20 & 5.00 & 1.04 \\
\hline \multirow{2}{*}{ Energy Savings } & Grain/Sprinkler & 98 & 17.60 & 5.00 & 3.52 \\
\hline & Tomatoes/Surface & 99 & 27.32 & 5.00 & 5.46 \\
\hline
\end{tabular}

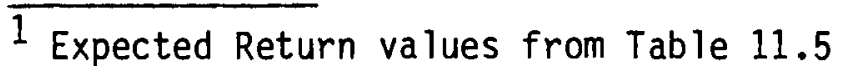

The economic performance of computerized scheduling depends on the conditions under which it is being used, however. No significant differences in energy use, water use, or crop yields were noted for surface irrigated grain and cotton, and, consequently, use of computerized scheduling would not return its cost in these situations. Cost savings as a result of water savings would not be realized if water is paid for on a per-acre basis, rather than on a per-acre-foot basis. In some areas energy costs are less than the minimum values calculated for energy savings.

A companion study to this one (Patton, et al. 1982) demonstrated that computerized scheduling that costs five dollars an acre would be costeffective in most locations when used in conjunction with any type of sprinkler irrigation system. Among the 17 largest irrigation states, computerized irrigation would be economically beneficial in all except two. It would generally not be cost-effective when used with gravity flow irrigation systems, except in locations with extremely high pumping lifts or water requirements

A final factor to note is that the potential for marketing computerized irrigation scheduling services is greatest for medium-sized farms of 1000 to 
5000 acres. Farms larger than this generally develop their own in-house scheduling capability. Smaller farms generally cannot afford to use computerized scheduling individually because economies of scale cause per-acre costs for computerized services to small farms to be much greater than the five dollar per acre charge assumed throughout the economic analysis. Some form of cooperative effort among small farmers is necessary in order for the computerized scheduling to be cost-effective. 


\subsection{INSTRUMENTED IRRIGATION SCHEDULING}

Providing irrigation water according to crop needs is an important part of optimizing the use of both water and energy in the irrigation process. However, in order to provide the correct amount of irrigation water at the correct time in the growing season, soil, crop, and weather conditions must be continuously monitored. The effort required to perform this continuous monitoring may cause irrigators to completely forego the use of rigorous irrigation scheduling techniques. In addition, monitoring soil, crop, and weather conditions by hand can result in significant measurement errors.

A totally automated system that monitors soil and crop conditions and provides data for determining the amount and timing of irrigation applications was developed in a project conducted by Prossen Industries. The system uses electronic moisture level monitoring instruments to collect field level data, then translates and transmits this data to a computer software package for analysis. By linking moisture sensing devices directly to a computer data base program, the system reduces the required labor and improves the accuracy of the irrigation scheduling process.

\subsection{TECHNOLOGY DESCRIPTION}

The instrumented scheduling system developed in the project includes three main elements. These elements are:

- sensor/actuator stations that monitor soil, crop, and weather conditions in the field and control water flow

- a field computer terminal that acts as a controller for the sensor/ actuator stations and compiles the information collected at the stations

- a data processing center that further compiles and refines the scheduling data and generates printed results.

A schematic diagram of the total instrumented scheduling system is shown in Figure 12.1. Each of the three major system elements is described below. 


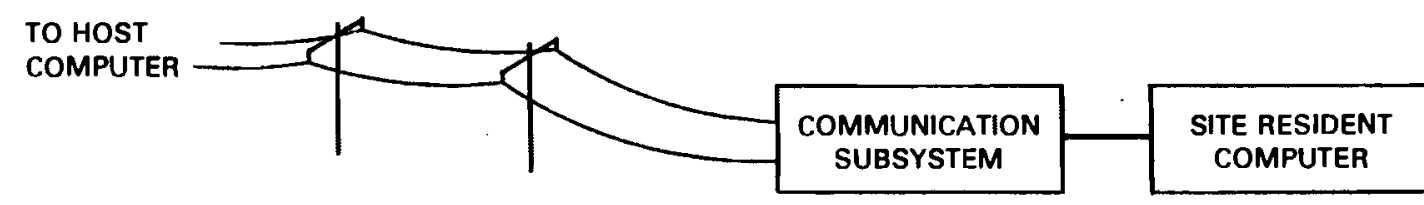

MULTIDROP POLLING CABLE

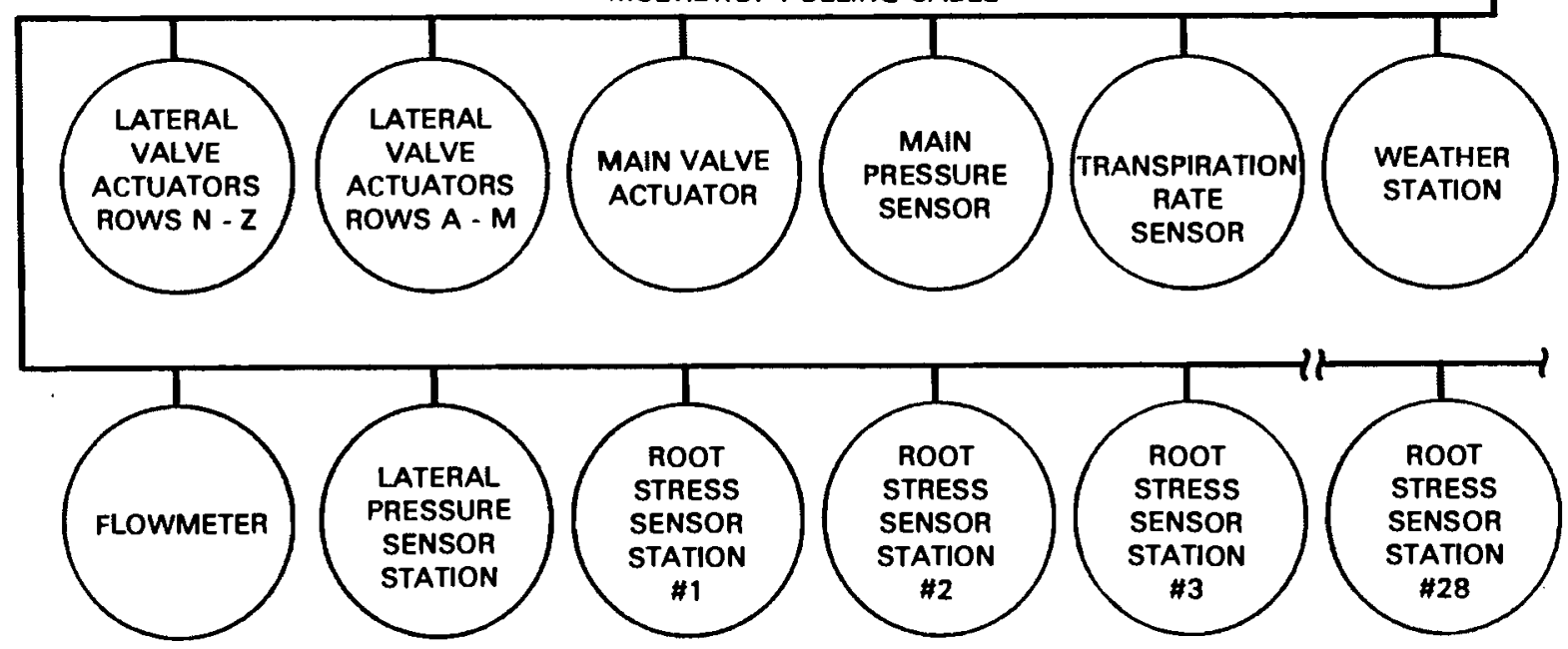

FIGURE 12.1. Schematic Diagram of the Total Instrumented Scheduling System

\subsubsection{Sensor/Actuator Stations}

The major innovation in the instrumented system is the sensor/actuator stations. A station consists of one or more moisture level sensing devices and/or water flow actuators and the interface electronics to a multidrop polling cable. The actuators are used to initiate and stop water flow when commanded to do so. The polling cable contains four conductors that transmit outbound data and incoming control cormands, supply power to the sensor/actuator stations, and ground the system.

The communications process between the sensor/actuator stations and the field computer that controls their operation is conducted in three phases-initialization, polling, and reply. During the initialization phase, the sensor/actuator stations are energized to the correct power level for data transmission. Commands, in the form of eight-bit words, are transmitted from the field computer to the sensor/actuator stations during the polling phase. In the reply phase, data are transmitted to the field computer from those 
sensor/actuator stations that were directed to transmit data during the polling phase. Replies from the actuators are merely reiterations of the commands issued in the polling phase, while sensor replies contain actual data measurements.

The root stress sensor used in the sensor/actuator is a tensiometer. It is installed at various depths in the active root zone and behaves essentially as a dummy root. The internal pressure of the instrument is similar to the osmotic pressure exerted on the soil by roots in drawing moisture. An illustration of a moisture sensor station is shown in Figure 12.2.

The osmotic pressure of the moisture level sensors is measured with a device known as a transducer. This transducer also serves to digitize the pressure measurements before they are transmitted to the field computer through the politing cable.

Two types of pressure transducers were developed specifically for use in the system. These transducers were developed to meet requirements that the transducers be inexpensive, be reasonably accurate with minimal calibration, be durable in an agricultural environment, be capable of interfacing with a digital system with a minimum of signal conditioning software, and have low power demands.

The first type of transducer is an encoded gauge and is illustrated in Figure 12.3. The sensitive element of the transducer is a Bordon tube. The deflection of the Bordon tube varies with its internal gauge pressure. The deflection is converted to a rotary motion that turns a seven-track encoding disc. The disc is illuminated by an array of infrared emitters and read by a matching array of infrared sensors. The applied pressure is digitized to binary code by the infrared system.

The design of the first type of transducer necessitated that it be connected to the tensiometer body by a hydraulic tube. Many problems with hydraulic leaks and absorption of carbon dioxide through the hydraulic tube were encountered in the initial year of field testing. To correct these problems, the second type of transducer was developed. 


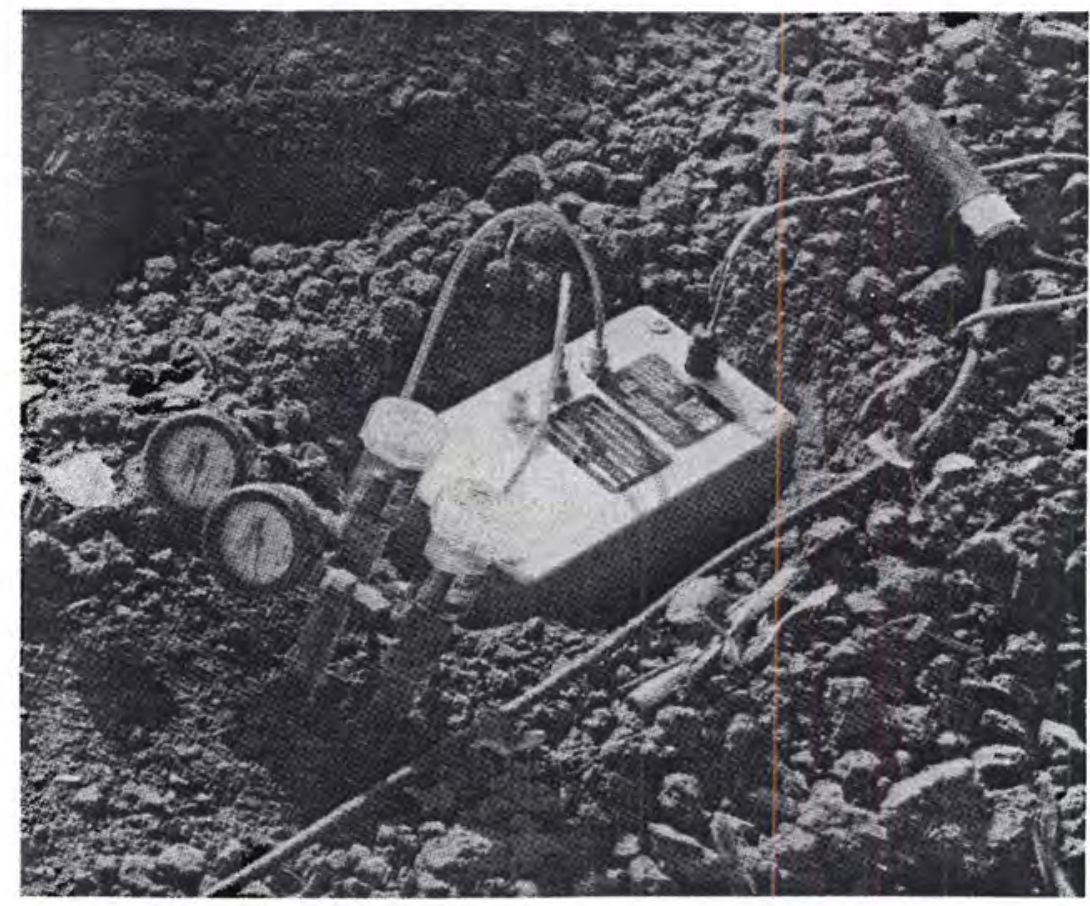

FIGURE 12.2. Typical Root Stress Sensor Station

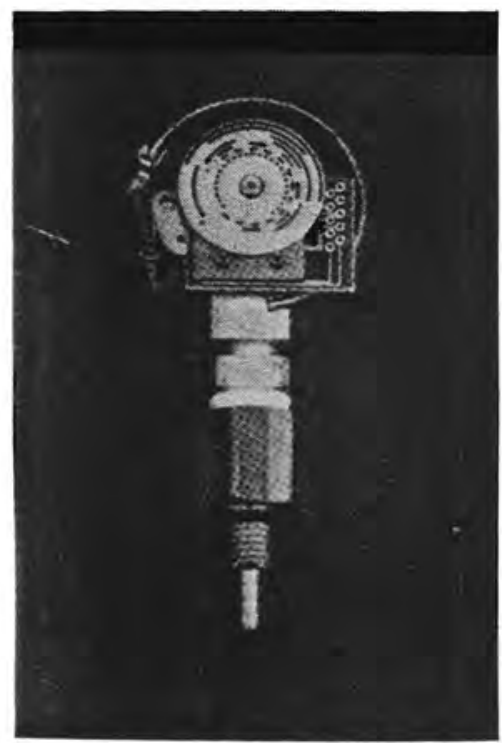

Optical Reader And Encoding Disc

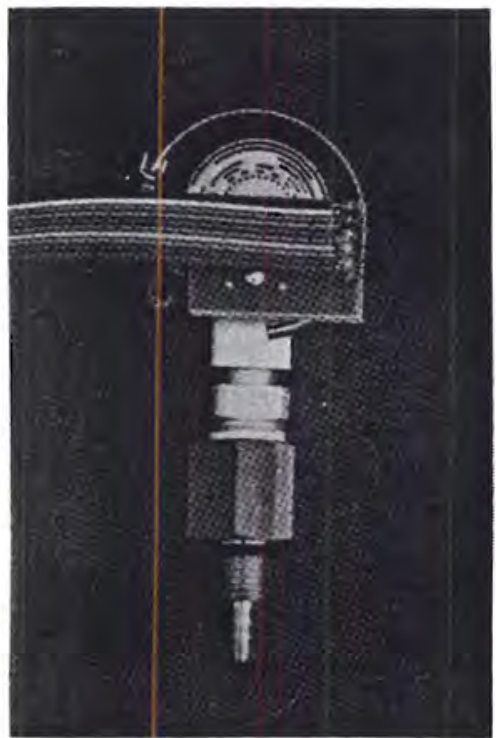

Unit With Infrared Emitter Array In Place

FIGURE 12.3. Encoding Gauge Transducer 
The second type of transducer is an integrated circuit whose sensitive element is a silicon substrate with a diffused strain gauge bridge. An illustration of this transducer is presented in Figure 12.4. Pressure variations between the two sides of the silicon substrate result in imbalances in the gauge bridge. The bridge transmits electrical impulses that vary according to the size of the pressure variations that occur. The impulses are then digitized by the cable interface for presentation to the reply circuits.

The second type of transducer is much more rugged than the first type and can be mounted directly on the tensiometer body so that the problems of the hydraulic system can be reduced. For purposes of expediting the research, the transducer and its conditioning circuitry were placed in the same weatherproof container as the polling cable interface circuitry. While this configuration is satisfactory for operating the system, it is probably not commercially acceptable because it causes the installation of the sensor stations to be very slow.

The water flow-valve actuator stations are designed to initiate and stop water flow at specific times and locations during the irrigation season. When the actuators are properly integrated with the moisture sensors, the irrigation

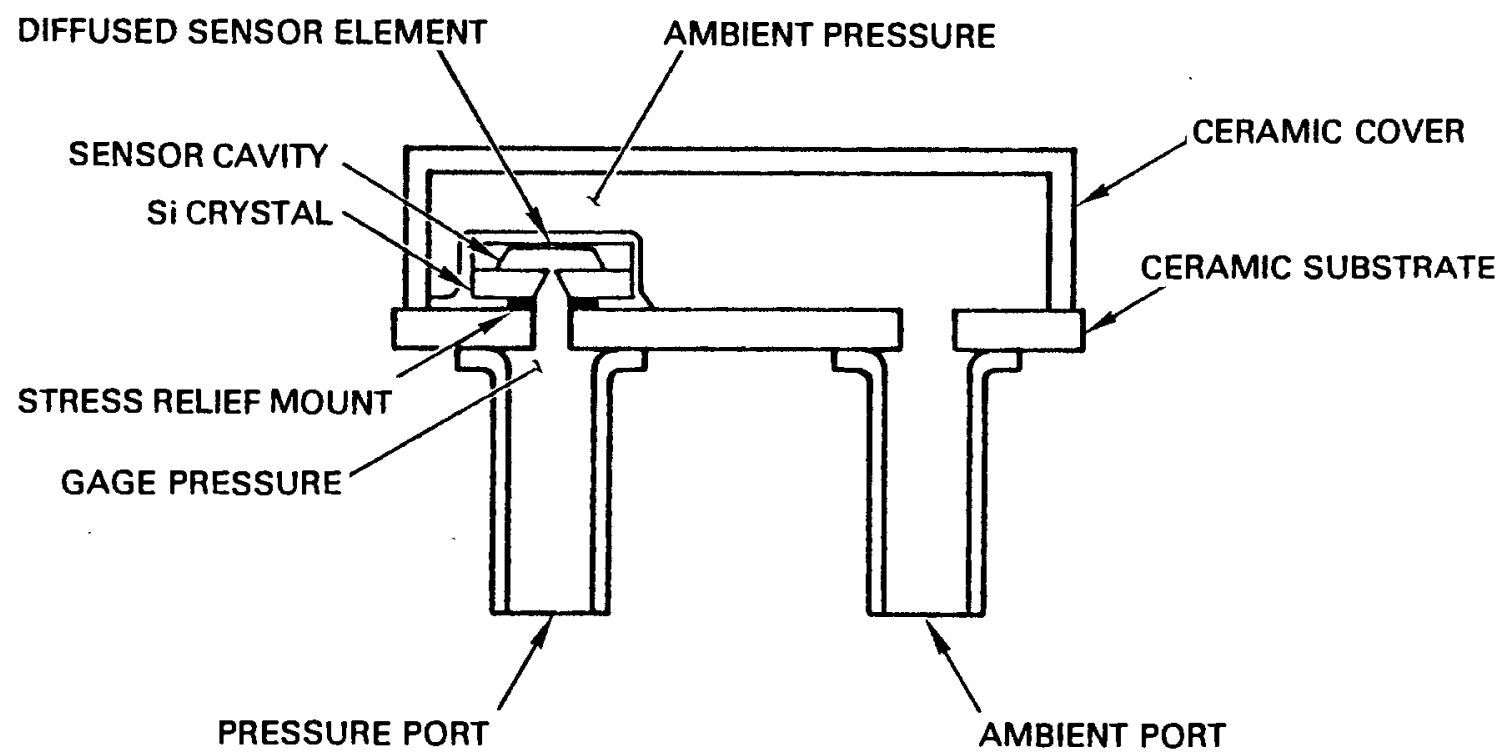

FIGURE 12.4. Schematic of Piezo Resistive Transducer 
system is totally automated. Water application is controlled by the actuator stations according to the data collected by the sensors.

An actuator station, as developed in the project, consists of command circuitry, matrix encoding logic, a coil driver circuit, and a magnetic latching pilot valve. The command circuitry is similar to that of the sensor stations, and control commands are transmitted and received through this circuitry.

Matrix encoding logic at the actuator stations is used to translate the control commands for a complex array of pilot valves. Coil driver circuits receive incoming electrical signals, and the operation of the pilot valves is controlled by the polarity of the signals. Forward polarity signals cause the pilot valves to turn off and reverse polarity signals cause the pilot valves to turn on.

In the original design of the instrumented system, it was intended that a weather station should be included. This weather station was to consist of an anemometer to measure wind, and solar, temperature, and humidity sensors. The weather station would be designed to interface directly with the field computer terminal in a manner similar to the moisture sensors. However, it was not possible to install the weather station at a field experiment site within the time frame of the project, although parts of the station were designed and partially fabricated.

\subsubsection{Field Computer Terminal}

The primary effort related to the field computer terminal was concentrated in the development of the system software. The development of the hardware for the field terminal received a lower level of effort, and basically involved the integration of a 6800 level micro-computer with the other components of the system. A telephone modem for transmitting data to the host computer is an important part of the terminal hardware.

The software for the field terminal is written in computer assembly language. A flow chart illustrating the basic segments of the computer sof tware program is presented in Figure 12.5. The decision box denoted as "ring interrupt" in Figure 12.5 determines whether the system collects or 


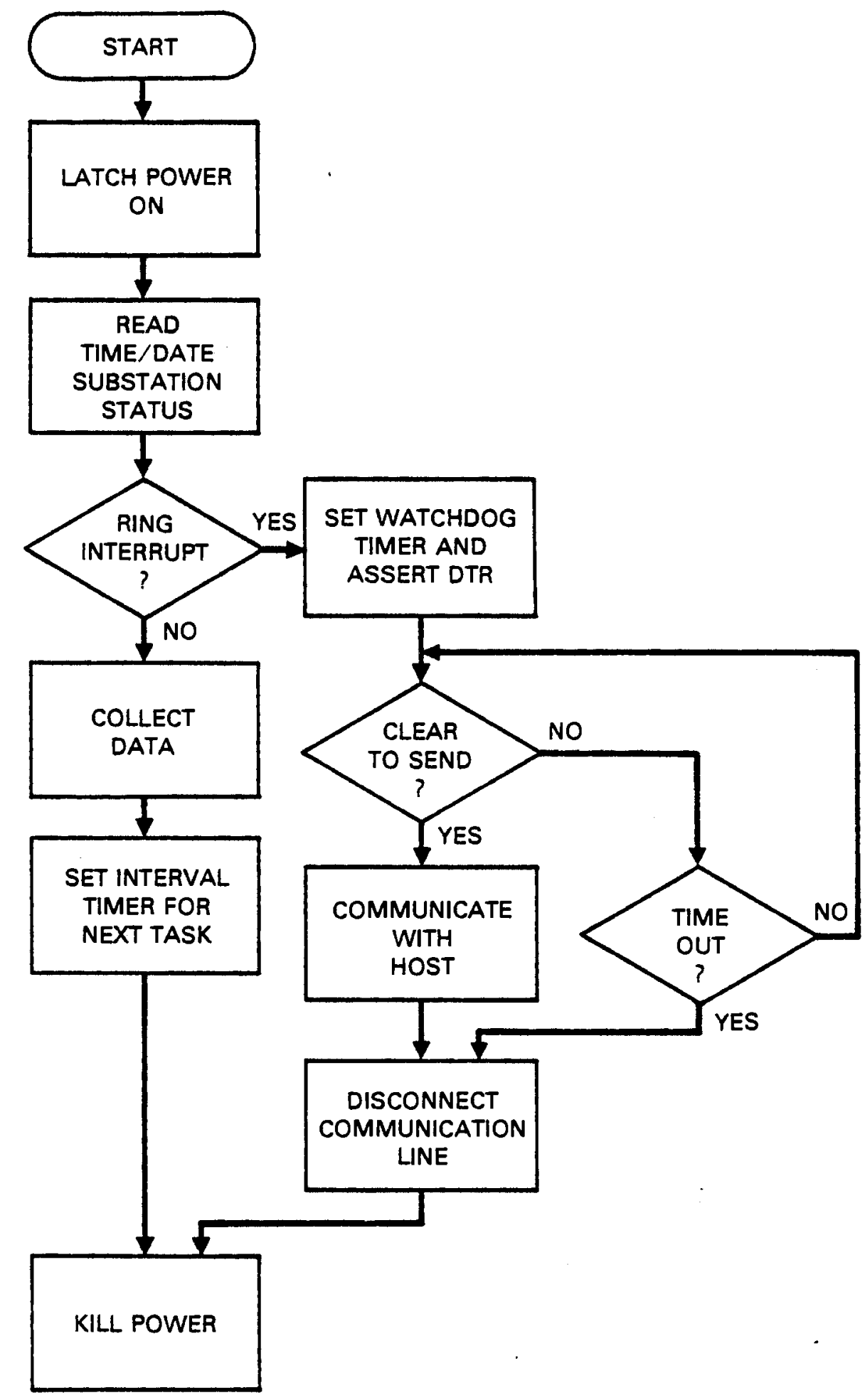

FIGURE 12.5. Flow Chart for System Field Terminal Program 
transmits data. If a ring interrupt is in effect, the field terminal attempts to gain access to the host computer for communication. If access cannot be obtained, the terminal continues to request access over the time period set on the watchdog timer. Eventually, either the specified time expires or communication is successfully completed.

The timing of the data collection and transmission process is controlled internally within the software program. Thus, the field terminal functions as a stand alone controller for all actuator and sensor activity at the site.

\subsubsection{Host Computer Data Processing Center}

The host computer data processing center features a general purpose computer system with a line printer, graphics capabilities, and a CRT terminal. In the experiment, the computer was used for software development, and data collection and storage for the field terminal communications. Eventually, it is intended that the host computer of the instrumented system should be used for executing optimizing irrigation scheduling algorithms. However, these algorithims and associated computer sof tware were not successfully implemented during the course of the experiment.

\subsection{METHOD OF TESTING}

To test the performance of the instrumented system, variations of the system were installed on three field experiment sites in southern California. These experimental sites were:

- Site 1 - a 6.7-acre avocado orchard irrigated by a permanent sprinkler irrigation system with a riser and sprinkler head at each tree

- Site 2 - a 67-acre field of chili peppers irrigated with movable sprinklers and gated-pipe

- Site 3 - a 37-acre field planted to broccoli in the 1980 crop year and cannery tomatoes during the 1981 season. Irrigation was done by gated-pipe. 
The layout of Site 2 is illustrated in Figure 12.6. The layouts of the other sites were essentially the same, but different types of equipment were installed on each site. Site 2 was the second site selected, but it was the first site on which the experimental installation was installed. Only moisture sensors were tested at Site 2, and water flow was controlled manually. The first type of transducer, an encoded gauge, was used at Site 2. The cable of the sytem was equipped with a stainless steel braid imbedded in the cable's outer polyethylene jacket to provide tensile strength and protection from rodent damage. Initially, root stress sensor density was approximately one station for every four irrigation laterals. Once experience is acquired concerning soil characteristics, it is expected that permanent locations can be established in homogenous soil areas of approximately one station for every eight laterals.

The experimental installation at Site 1 included valve control actuator stations, as well as sensors. A hydraulically actuated valve was installed at the head of each row of trees to permit irrigation selectivity by rows. Because unattended irrigation was intended at Site 1, experimental sprinkler heads that are more resistant to stoppage by obstructions than conventional sprinkler heads were installed on the sprinkler risers.

A total of 36 moisture-sensing stations were installed at Site 1 . Three soil depths--10, 20, and $39 \mathrm{in}$. were monitored at each station. The sensors could be attached to any part of the backbone polling cable, allowing for relocation of the sensor stations as additional information on soil hydraulics is gained.

The second type of transducer, an integrated circuit with a silicon substrate and diffused strain gauge bridge, was used at Site 1. Initially, the hydraulic coupling on the transducer was made of a hard, thick-walled nylon substance, but because of operational problems the nylon couplings had to be replaced by copper refrigeration tubing.

The installation of equipment at site 3 was required because of problems encountered at Site 2 during the 1979 growing season. The second type of 


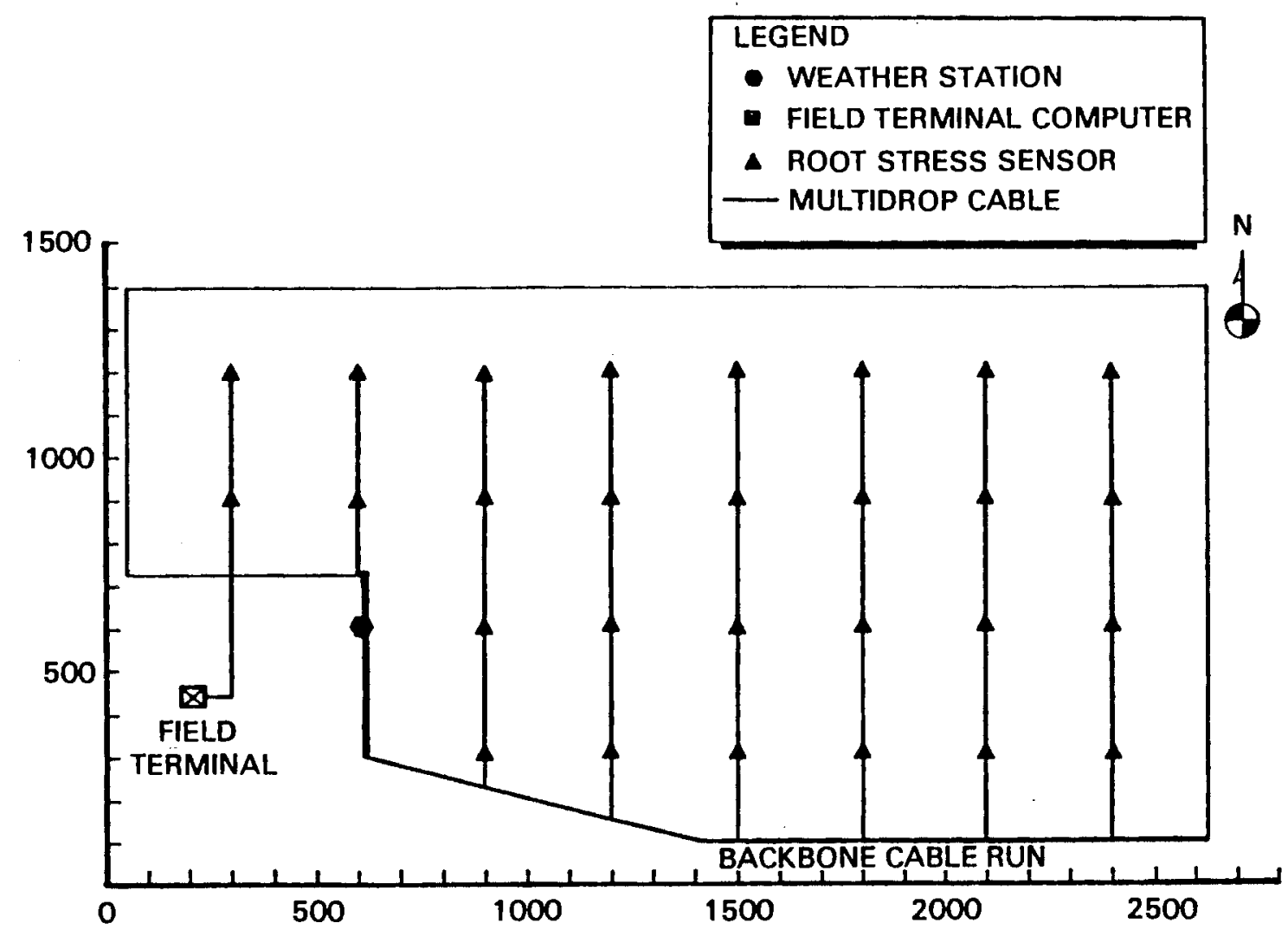

FIGURE 12.6. Layout for Experimental Site 2

transducer was utilized at Site 3 . Sixteen sensor stations were installed at Site 3, with two tensiometers installed at depths of 10 and 20 in. No waterflow actuator stations were installed at Site 3.

\subsection{PERF ORMANCE RESULTS}

Several problems were encountered during testing of the instrumented system, and a number of solutions to the problems were implemented as the testing proceeded. The prospects for successful implementation of the system's concepts in a commercial agricultural setting were also assessed.

The first type of transducer, the encoded disc, used in the system encountered many operational problems. Problems of hydraulic leakage and $\mathrm{CO}^{2}$ absorption by the hydraulic tube of the transducer have already been noted. In addition, the calibration of the encoding disc was frequently 
destroyed by attempts to purge trapped air from the tensiometer stations. The effect of these problems was to cause the sensor stations to require servicing every six days in order to obtain reliable measurement performance. This conflicted with the original intention of the research, i.e., to design an irrigation system that would successfully operate with little required attendance.

The system at Site 2 provided very little successful performance. Two of the 28 stations were selected for intensive maintenance and provided reasonable data through the season. However, one of these stations was shut down for a time when a tractor implement snagged and damaged a segment of the backbone cable. This event illustrates the problems that may be encountered in using the hardwired instrumented system in a field that must frequently be deep tilled.

Installation of the second type of transducer, equipped with a nylon coupling, resulted in fairly reliable system performance at Site 1 during the rainy part of the growing season. However, as it became drier, increased pressure on the tensiometer resulted in gas leakage through the nylon.

In response to the leakage problems, the nylon couplings were replaced with copper refrigeration tubing. This eliminated the leakage problems. However, after a few months, the copper coupling tubes at certain stations began to galvanize and erode. This problem occurred only at those stations where the entire instrument cavity had been backfilled by gophers. This backfilling caused a current path to be completed from the internal chamber of the transducer back to the external surface of the transducer by way of the copper tubing.

The experimental results at Site 1 were damaged by a killing frost. A number of trees were pruned back significantly causing the water usage of the field during the experimental period to vary significantly from historical levels.

Despite all of the problems, some successful performance from the instrumented sensor system at Site 1 was obtained. In addition, the waterflow actuator system performed adequately. 
The most successful performance of the sensor system was obtained at Site 3. Initially, some problems occurred at Site 3 as a result of pressure buildup within the weatherproof containers that housed the pressure transducers. The solution to this problem involved venting the containers through a moisture trap and placing a quantity of napthalene outside the container. Once this solution was implemented, accurate moisture level samples were successfully obtained for a full growing season at Site 3 .

The experiences at the three sites indicated that the instrumented system, in its current form, is not ready for commercial use. However, the research did uncover the major problems inherent in the system and provides a basis for developing potential solutions.

In its current form, the transducer is believed to be the weak element of the instrumented system. A preliminary design of a transducer that makes use of an isolation chamber and connects directly to the body of a tensiometer has already been developed. Another potential improvement in the instrumented system is the replacement of tensiometers with other types of soil moisture measuring devices. An additional potential improvement in the instrumented system is the development of a wireless system for use in fields where heavy cultivation is necessary.

\subsection{ENERGY SAVINGS RESULTS}

No rigorous field tests of the energy savings of the instrumented scheduling system relative to other types of scheduling methods were performed during the project. It is estimated that the use of the instrumented system should result in an average energy and water savings of 20 percent compared to conventional methods of scheduling irrigations. In a companion volume to this one (wilfert et al. 1982), the aggregate energy savings of using the instrumented scheduling system within the 17 largest irrigating states in all locations where such use is cost-effective were estimated to be less than 0.2 trillion Btu. The small level of estimated energy savings was caused primarily by the fact that, in its current form, use of the instrumented system would not be cost-effective in most locations. 


\subsection{COST SAVINGS RESULTS}

The estimated capital cost of the instrumented system in its current form is over $\$ 30,000$. If the system performs reliably, it is possible that the initial capital costs of the system will be returned by energy, labor, water and tax cost savings over the life of the system. In addition, the possibility exists for a reduction in the capital cost of the system if the system components are mass produced.

It appears, however, that even if a reliable instrumented scheduling system is developed, its use will only be cost-effective in areas where extremely energy-intensive crop production is practiced and where the prices of energy and water for growing these crops are high. Use of the instrumented system in other areas will probably not be profitable until the capital cost of the system is reduced significantiy. 

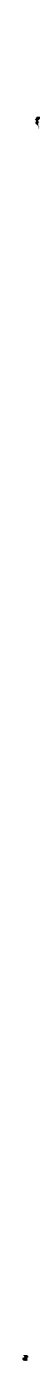


\section{REFERENCES}

Fischbach, P. E., and T. L. Thompson. 1981. Irrigation System Cost Analysis. AGNET, A Remote Accessed Computer Program. University of Nebraska, Lincoln, Nebraska.

Foster-Miller Associates, Inc. 1981. Variable Speed Pumps for Agricultural Irrigation: An Approach to Energy Conservation. Foster-Miller Associates, Inc., Waltham, Massachusetts.

Gilley, J. R., L. M. Mielke, and W. W. Wilhelm. 1981. Low Energy Center Pivot Sprinkler Irrigation System. University of Nebraska, Lincoln, Nebraska.

Hamrick, J. T. 1980. Redesign of Turbine Pump Impeller and Diffuser Using Hydrodynamic Design Techniques. Aerospace Research Corporation, Roanoke, Virginia.

Helweg, 0. and V. Scott. 1981. Groundwater Irrigation Supply System Optimization. University of California, Davis, California.

Lord, J. M., Jr., and J. L. Gartung. 1981. The Effect of Irrigation Scheduling on Energy Consumption. J. M. Lord Incorporated, Fresno, CaTifornia.

Lyle, W. M. and J. P. Bordovsky. 1981. New Irrigation Systems Design for Improving Irrigation Efficiencies and Enhancing Energy Conservation. Texas Agriculture Experiment Station, Lubbock, Texas.

Manges, H. L. and H. R. Blom. 1981. Automation of a Gated-Pipe Irrigation System. Kansas State University, Manhattan, Kansas.

Pacific Northwest Laboratory. 1982. Conserving Energy Through New Irrigation Technologies. PNL-4339, Pacific Northwest Laboratory, Richland, Washington.

Patton, W. P., G. L. Wilfert, B. J. Harrer, M. A. Clark, and K. L. Sherman. 1982. Potential Cost Savings from Investments in Energy-Conserving Irrigation Systems. PNL-3930, Pacific Northwest Laboratory, Richland, Washington.

Prossen, Peter J. 1981. An Agriculture Instrumentation System for Optimal Use of Irrigation Water. Prossen Industries, Los Alamitos, California.

Watters, G. Z. and J. Keller. 1980. User Manual for Computerized Irrigation Pipe Network Design Program. Keller Engineering, Logan, Utah.

Werner, H. D., T. F. Scherer, and T. 0. Kajer. 1980. Effects of Irrigation Wel1 Efficiency on Energy Requirements. Staples Irrigation Center, Staples, Minnesota.

Wilfert, G. L., W. P. Patton, B. J. Harrer and M. A. Clark. 1982. Energy Savings Potential for Energy Conserving Irrigations Systems. PNL-3958, Pacific Northwest Laboratory, Richland, Washington. 


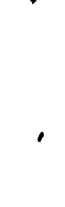


APPENDIX A

List of addresses and phone numbers of people to contact for further information on the ten technologies described in this report. 


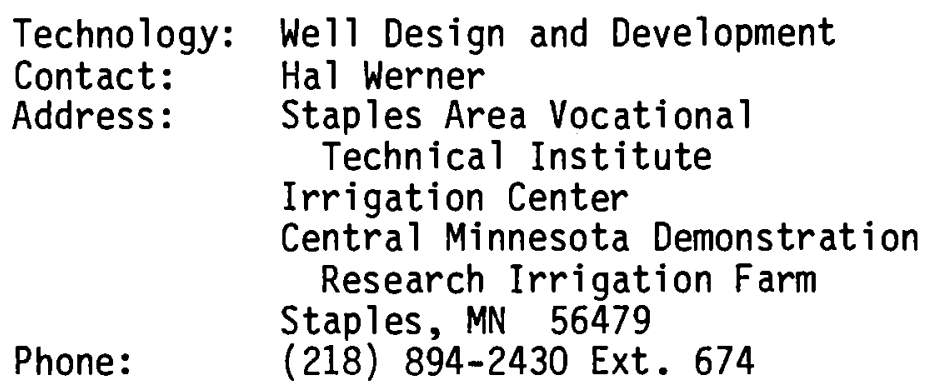

Phone: (218) 894-2430 Ext. 674

Technology: Groundwater Supply System Optimization

Contact: Otto Helweg

Address: University of California, Davis Department of Civil Engineering Davis, CA 95616

Phone: (916) 752-0586

Technology: Variable-Speed Pumping

Contact: Ron Griffith

Address: $\quad$ Foster-Miller Associates, Inc. 350 Second Avenue Waltham, MA 02154

Phone: (617) 890-3200

Technology: Pipe Network Optimization

Contact: Jack Keller

Address: Keller Engineering 35 Riverpark Drive Logan, UT 84321

Phone: (801) $750-2785$

Technology: Reduced Pressure Center-Pivot Systems Contact: James Gilley

Address: University of Nebraska Agricultural Engineering Bldg., East Campus

Phone: (402) 472-1637 


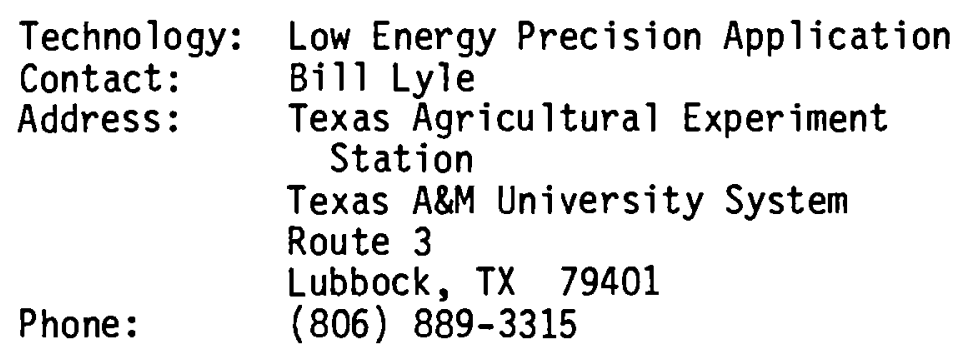

Technology: Automated Gated-Pipe

Contact: H. L. Manges

Address: Kansas State University

Department of Agricultural

Engineering, Seaton Hall

Phone: (913) $532-5580$

\section{6}

Technology: Computerized Irrigation Scheduling

Contact: Joe Lord, Jr.

Address: J. M. Lord, Inc .

1685 E. Street, Suite 109

Fresno, CA 93706

Phone: (209) 268-9755

Technology: Instrumented Irrigation Scheduling

Contact: Peter Prossen

Address: Prossen Industries 3822 Cerritos Avenue Los Alamitos, CA 90720

Phone: (213) $493-2484$ 


\section{DISTRIBUTION}

No. of

Copies

OFFSITE

27 DOE Technical Information Center

10 M. Corrigan

Department of Energy

Forrestal Building

Washington, D.C. 20585

J. T. Hamrick

Aerospace Research Corporation 5454 JAE Valley Road, S.E.

Roanoke, VA 24104

0 . He Tweg

University of California, Davis

Department of Civil Engineering

Davis, CA 95616

R. Griffith

Foster-Miller Associates, Inc.

350 Second Avenue

Waltham, MA 02154

J. M. Lord, Jr.

J. M. Lord, Inc.

1685 E. Street, Suite 109

Fresno, CA 93706

H. L. Manges

Kansas State University

Department of Agricultural

Engineering, Seaton $\mathrm{Hall}$

Manhattan, KS 66506

J. Keller

Keller Engineering

35 Riverpark Drive

Logan, UT 84321
No. of

Copies

H. Werner

Staples Area Vocational

Technical Institute

Irrigation Center

Central Minnesota Demonstration

Research Irrigation Farm

Staples, MN 56479

J. R. Gilley

University of Nebraska

Agricultural Engineering Bldg., East Campus

Lincoln, NB 68583

P. J. Prossen

Prossen Industries

3822 Cerritos Avenue

Los Alamitos, CA 90720

W. M. Lyle

Texas Agricultural Experiment

Station

Texas A\&M University System

Route 3

Lubbock, TX 79401

J. L. Butler, Manager

SEA Southern Agricultural Energy Center

Tifton, GA 31793

W. Sonnett

Department of Energy

Forrestal Building

Washington, D.C. 20585

W. R. Nave

U.S. Department of Agriculture

Science and Education

Administration

Beltsville, MD 20705 
No. of

Copies

J. Archbold

Foxlease Farms of Archbold Investment $\mathrm{Co}$. Upperville, VA 22176

T. Snider

CENTEC

11800 Sunrise Valley Drive

Reston, VA 22091

D. A. Malish

SumX Crop.

P.0. Box 14864

1300 E. Braker Lane

Austin, TX 78761

W. E. Splinter

Department of Agricultural

Engineering

University of Nebraska

Linco 1n, NB 68583

R. S. Combes, Director

Technology Applications Laboratory

Engineering Experiment Station Georgia Institute of Technology

Atlanta, GA 30332

G. Pratt

Agricultural Engineering Department

North Dakota State University

P.0. Box 5435

Fargo, ND 58105

A. G. Alexander

Center of Energy and Environmental Research University of Puerto Rico

Caparra Heights Station

San Juan, PR 00935

L. P. Walker

Agricultural Engineering Department

Cornell University

Ithaca, NY 14853
No. of

Copies

D. Pinkerton

Energy Management Corporation

19208 S. Vermont

Gardena, CA 90248

v. Benson

United States Department of Agriculture

435 Federal Building

Lincoln, NB 68508

R. Lacewell

Department of Agricultural Economics

Texas A\&M University

Lubbock, TX 79401

J. Runk les, Director

Texas Water Resources Institute

Texas A\&M University

College Station, TX 77840

B. Beattie, Chairman

Department of Agricultural Economics and Engineering

Montana State University

Bozemen, MT 59715

G. Sloggett

United States Department of Agriculture

Ok Iahoma State University

Stillwater, OK 74074

M. Jensen

United States Department of Agriculture

Washington, D.C. 20250

L. James

Washington State University

Department of Agricultural

Engineering

Pullman, WA 99163 
No. of

Copies

B. Furhman

Federal Land Bank Association 4305 E. Trent

Spokane, WA 99202

E. Gavett

United States Department of Agriculture

Office of Energy

$144 \mathrm{E}$. Administration Building

Washington, D.C. 20250

A. Ingram

Bonneville Power Administration P.0. Box 3621

Portland, OR 97208
No. of

Copies

S. Levy

Bonneville Power Administration

P.0. Box 3621

Portland, OR 97208

DOE Richland Operations Office

H. E. Ransom

40 ONSITE

J. E. Danko

T. E. Divine

D. E. Eakin

B. J. Harrer (3)

W. P. Patton

G. L. Wilfert (25)

Publishing Coordination (2)

Technical Information (5)

J. W. Currie 


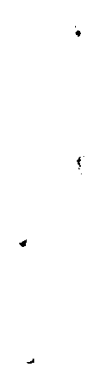

